\title{
ABOVE THE DEBRIS
}

by Anthony Mak

a 120-point thesis

submitted to the Victoria University of Wellington in partial fulfilment of the requirements for the degree of Master of Architecture (Professional)

Victoria University of Wellington

School of Architecture

2017 



\begin{abstract}
At an accelerating rate, over half of the world's population is living in urban centres. The catastrophic risk to environmental, cultural, and economic resources amidst these high concentrations of livelihoods upon the wake of a disaster has the potential to be devastating.
\end{abstract}

A city's urban form consisting of its open space networks and street structures are important spatial resources that provide affected communities with efficient evacuation routes, assembly areas, temporary market spaces, and room for temporary shelters in the aftermath of a disaster. Open public spaces are especially important during these scenarios as they provide large volumes of space that can be adapted to a variety of different functions. However, these spaces are seldom designed with resilience in mind.

This thesis investigates how open spaces are able to contribute to the disaster resiliency of urban centres, ensuring that the needs of the present are in light of the needs of the future. 



\section{ACKNOWLEDGEMENTS}

For their love and continual support, this is to Lisa, Warren, and Jeremy. 



\section{TABLE OF CONTENTS}

\subsection{Introduction}

1.1 Problem Statement

1.2 Aims and Objectives

1.3 Design Scope

\subsection{Literature Review}

2.1 Resilience

2.2 Urbanism

\subsection{Context Analysis}

3.1 Site Selection

3.2 Wellington City

3.3 Wellington's Seismic Vulnerabilities

3.4 Kaikoura Earthquake, November

2016

3.5 Wellinton's Hazards

3.6 DepthmapX

3.6.1 Testing

3.7 Wellington's Open Space Network

3.8 Conclusion

\subsection{Kent and Cambridge Terrace}

4.1 History

4.2 SWOT Analysis

4.2.1 Strengths

4.2.2 Weaknesses

4.2.3 Opportunities

4.2.4 Threats

4.3 Proposed Redevelopment

4.4 Conclusion

\subsection{Programme Analysis}

5.1 Vertical Garden and Walkway

5.2 International Federation of Red

Cross and Red Crescent Societies

Guidelines

\subsection{Project Review}

6.1 The Dryline

6.2 Yanweizhou Park

6.3 The Highline

\subsection{Preliminary Design}

8.0 Developed Design

\subsection{Conclusion}

\section{References}

10.1 List of References

10.2 Sources of Figures 



\section{0}

\section{INTRODUCTION}

Proportionately, over half of the world's population resides in urban centres and this number is accelerating. The catastrophic risk to environmental, cultural, and economic resources amidst high concentrations of livelihoods upon the wake of a disaster has the potential to be devastating. Efforts to improve the resilience of vulnerable cities have primarily been discussed at a systematic level. These discussions have started to break into the design of the built environment, particularly urban form and the quality and arrangement of open spaces.

Historically, attention has been directed towards the sustainability of these spaces. Namely, their ability to provide delight and functionality that integrate into the daily activities of its expected inhabitants and pedestrians, whilst responding to, environmental, social, and economic issues. The inclusion of disaster resilience has been neglected in practice, despite the explicit correlation it has 
to the aforementioned aspects of sustainability. Ensuring that the links between environmental, economic, and societal factors are capable of maintaining their functionality throughout the aftermath of a disaster is very much under the umbrella of what sustainability should be responsible for.

A city's urban form consisting of its open space networks and street structures are important spatial resources that provide affected communities with efficient evacuation routes, assembly areas, temporary market spaces, and room for temporary shelters in the aftermath of a disaster. Open public spaces are especially important during these scenarios as they provide large volumes of space that can be adapted to a variety of different functions. These spaces are already well known destinations in the city for ease of wayfinding, and have the potential to assemble people groups and communities to plan, grieve, and share resources with one another. Urban design guidelines for disaster resilience are yet to be formally established. It does not help that disasters are varying in magnitude, originating from ecological or man made circumstances, and can occur when society least expects it. However, to the cities of which disasters are foreseeable, the discipline of architecture has the ability to spatially innovate how urban spaces can contextually respond to the immediate effects of a foreseeable disturbance, whilst creating enticing and delightful spaces that can be both enjoyed and safely occupied during day to day scenarios.

\subsection{Problem Statement}

Cities are complex systems containing high densities of livelihoods. Urban centres which are highly vulnerable to disasters pose an incredible risk to the many communities that live within them. How these urban centres are structured, particularly the distribution and arrangement of open spaces, play an important role in facilitating a range of activities to allow communities to recover and maintain autonomy following a disaster. These spaces, engrained into the built environment, are a resource for communities to use for the purposes of evacuation, assembly, shelter, access to food and water, recreation, social amenity, and temporary accommodation. However, these spaces are seldom designed for disaster resilience or with these purposes in mind. 


\subsection{Aims and Objectives}

Research Question:

- How can open space networks contribute to the disaster resilience of urban centres?

The aim of the thesis is to investigate how resilience can be manifested spatially within cities at risk of foreseeable disasters, and how communities in these urban centres can benefit from resilient open spaces both before and after a disastrous event.

The objectives of the thesis are to investigate resilient design ideas for open spaces within vulnerable urban centres that can:

- withstand the foreseeable impacts and risks of a specific site's vulnerabilities

- be economically, environmentally, and culturally sustainable to the site's wider immediate and surrounding context

- safeguard and provide basic necessities to displaced people following a disaster

- efficiently accommodate the diverse range of social activities necessary for the recovery of communities following a disaster

\subsection{Design Scope}

This design research is focused on spatial disaster resilience, concentrating on urban centres with foreseeable disaster risk and the open spaces that are distributed within them. A current unused civic space will be redesigned with the intention of being inhabited in a post disaster scenario. This will consider the real hazards associated with the site in order to produce a proposal that will be pragmatically resilient to its physical vulnerabilities and provide a space for displaced communities to recover and regain their autonomy. 


\subsection{Thesis Structure}

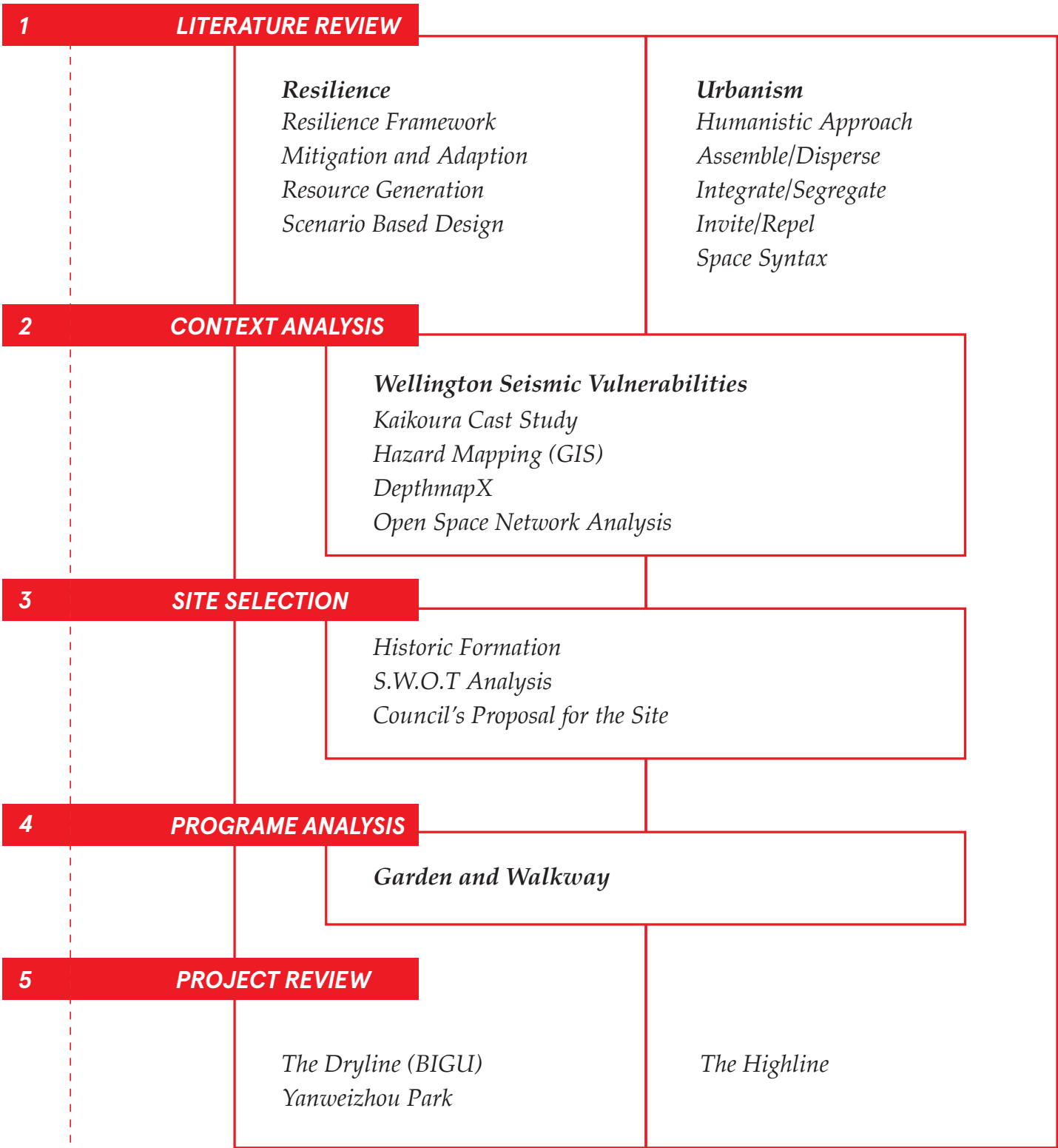

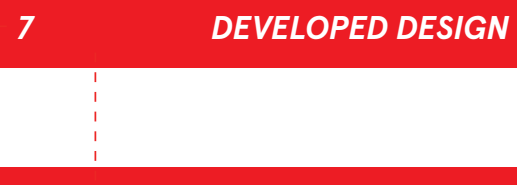


Urban design could make cities resilient. A well-designed, well-built city could be the most efficient, safe, and enriching place on earth. It could be a place that can adapt to extreme weather with no more danger to its inhabitants from a storm surge than from a spring shower. It could be a place where the greatest creativity is applied to economic development, education, health, and art. It could be a place where even walking down the street is a spectacle (Washburn 17). 


\section{0}

\section{LITERATURE REVIEW}

This section looks to theoretical strategies that explore the relationship between resilience and urbanism. The section is broken into two parts. The first section explores the concept of resilience and the way in which the city and its built environment can start to be shaped by adapting to foreseeable risks. The second section analyses fundamental ideologies of urbanism from Jan Gehl and Jane Jacobs and compares them to Bill Hillier's theories whose ideologies have been formulated to be represented quantitatively and graphically in an attempt to gauge a city's level of connectedness. 


\subsection{Resilience}

Penny Allan and Martin Bryant, Professors of Landscape Architecture at Victoria University of Wellington, have opened the discussion of resilience in the architectural realm by linking the characteristics associated with resilient systems, as outlined in 'Resilient Thinking' by David Salt and Brian Walker, with those embedded in urban design theory. The attributes: diversity, modularity, innovation, tight feedbacks, overlap in governance, ecosystem services, social capital, and variability have spatial manifestations on the scales of regional planning scales and those of smaller urban interventions (40). These attributes have been prescribed to act as a design framework for urban designers, to inform the ways in which urbanism can look to meet the needs of both the present and the unforeseen, but expected future (25). To be effective, the framework must be calibrated to a 'city's particular structure, function, identity, feedbacks, and the multiplicity of social, political, economic, and environmental forces that drive it' (43).

Similar to Allan and Bryant, Alexandros Washburn shares the view that urban design that seeks contain protective measures cannot simply be a fortress of technology. Washburn's approach to resiliency in public spaces is an extended view of sustainability, where complex social, economic, and environmental needs are balanced, but with climate change and the risks associated with it at the forefront of the urban design process. He suggests that mitigation and adaption are key strategies for resilience in urban centres (162). Mitigation involves reducing the footprint an intervention has on the probability of a future consequence occurring. A salient component of mitigation is involves resource creation. This involves prioritising a focus onto replacing resources instead of reducing them. In post disaster scenarios, this could include a range of measures, ensuring that food, water, and energy can be created when day to day infrastructure is inaccessible. Adaption involves designing with precautionary measures. In regards to cities, this can involve hardening edges through fortification, being resilient to bend but not to break, and to retreat from harm's way.

J. Barry Hokanson and James C. Schwab assert that the ultimate success of any pre-disaster planning relies on the behaviour and decision making of communities during post disaster scenarios. Hokanson and Schwab question the objective of pre-disaster planning if communities are unable to anticipate the possibility and potential severity of a disaster before it occurs (35). With specific reference to civic spaces, this raises the question as to whether public spaces are able to inform 
communities of the potential potency of foreseeable disasters, but in the same manner, communicate that the boundaries of their area are safely and adequately capable of providing refuge during these events. This is a proposition which can be answered architecturally.

\subsection{Urbanism}

As the frequency of some disasters cannot be predicted, the occupancy of inner city civic spaces for the majority and possible entirety of their existence will be to provide delightful outdoor experiences for those who visit and pass by. Such spaces should look to complement the needs of their context, ensuring their intervention is functional and pleasurable and not an embitterment to its residents.

Jane Jacobs, an influential urban theorist and activist provides two approaches to civic space implementation in her renown publication, 'The Death and Life of Great American Cities.' The ultimate goal of such spaces is expressed to successfully generate delight and give back to the communities that surround these areas (111). These approaches are determined by the degree of functional physical diversity that exists around the location of the park, as this provides an indication into the types of people that would interact with the park. For locations surrounded by an array of diverse amenity, Jane advocates that public spaces should contain general purposes and knit together their diverse functional surroundings in a pleasant joint facility for impromptu occupancy (101). Conversely, out of reach public parks with minimal surrounding functional diversity should specialise, creating diverse utilities and attracting a deliberate set of users (108). Jane strongly promotes an approach to urban design that generously and efficiently upholds the necessities and well being of the end user. However, resilience theory suggests that future adversities should be at the forefront of the design process. Given that disasters put the lives of many at risk, guaranteeing that such spaces maintain their utility is extremely crucial, even if a disaster's occurrence is unlikely. Marrying these theories in a way that ensures both current and future needs can be met will limit the degree that each of which is compromised.

Jan Gehl, the founder of Gehl Architects, professor, and critically acclaimed urban designer is a clear advocate of venturing into public spaces from a humanistic point of view. He provides prescriptive urban recommendations for designers to employ with the confidence that public spaces can be made desirable and more pleasurable when their composition is thoughtfully executed. Gehl insists that people come where people go, and being able to capitalise on this phenomenon 
through intimacy and warmth can create opportunities for public spaces to be stimulating for the human senses (23). The polarities of assembly and dispersion, integration and segregation, and invitation and repulsion are design variances that dictate the efficiency and success of people how intuitively enter and populate the site. Gehl establishes that necessary activities, mostly consisting of walking and delivering goods, are minimally affected by physical conditions wheresas optional and their resultant activities are heavily influenced by them (9).

Contrary to the theories of Jane Jacobs and Jan Gehl, Bill Hillier, a professor of architectural and urban morphology in the University of London, observes space from an organisational and formulaic perspective. He believes that all cities have a pattern embedded within them. Not simply a physical configuration, but a complex economic and social configuration that changes more rapidly than the structure of the city (113). His theories bring light to a space syntax methodology, a process that can assess a city's complex social and economic pattern capable of determining living densities, land use, sense of well-being and levels of security (125). This process hinges on the theory that the correlation between a city's physical configuration and its social pattern is movement, as it is a by-product of how the city grid provides connections from everywhere to every where else (127). The application of this theory can help to pinpoint safe, well accessible, and well connected locations suitable for displaced residents to assemble to and occupy. 


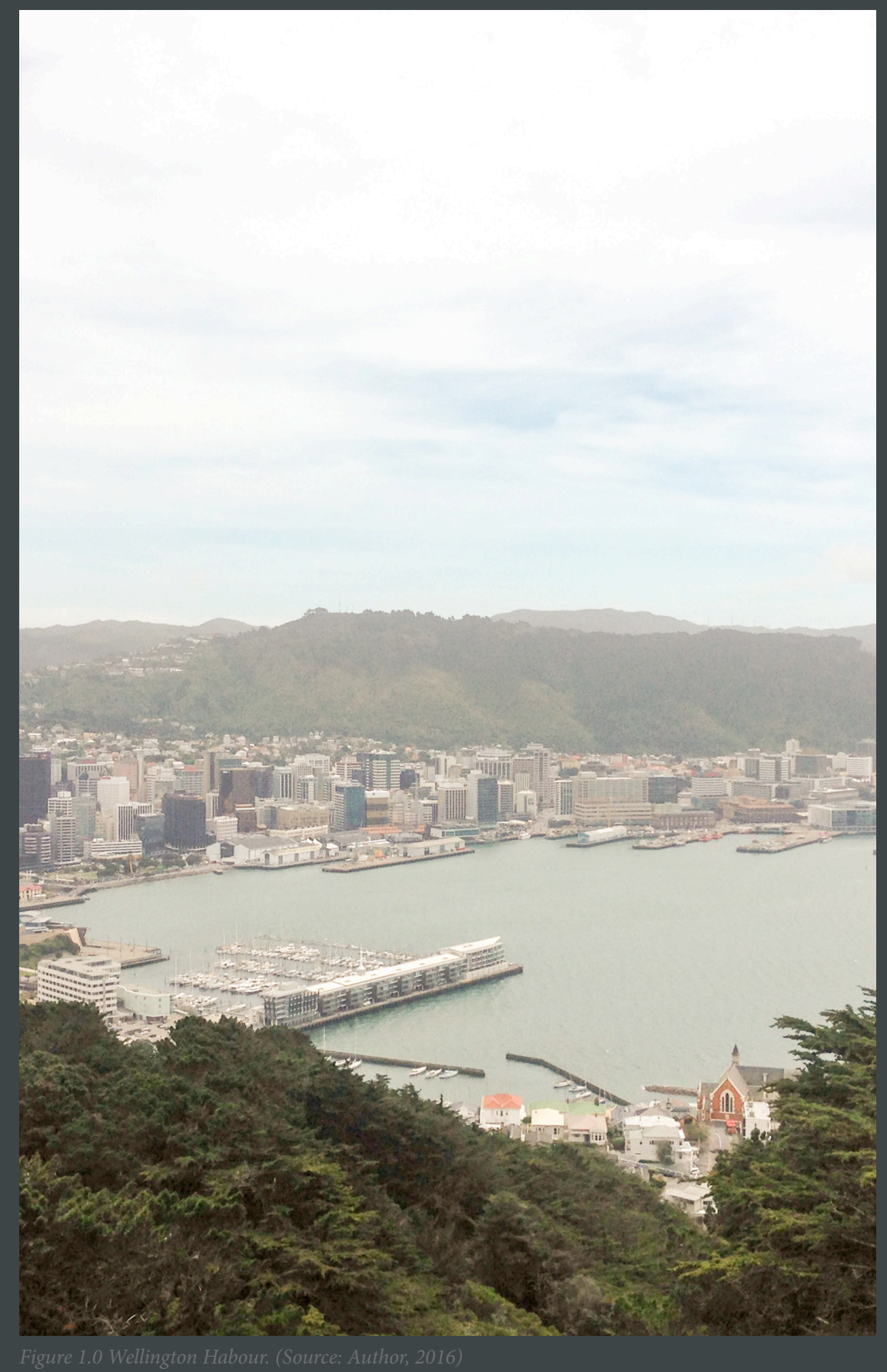




\section{0}

\section{CONTEXT ANALYSIS}

This section aims to investigate the vulnerabilities of a city that has historically been susceptible to disasters and is foreseen to face more severe disasters of the same variety in the future. Wellington, the capital city of New Zealand, has been selected as the pilot site. An analysis of Wellington's disaster catalogue and its specific disaster vulnerabilities through digital mapping techniques will help to identify the city's foreseeable contingencies that can be expected in a post disaster scenario. DepthmapX will be used as a means to observe how the accessibility of the city would behave when portions of the city are inundated due to disaster related effects. This will communicate how the city structure will hold up to foreseeable hazards and help to locate a suitable site within Wellington's city centre to continue the thesis investigation. 


\subsection{Site Selection}

Requirements for choosing city

- a metropolis with diverse historic, cultural, and economic richness

- is forecasted to face severe disasters in the future, given historic records of occurence, climate or geographic location

Requirements for choosing project area

- accessible to pedestrians and main transport routes

- on or in close proximity to an area at risk of being affected by a foreseeable hazard

- not fully utilised and / or has potential to better enhance surrounding pedestrian activity

\subsection{Wellington, New Zealand}

Wellington is the capital city a New Zealand, located at the south western tip of the country's north island, and the country's second most populous city. The city contains the nation's parliamentary grounds and government organisations, and is nationally touted for its cultural richness. The city centre sits within a valley between tall suburban hills and a habour, providing the inner city with a wide variety of recreational outdoor amenity near and along the waterfront (Figure 1.0).

\subsection{Wellington's Seismic Vulnerabilities}

Wellington is notorious for its frequent exposure to seismic activity. Figure 1.1 illustrates the number of active fault lines in the Wellington region, and Figure 1.2 displays the region's proximity to the intersecting Australian and Pacific Plates. The city's severe historic catalogue of earthquakes has shaped the urban formation of the city; their lasting effects still visible to date. The 18558.2 magnitude Waiarapa Earthquake is the biggest recorded in New Zealand history and provided substantial uplift to the city centre. Low lying blocks within the central business district were raised above sea level, and the basin reserve, originally designated to be a shipping basin, was repurposed into a cricket ground (McSaveney).

There is expert opinion that more seismic events at equal and greater severities than that of the 1855 Waiarapa Earthquake will strike Wellington in the future. A GNS Science report has modelled eight large Wellington Region earthquakes in an attempt to estimate the potential damages, casualties and amount of people 
This content is unavailable.

Please consult the print version for access. Science, 2009)
This content is unavailable.

Please consult the print version for access.

Figure 1.2. Wellington's proximity to the colliding Australian and Pacific Plate. (Source: GNS Science, 2009)

This content is unavailable.

Please consult the print version for access.

Figure 1.3. Wellington area bulk water supply system showing water sources (yellow stars), bulk mains (black dotted lines), Wellingtton fault line (red line), area where bulk mains cross Wellington fault line (purple circles), and main supply nodes for eastern Wellington (blue triangles). (Source: J. Cousins 2012) 
displaced should one of these scenarios occur. In the event that a 7.8 magnitude earthquake ruptures the Wellington Fault line, the city is estimated to experience 9400 casualties, more than $\$ 11$ billion in building repair costs, and 64000 of its residents to be displaced (Cousins et al 21-27). Of the 64000 people displaced, approximately 21000 are estimated to be displaced for a period of 6 months or longer, primarily due to building damage (Cousins et al 31). Up to 25000 people within the city centre will be without water for over 30 days if requiring $20 \mathrm{~L}$ of water per day per person (Cousins 43). Wellington's bulk water supply system crosses the Wellington fault line multiple times and cross liquefaction prone areas (Figure 1.3). Furthermore, residents in the city centre may be cut off from the rest of the country as state high ways will be affected by landslides and liquefaction. Further isolation of the city will be a result of inaccessibility to power, wastewater, and gas infrastructure (Mowll 2012). The lifelines with which Wellington relies upon for day to day usage can expect to be heavily compromised in the event of a large earthquake.

Local authorities are persistent that more can be done to better prepare its residents reduce the impacts of natural hazards. Currently, no measures within the district plan have been made to connect public spaces to disaster resilience. However, the Wellington City Council's newly published 'Central City Framework,' formally establishes a need for open spaces to be resilient to changing climate conditions and provide refuge for environmental emergencies (52). The implementation of this framework is ongoing, providing a timely opportunity for this design investigation to test the extent to which open spaces may contribute to the disaster resilience of Wellington City.

\subsection{Kaikoura Earthquake, November 2016}

Wellington's most recent moderately sized earthquake occurred at midnight on November 14, 2016. Understanding how residents responded to the unfolding events can provide necessary insight into how civic spaces can accommodate sudden changes in social activity within the city. Tsunami warnings were given on the night of the earthquake, forcing the evacuation of low lying communities to higher ground. However, not all residents were clear about their need for evacuation, due to the absence of tsunami sirens (Sachdeva). The earthquake forced 300 residents out of their city apartments for over a week (Shadwell). Immediately displaced residents and visitors took shelter within local businesses and parliamentary grounds on the night of the earthquake (Stuff). The event highlighted imprecisions in the response phase, with some Wellington residents 
expressing confusion of when and where to evacuate.

\subsection{Wellington's Hazards}

Depending on the size and location of the earthquake, areas close to the waterfront will be at risk of tsunami inundation. Tsunamis produce large impact torrents, carry debris, create fire risks, and carry contaminants (Power 2013). Figure 1.4 depicts areas of potential inundation based upon varying levels of tsunami threat illustrated by red, orange, and yellow boundaries. A GNS Science Report concerning boundaries of these zones specified that the orange zone bordering Wellington Habour corresponded to a probabilistic 3.6 meter high wave surge with a 500 year return period (Leonard et al, 4). Additionally, yellow zones corresponded to a 12.3 meter high wave with a 2500 year return period (Leonard et al, 4).

A large portion of the city centre is built upon reclaimed land and susceptible to liquefaction. The phenomenon often sinks and tilts ground surfaces which can cause damage to buildings, roads, and underground infrastructure (Environment Canterbury). Wellington's moderate to high risk areas include the city's waterfront, ports, and central business district, as well as many of the city's arterial roads and public transport stations (Figure 1.5).

The majority of open spaces within the south half of the city are deemed to be prone to flooding (Figure 1.6). These include a number of high traffic vehicular routes as well as main pedestrian paths along the city's Golden Mile. These risks can be provoked during periods of heavy rain fall which the city occasionally experiences.

High winds within the capital city have been exhibited to blow over shipping containers, knock people over, temporarily put trolley buses out of service, and cancel plane and ferry departures. The city centre largely experiences moderate to extra high winds, particularly areas close to the harbour (Figure 1.7). Strong gusts create uncomfortable outdoor environments, and reduce public desire to participate in outdoor activities. 


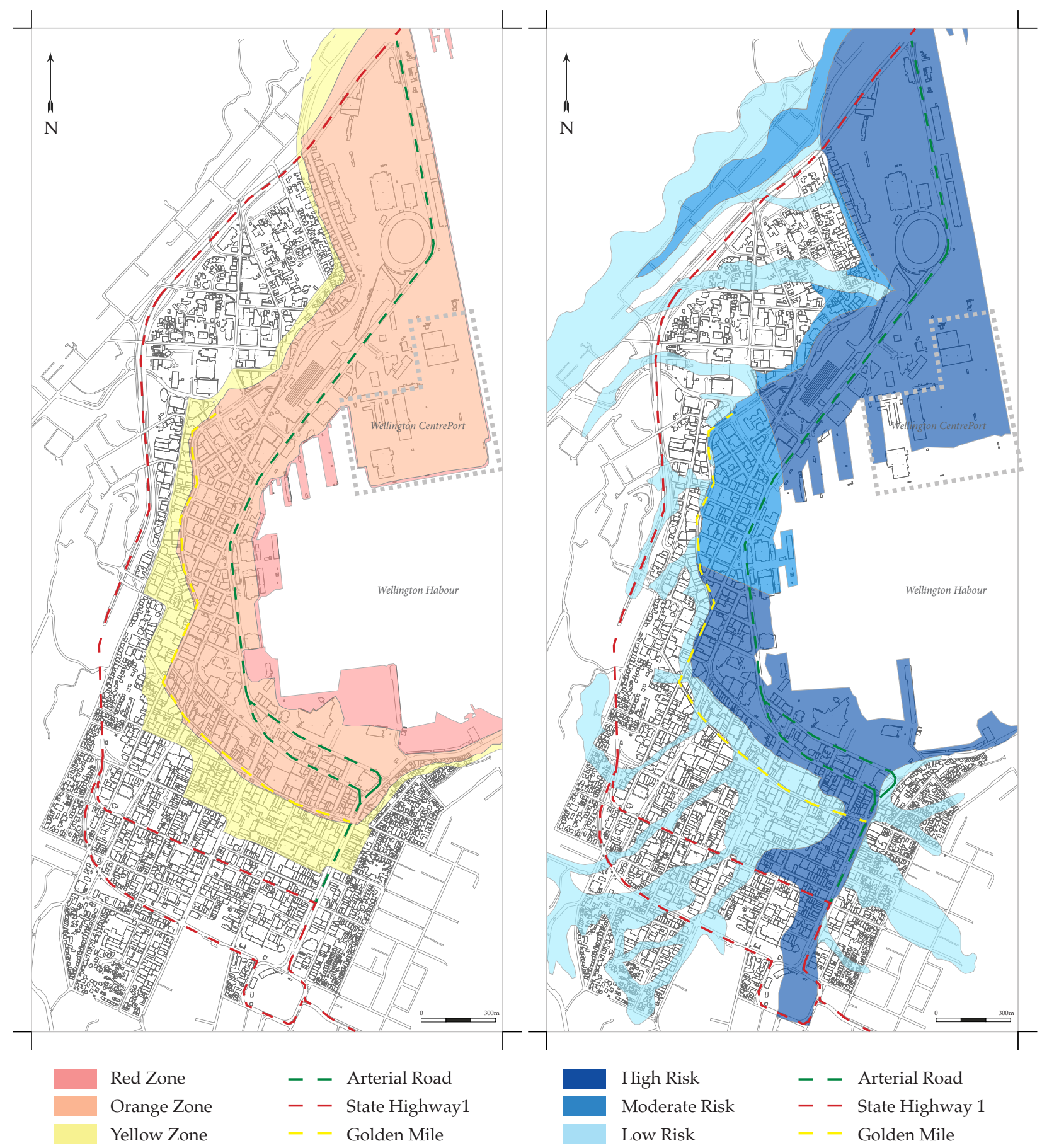

Figure 1.4. Tsunami risk zones for Wellington's city centre.

Figure 1.5. Liquefaction risk zones for Wellington's city centre. 


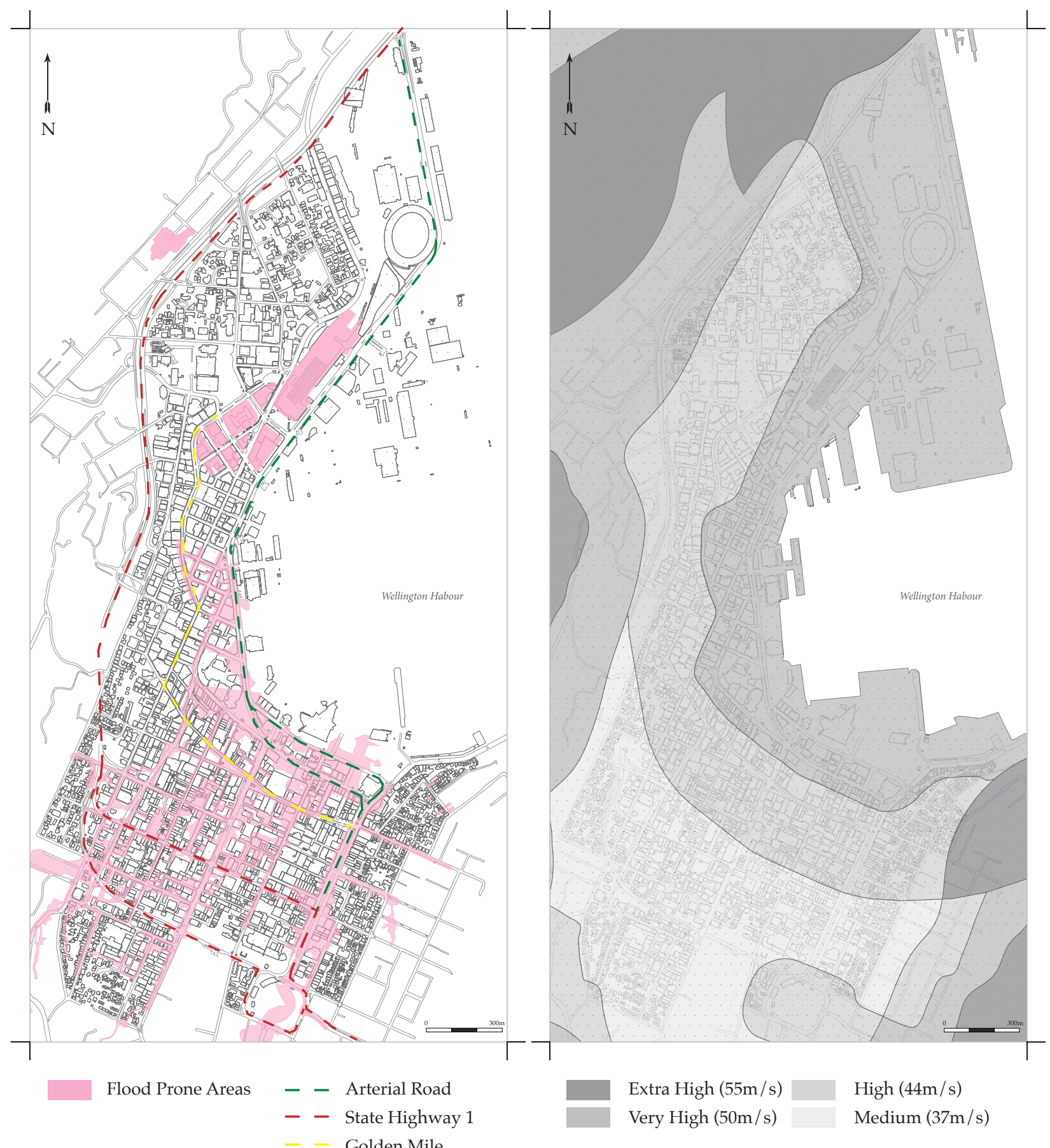

Figure 1.6. Potenial flood hazard areas for Wellington's city centre. 


\subsection{DepthmapX}

DepthmapX is a spatial analysis software derived from Bill Hillier's space syntax theory. Based upon the configuration of a city's street pattern, DepthmapX is able to determine a city's pattern of movement and locate which regions of the city are naturally accessible, or integrated. Using this, it is possible to monitor how these movement patterns change when areas of the city are inundated, to understand if highly accessible areas are resilient and and still highly accessible following disruption. The software analyses a set of lines, representing roads or accessible paths, and calculates the amount of turns each path would require in order to connect to all other lines in the scenario. In this method, all lines are weighted equally. DepthmapX uses these line paths to calculate integration. Integration is a measure that outlines which paths require the least amount of connections to access relative to all other lines in the network (Charalambous \& Mavridou 2). This is irrespective of metric distance, but instead, directional changes. In an integration assessment, maps are coloured in a gradient from red to blue, indicating each segment's integration value from high to low. These colours give insight into the type of activities that could take place in such areas, with highly integrated areas more suitable to contain high quality amenities and civic spaces (Hillier 123).

Wellington's road centrelines will be used to represent Wellington's path's of accessibilty in DepthmapX. Tsunami and liquefaction risk zones provided by Wellington City Council will be the areas used to define inundated areas under a strong earthquake scenario. Although the city centre is the area of focus, Wellington's entire road network, tsunami, and liquefaction risk areas will be considered (Figure 1.8). Inundated areas outside of the city centre may change the movement patterns of the city centre. Assessing the accessibility of Wellington's city centre using only tsunami and liquefaction risk areas will not be fully indicative of the effects of a strong earthquake scenario. However, this assessment will provide a starting point to locate the integrated areas that would best serve Wellington's displaced population.

\subsubsection{Testing}

The road pattern of Wellington's city centre is naturally integrated, illustrated by the dominant presence of red and orange coloured road lines (Figure 1.9). This can be attributed to the centre's compact nature, its rigid structure, and alignment of collector roads which extend between the edges of the CBD to the waterfront providing clear sightlines and efficient pedestrian links. 


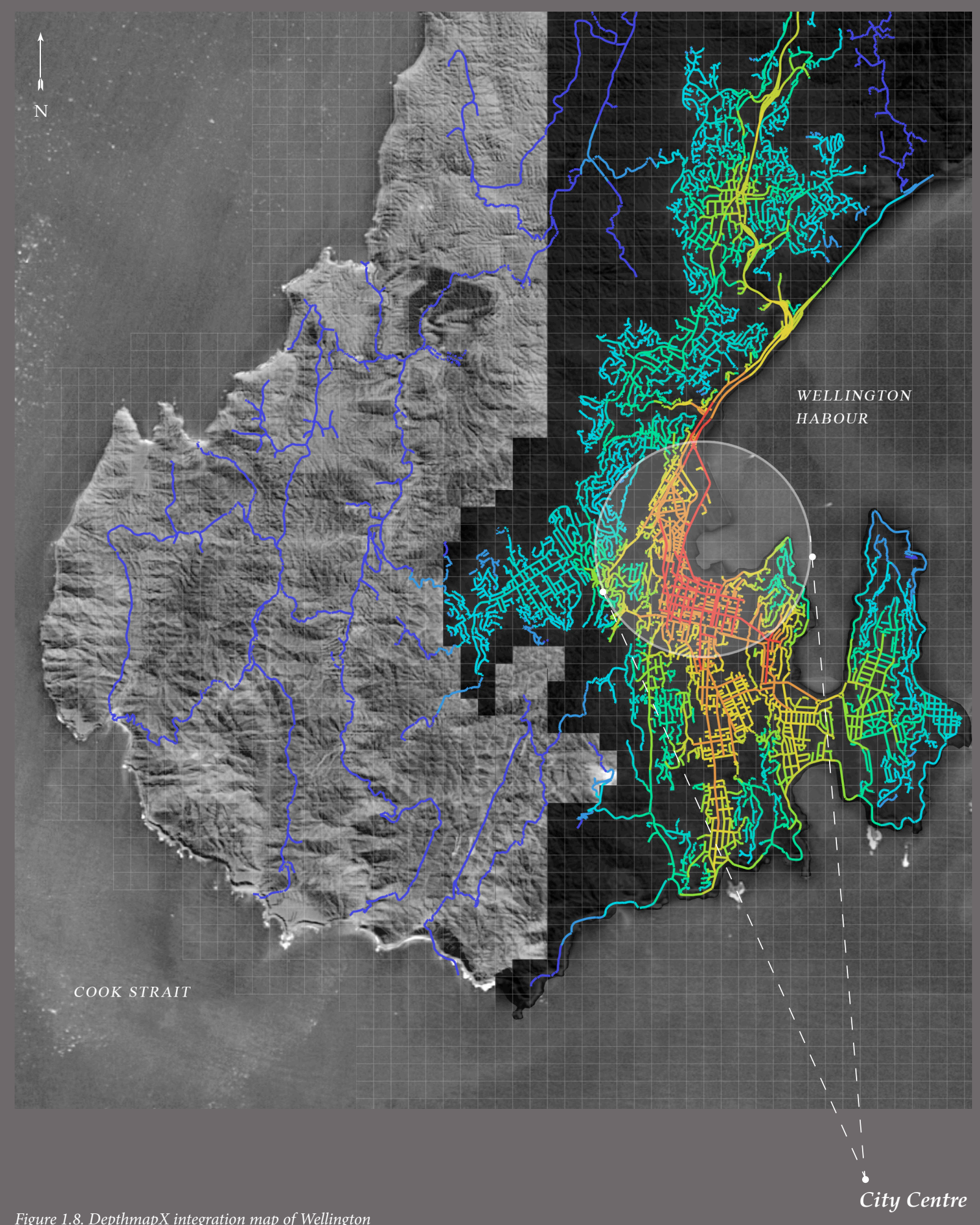

Region. (Aerial image source: NASA, 2000) 
Base Graph

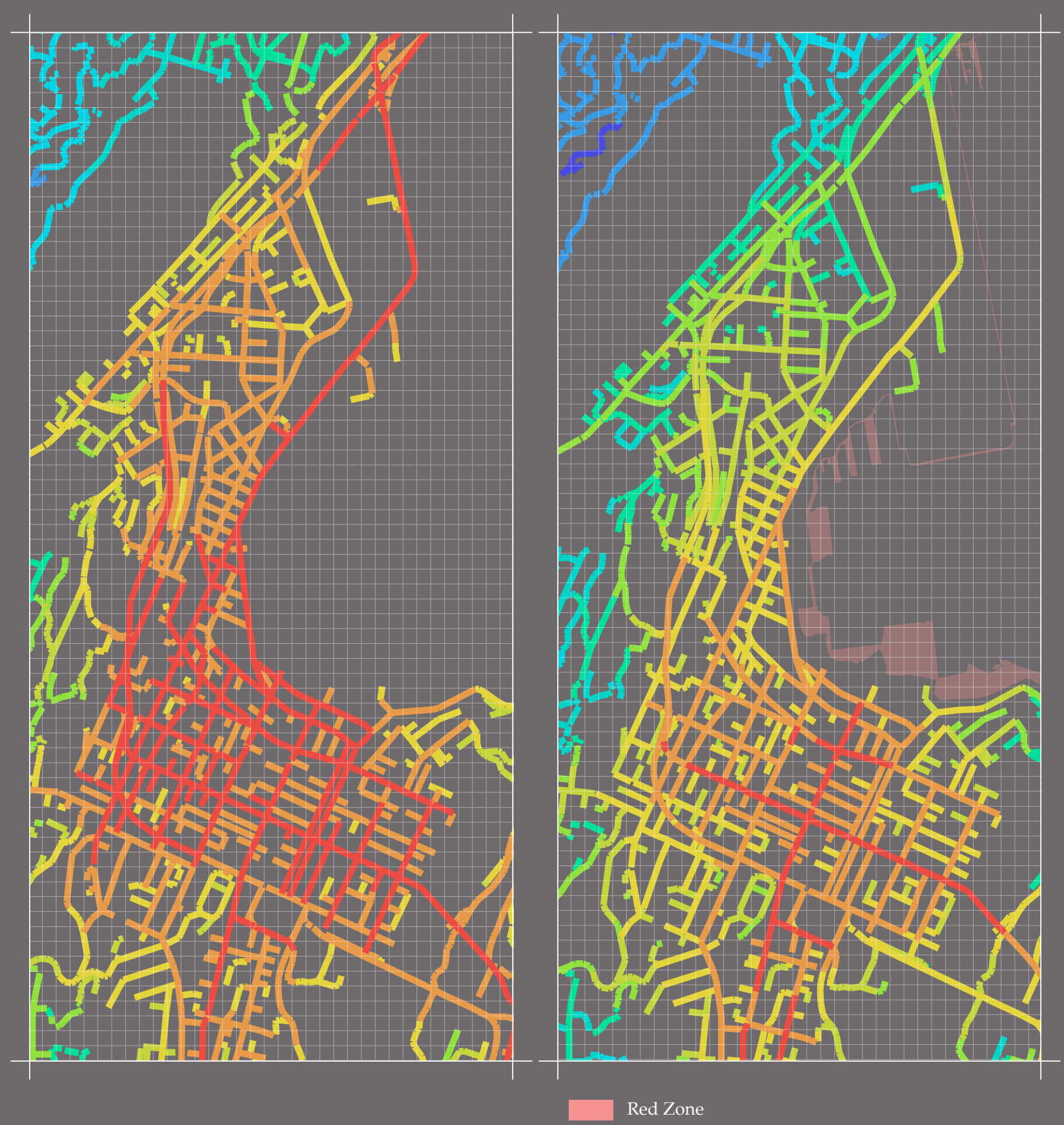

1 in 100 Year Tsunami Inundation

Connectivity Spectra

Secluded

Figure 1.9. Depthmapx integration graph of Wellington's city centre 
1 in 500 Year Tsunami Inundation

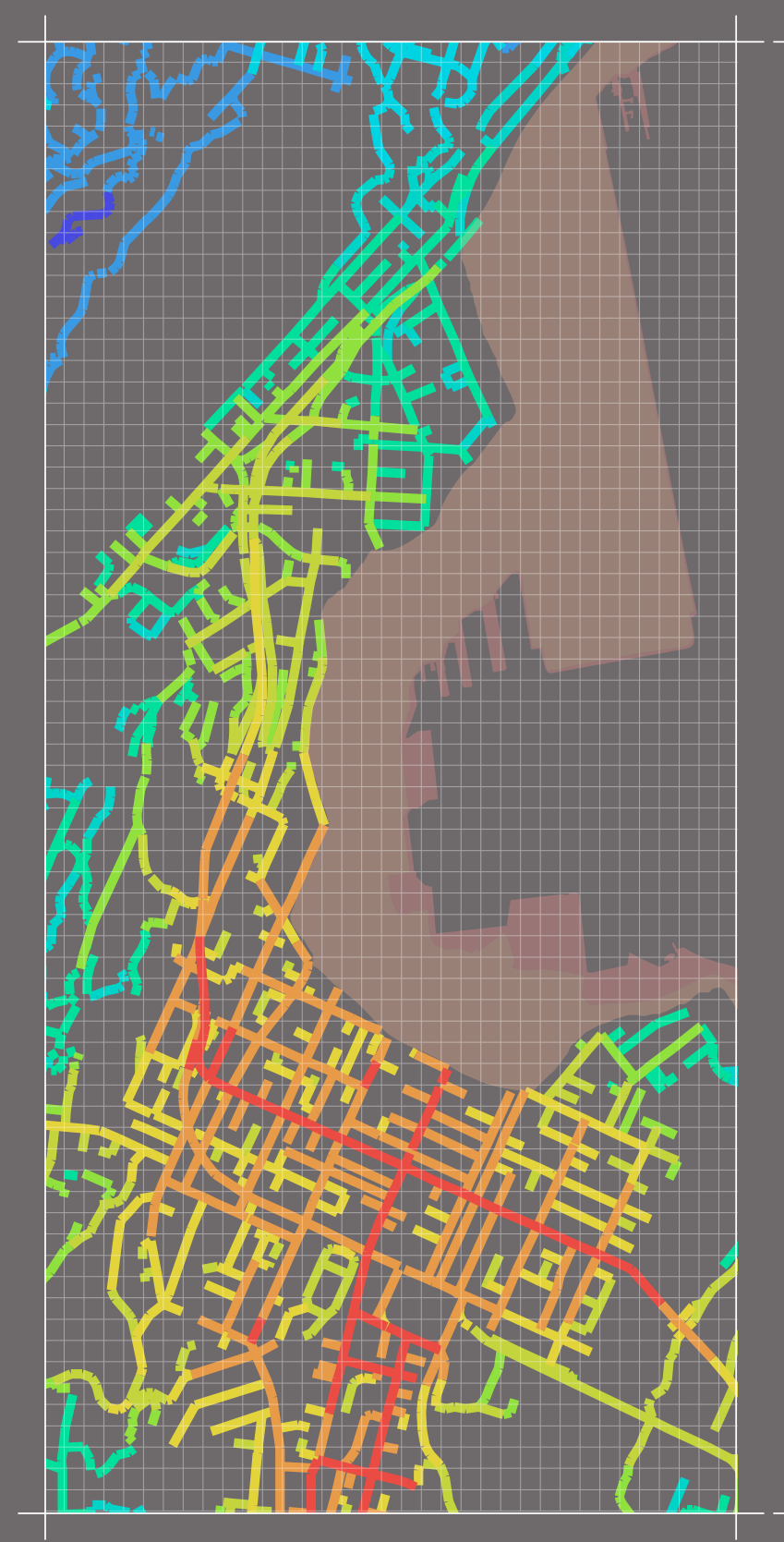

Red Zone

Orange Zone
1 in 2500 Year Tsunami Inundation

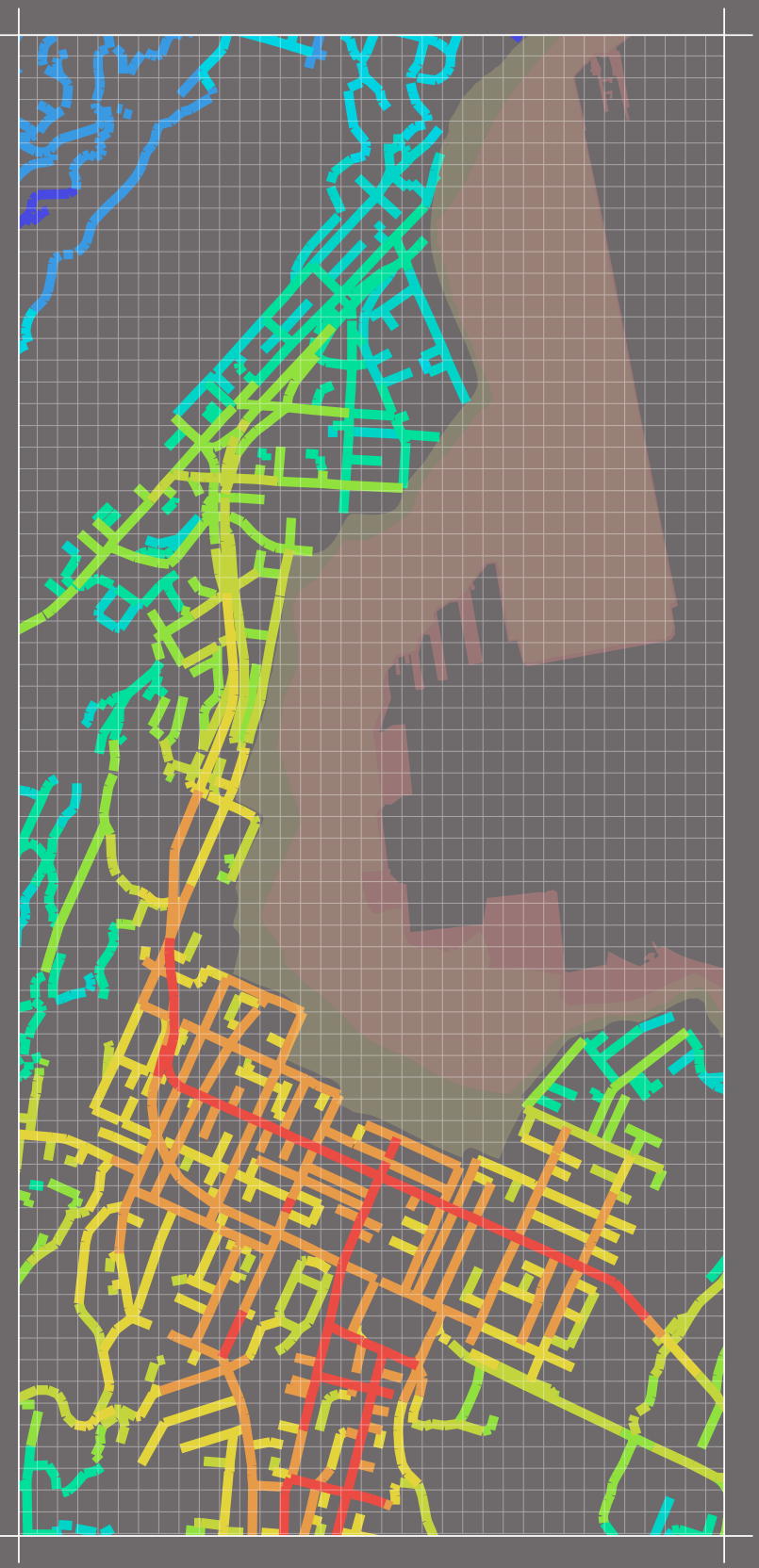

Red Zone

Orange Zone

Yellow Zone

Connectivity Spectra

Secluded

Figure 1.11. Depthmapx integration graph of Wellington's city centre road lines when region's red and orange zone areas are inundated
Figure 1.12. Depthmapx integration graph of Wellington's city centre road lines when region's red, orange, and yellow zone areas are inundated. 
High Risk Liquefaction Inundation

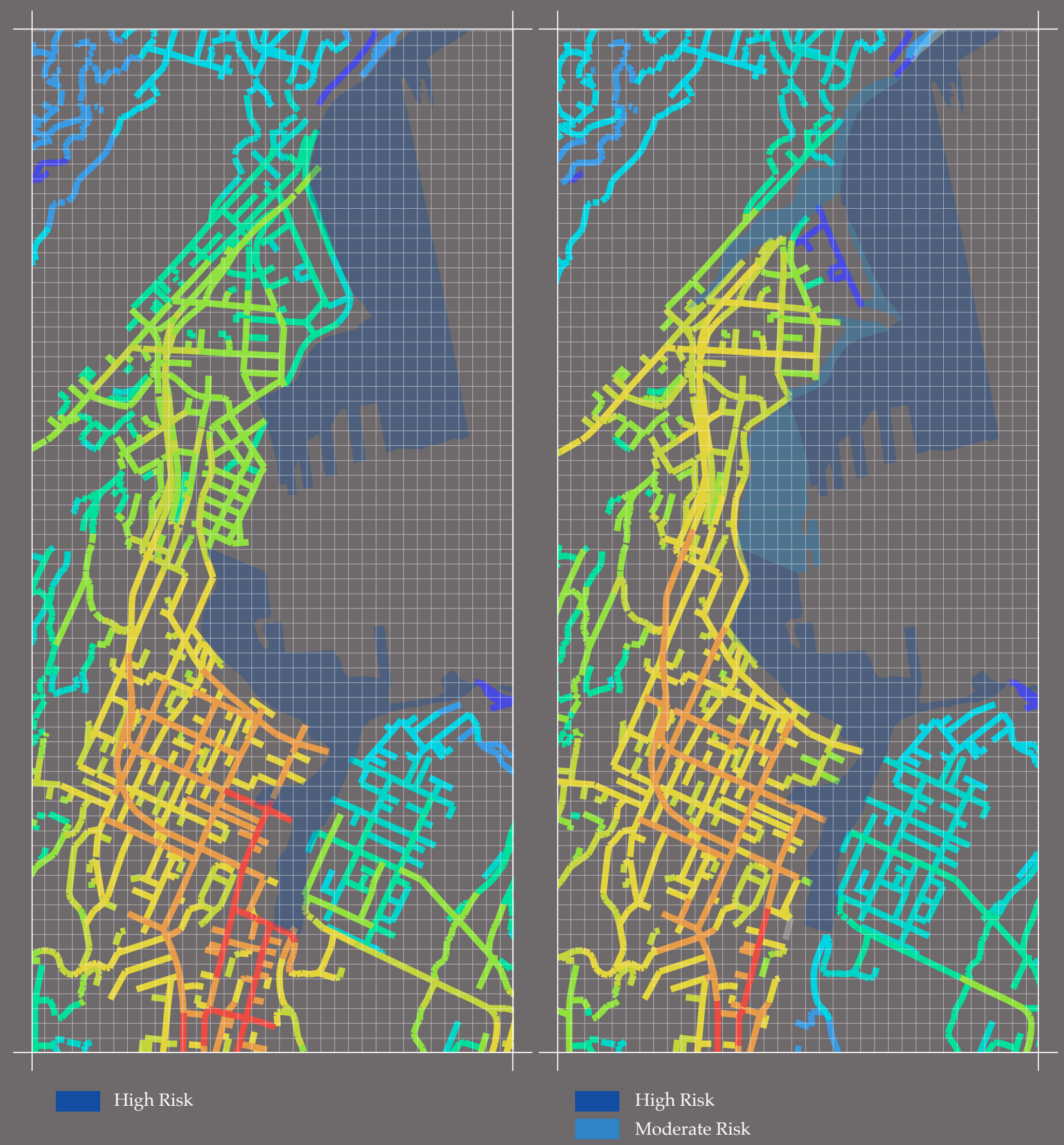

High and Moderate Risk Liquefaction Inundation

Connectivity Spectra
Integrated

Figure 1.14. Depthmapx integration graph of Wellington's road lines when region's high and moderate risk liquefaction areas are inundated 
Figures 1.11 and 1.12 paint disastrous scenarios of how far inland tsunamis can infiltrate the coastline of Wellington Habour. In these scenarios where there will be significant tsunami inundation in low lying central areas, the rigidity of the city centre's street structure remains strong. The integrated areas mostly reside along the strong east-west State Highway 1 connection providing valuable links to central eastern suburbs. These particular links retain their connective capacity, and some below the basin reserve towards Newtown, become more integrated (Figure 1.12).

Figures 1.13 and 1.14 show the effects of liquefaction to the city's accessibility if moderate and high risk zones were inundated in a disastrous earthquake event. The effects of potential inundation to the city centre's integration pattern is observed to be more drastic than that of a tsunami. A portion of the liquefaction high risk zone extends south along the eastern edge of the city centre, impeding connections to Mount Victoria, a residential neighbourhood located east of the city. DepthmapX illustrates that the effects of this scenario would cause the entirety of this neighbourhood to become more secluded. Local links within the city remain relatively integrated, especially main transport routes and pedestrian connections.

If accessible links within Wellington's inner city conserve moderate to high levels of integration, and therefore relative accessibility during large seismic scenarios, there is potential for civic spaces to have a significant role in the daily lives of those remaining and assembling in the city centre. Open spaces in integrated areas are in prime locations to be used for recovery purposes.

\subsection{Wellington's Open Space Network}

Although Wellington's array of open spaces is scattered throughout the city centre, its largest and most spacious areas are positioned in close proximity to the habour (Figure 1.15). Many of the smaller open spaces within the city are located on or near high pedestrian traffic areas and contribute to the enjoyment of the inner city, but their capacity to independently contribute to the resilience of the city is limited due to their inability to accommodate or provide utility for large numbers of people. Additionally, their close proximity to tall and old buildings may cause their premises to be uninhabitable due to building structural failure and the risk of falling debris.

Wellington's hazard maps have illustrated that areas nearest to the harbour are 


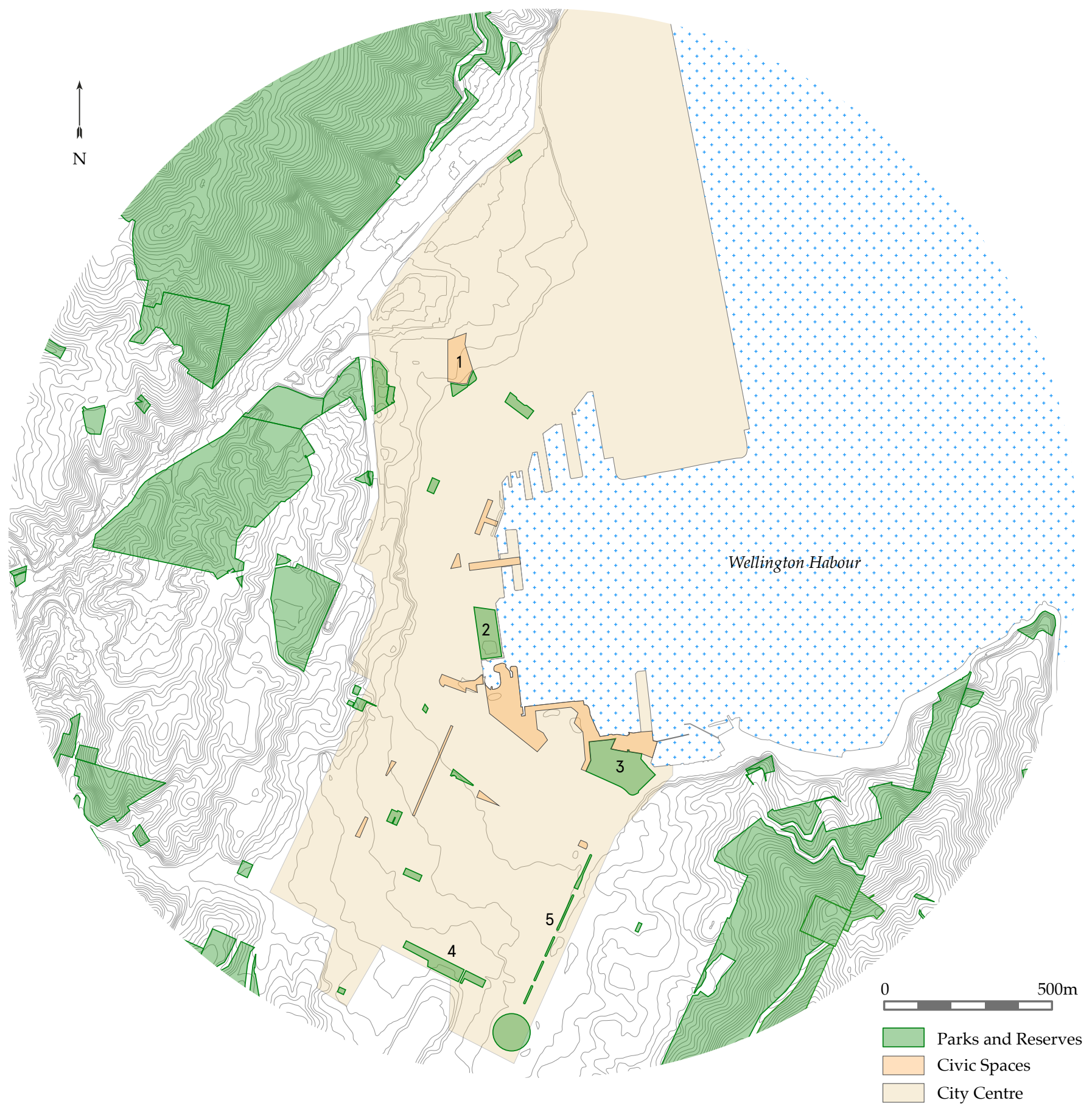

Figure 1.15. 5 m contour map of Wellington's City Centre and its open space network. 1. Parliamentary Grounds 2. Frank Kitts Park 3. Waitangi Park 4. Pukeahu National War Memorial Park 5. Cambridge and Kent Terrace. 
highly susceptible to tsunami and liquefaction inundation (Figures 1.4 and 1.5). Unfortunately, this is where Wellington's largest volume of civic space resides. This only leaves Parliamentary Grounds, Pukeahu National War Memorial Park, and the medium strip between Kent and Cambridge Terraces as potential spaces that can be used as assembly and recovery areas. DepthmapX has shown that the links Pukeahu Park and Kent and Cambridge Terrace are located on and are connected by retain a moderate degree of connectivity under forecasted tsunami and liquefaction inundation simulations. If these open spaces will be locally accessible, these spaces need to equipped and designed to cope with the sudden influx of displaced people and their needs.

\subsection{Conclusion}

Wellington's seismic vulnerability is embedded within the culture of its residents. The shape of the coastline serves to remind its residents of the enormous power these natural occurrences have. But, the Kaikoura earthquake in 2016 exposed social ambiguity and vagueness in evacuation procedures. Even if there had been clarity in these areas, there are no formally designated safe or refuge areas where displaced residents and communities can evacuate to and assemble. Reports have forecasted what Wellington will experience in a devastating quake. Buildings will be damaged, and electrical, water, transport, and sanitation infrastructure will be heavily compromised for months. Residents will be without homes.

Open spaces, particularly those in the city centre where there is the highest density of people, have the potential to prepare residents for their foreseeable disaster vulnerabilities, and provide refuge, resources, safeguard, and clarity during periods of turmoil and calamity. 


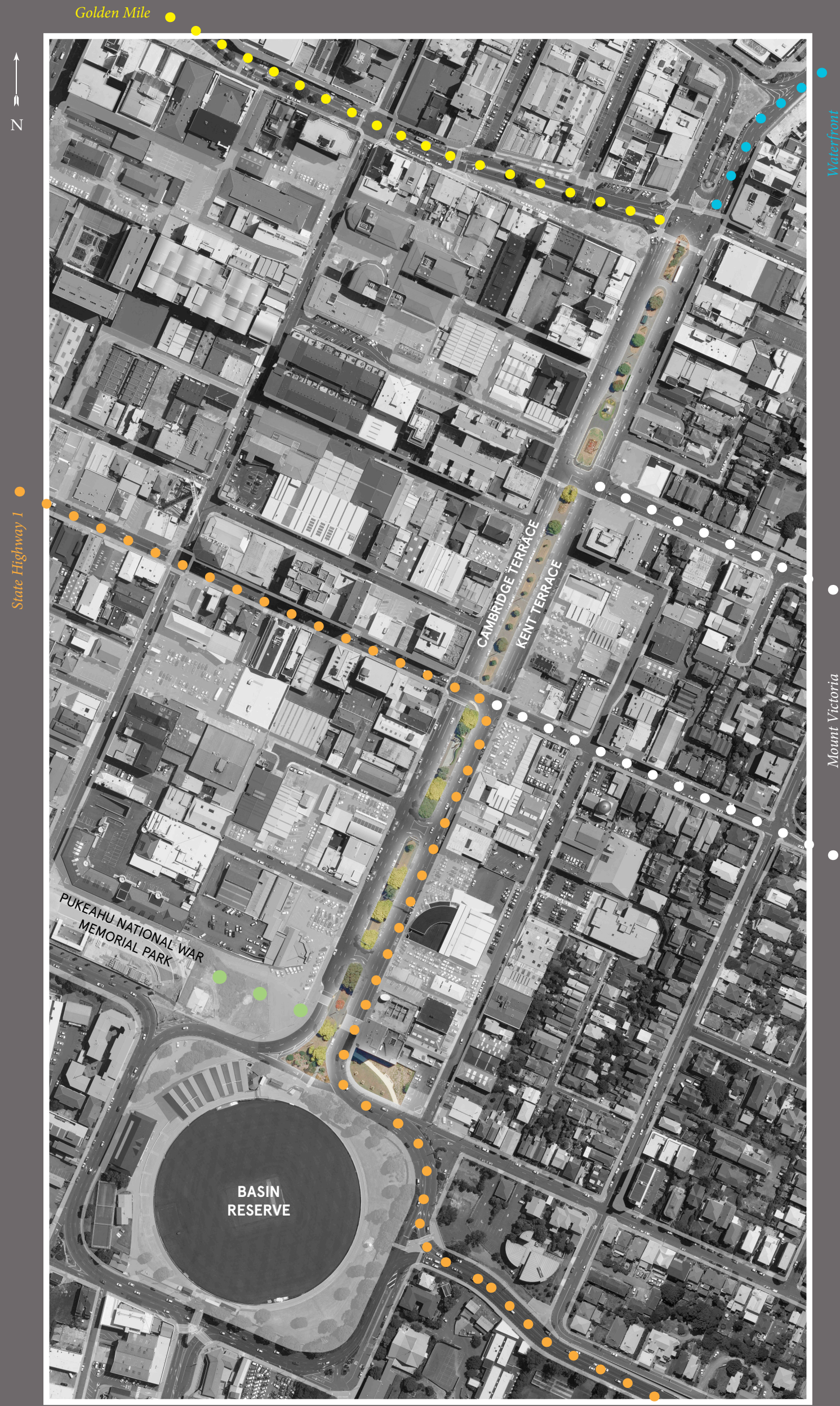

Figure 2.0. Aerial imagery of Kent and Cambridge Terrace, the public space that is located between them, and its connections. (Aerial image source: Land Information New Zealand) 


\section{0}

\section{SITE: KENT AND CAMBRIDGE TERRACE}

Deemed a park and recreational space by the Wellington District Plan, the long and narrow median strip located between Kent and Cambridge Terrace will be chosen as the pilot site of this thesis (Figure 2.0). It is a space that is significantly under utilised given its formal recognition as a park. This is largely the result of the predominance of high vehicle traffic occupying the both Kent and Cambridge Terrace. The site is vulnerable to tsunami and liquefaction inundation, but is a crucial link for residents to access the city from the central eastern suburb of Mount Victoria. There is potential for this space enliven the terraces and extend the city's golden mile, but also act as a refuge area in the aftermath of a seismic disaster. 

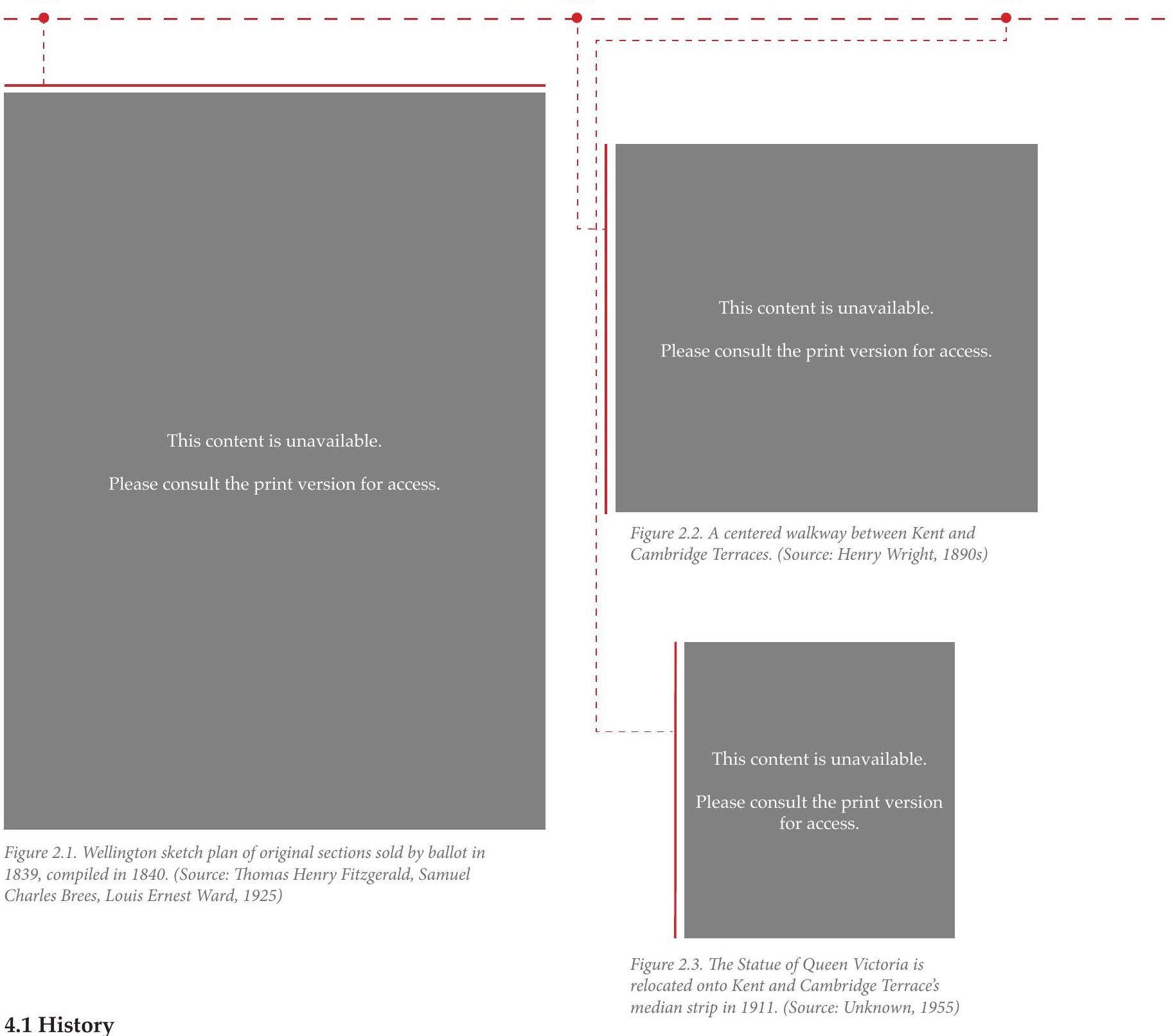

\subsection{History}

The site of Kent and Cambridge Terrace was originally destined to become a stream that lead into a lagoon now known as the Basin Reserve. It was to become a canal that connected the waterfront to the Basin Reserve (Figure 2.1). This plan was abandoned after the 1855 Waiarapa earthquake caused uplift to the site and the Basin Reserve. Now inhabitable, the site was made into a set of terraces and the median space between them was paved with a walkway for pedestrian use (Figure 2.2). Figure 2.4 illustrates how the walkway was laid out. The median stretched along the entirety of the terraces allowing pedestrians to seamlessly traverse the site without encountering vehicles. The Statue of Queen Victoria, the most prominent feature on the median, was erected on the site in 1911 (Figure 2.3). 


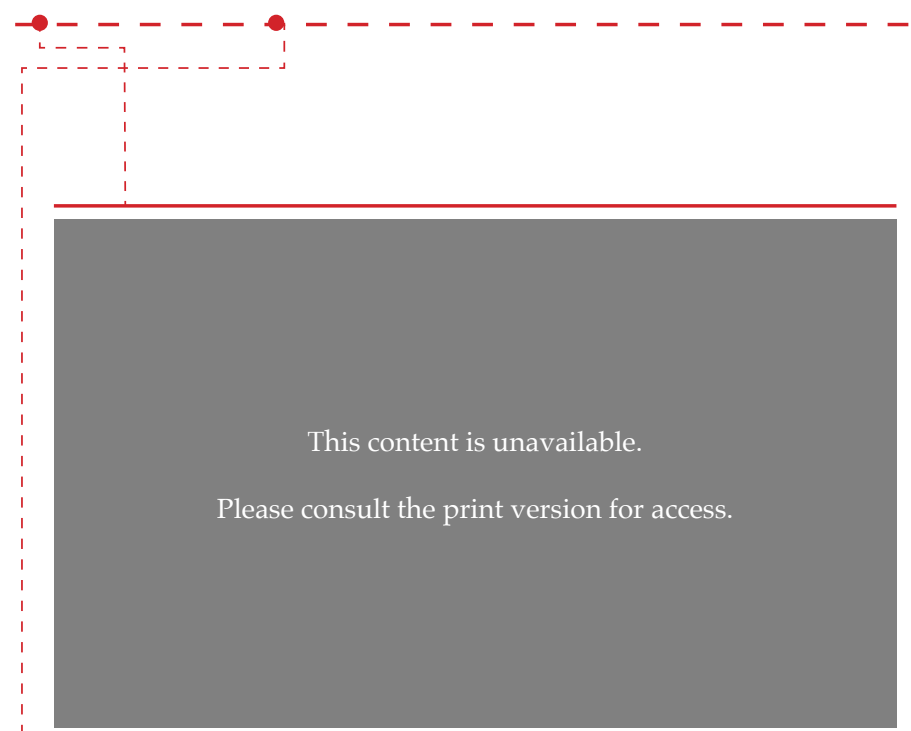

Figure 2.4. Top down view of the site and its wide footprint (Source: Transpress, 1920s)

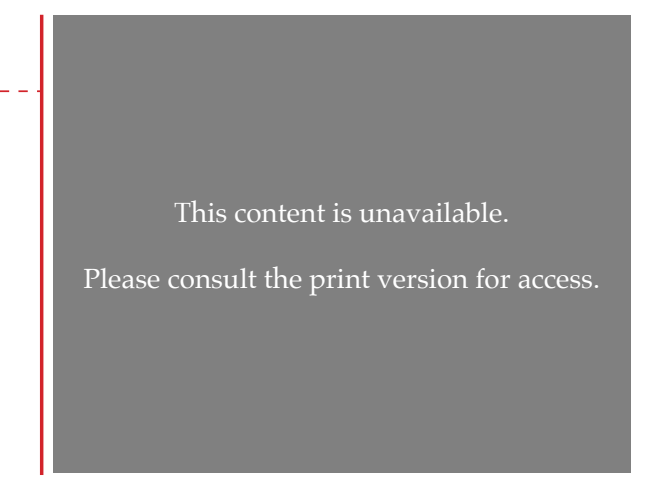

Figure 2.5. Green spaces now occupy the centre of the median, pushing pedestrian walking areas to the perimeter. (Source: W H Thorley, 1927)

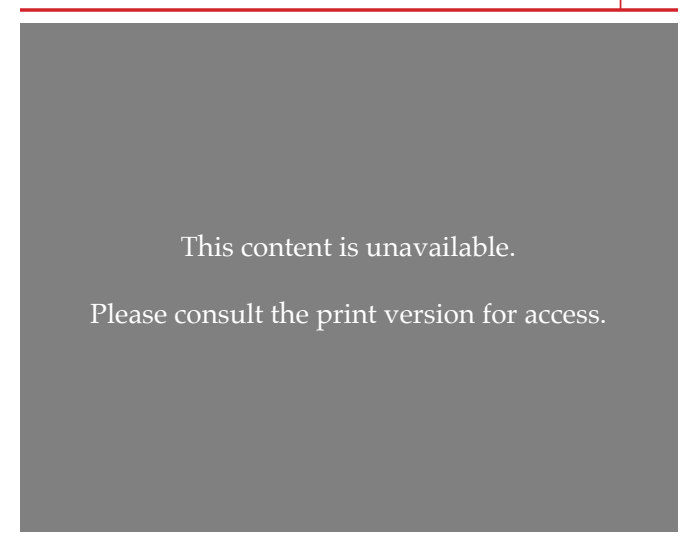

Figure 2.6. James Smith's Christmas Parade floats passing down Kent Terrace. (Source: K E Niven, 1962-1968)

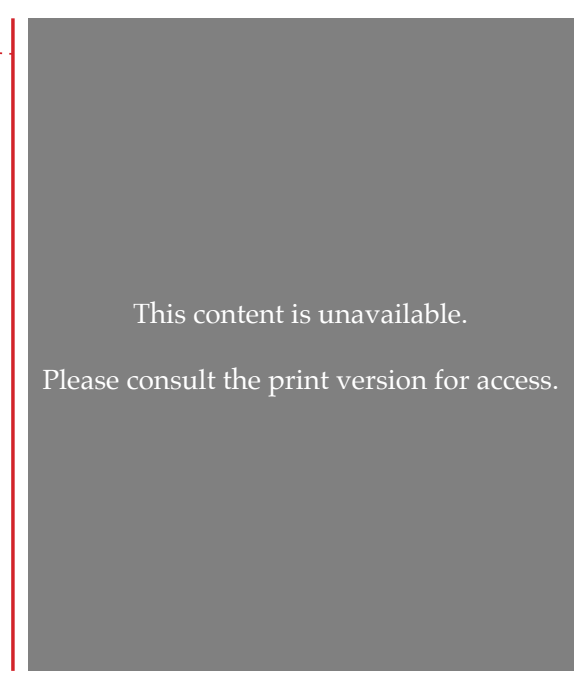

Figure 2.7. Aerial view of the median looking south after its largest transformation (Source: Evening Post, 1931)

The typology of the median was then restructured. Grass, flower beds, and trees were moved to the centre of the median, pushing pedestrian walking areas to the perimeter (Figure 2.5). This new typology allowed pedestrians to line the streets of large annual parades such as the James Smith's Christmas Parade (Figure 2.6). The use of Kent and Cambridge Terrace for similar entertaining purposes has since been lost. But, due to the heavy vehicular presence on the site such activities would be ill-fitting. Figure 2.7 shows the median's largest transformation, where the width of the space is narrowed and segmented to prioritise the flow of motorised transport. This iteration of the park remains at the time of writing. 


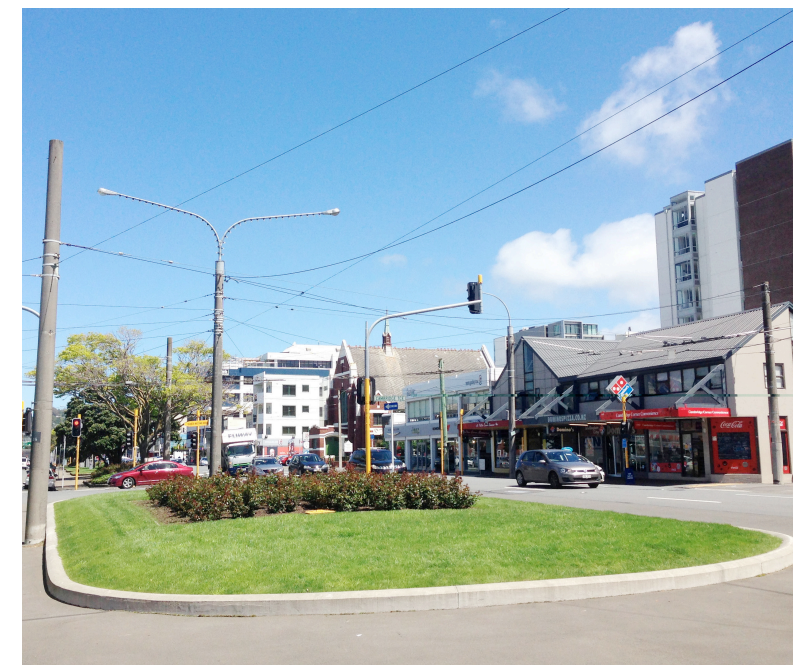

Figure 2.8. The median strip's grassy open areas. (Source: Author's photograph)

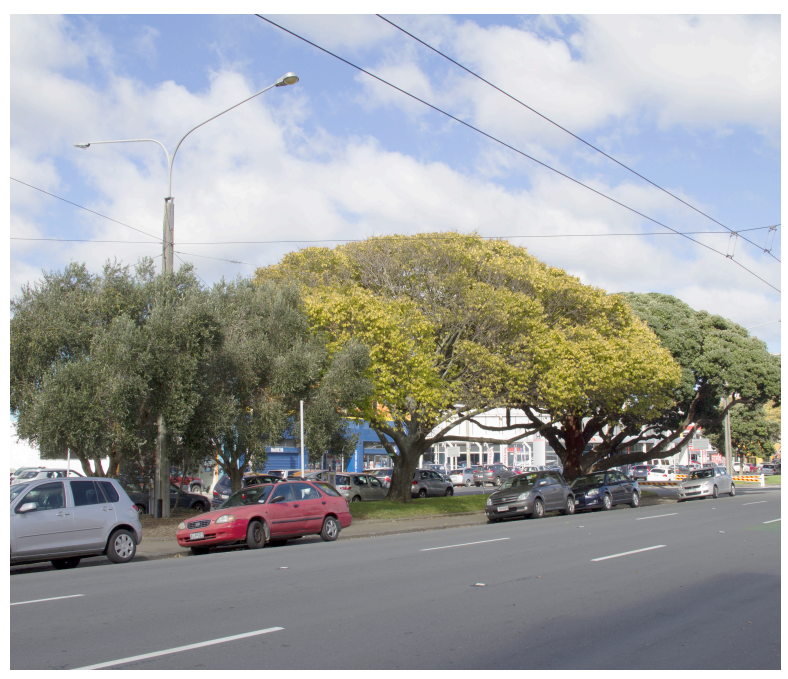

Figure 2.10. Large trees dwarf the size of the median. (Source: Author's photograph)

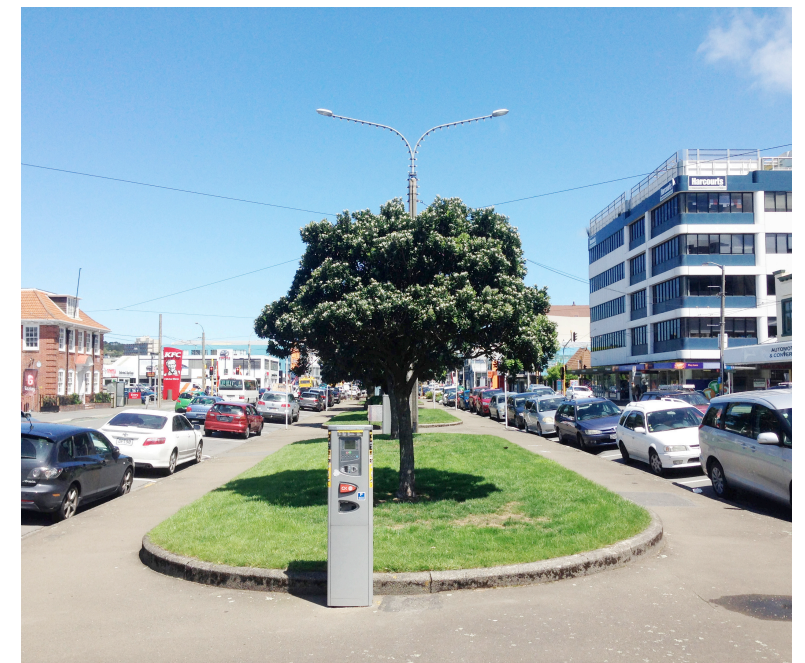

Figure 2.9. View of the median strip amidst the typical vehicular activity moving along the terraces. (Source: Author's photograph)

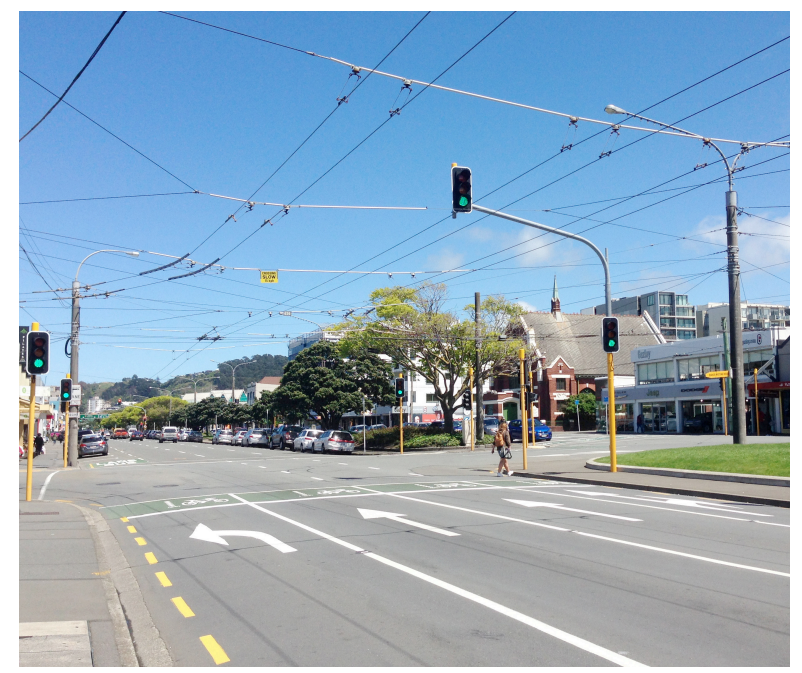

Figure 2.11. Traffic signals are the only safe way of accessing the median. (Source: Author's photograph) 


\subsection{SWOT Analysis}

\subsubsection{Strengths}

Naturally, the site of Kent and Cambridge Terrace contains strong north to south sight lines (Figure 2.0). Its linearity provides efficiency in wayfinding, and as DepthmapX has communicated, connects with a multitude of highly accessible links that run from east to west (Figure 1.9). The Basin Reserve, Courtenay Place, Mount Victoria, the Waterfront, and Pukeahu National War Memorial Park are the major areas the site directly links with (Figure 2.0). The site provides a strong physical link in connecting some of Wellington's largest open space network assets. Additionally, the median park has sufficient sunlight exposure that warms and brightens the few seating areas that are installed on site (Figure 2.8).

\subsubsection{Weaknesses}

The entirety of the site is prone to flooding, considered to highly vulnerable to liquefaction, and a portion of its northern end is conceived to be within varying tsunami inundation zones (Figure 2.13). Predicting that the site's street level can be occupied in a large earthquake scenario cannot be guaranteed. Currently, the Kent and Cambridge Terraces are arterial roads, functioning to accommodate a significant amount of vehicular traffic for the city. There are three lanes of traffic in each direction, and as a result, there is a large presence of moving motorised vehicles on the site (Figure 2.12). The ample car parking and numerous car yards within the vicinity amplify the dominant presence of vehicles on site (Figure 2.9).

The median itself is unattractive and seldom utilised by pedestrians for leisurely purposes, even when the weather is favourable. The layout of the park is predictably rhythmic, offering minimal intricacy as one moves through the space. Some of the trees that line the median actually dwarf the width of the median, reducing the perceived usable area of the park (Figure 2.10). Access between the segmented median is incredibly inefficient. The only way for pedestrians to travel between median segments is to jaywalk. Pedestrians will need to take inefficient routes to cross medians if wanting to do so safely, having to interact with 3 traffic signals in order to cross one segment of the median (Figure 2.11). 


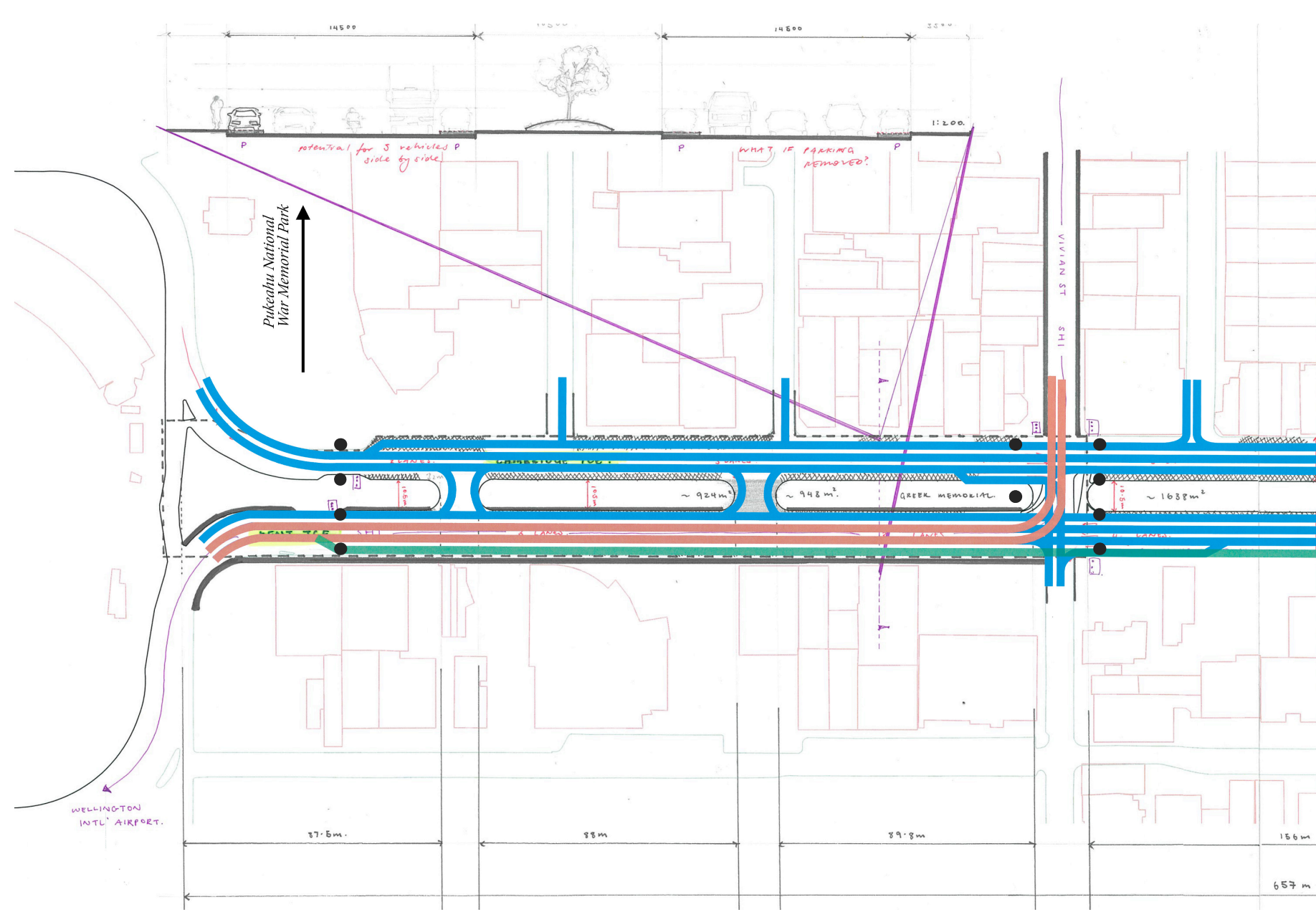

Figure 2.12. Plan of the current median strip against the roading infrastructure of Kent and Cambridge Terrace.

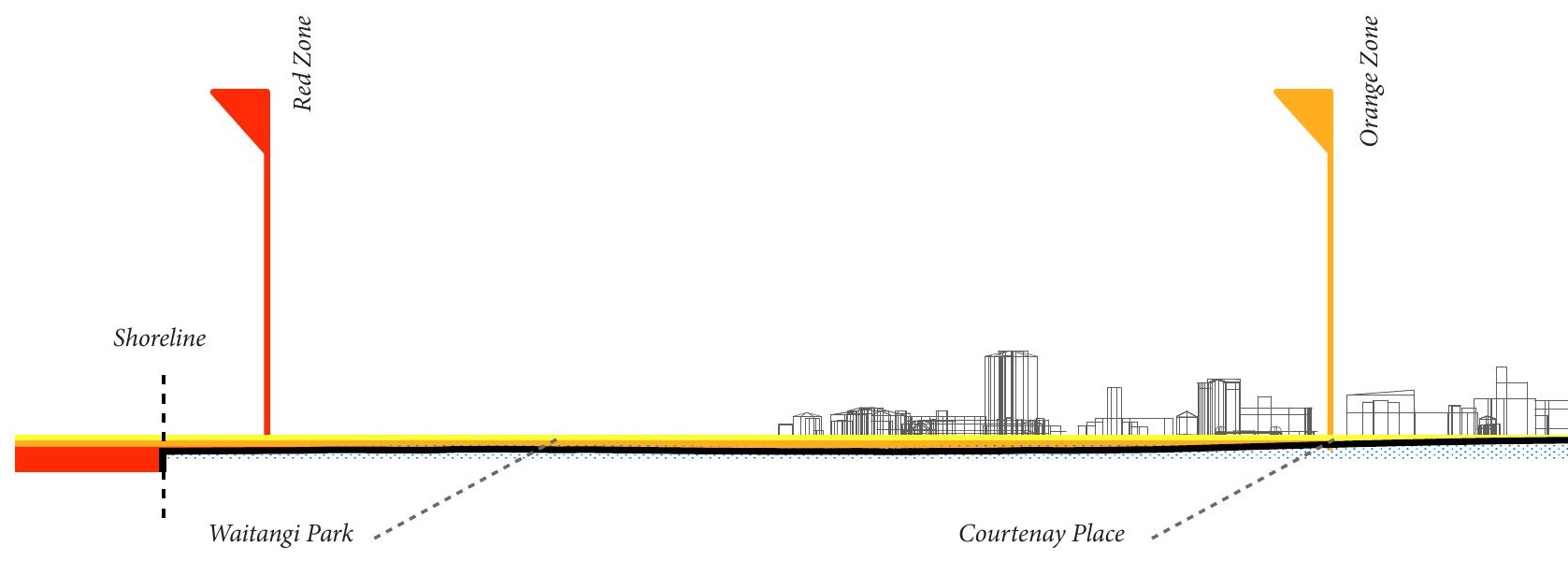

Figure 2.13. Long section of the median site and the range of forecasted tsunami inundation. 


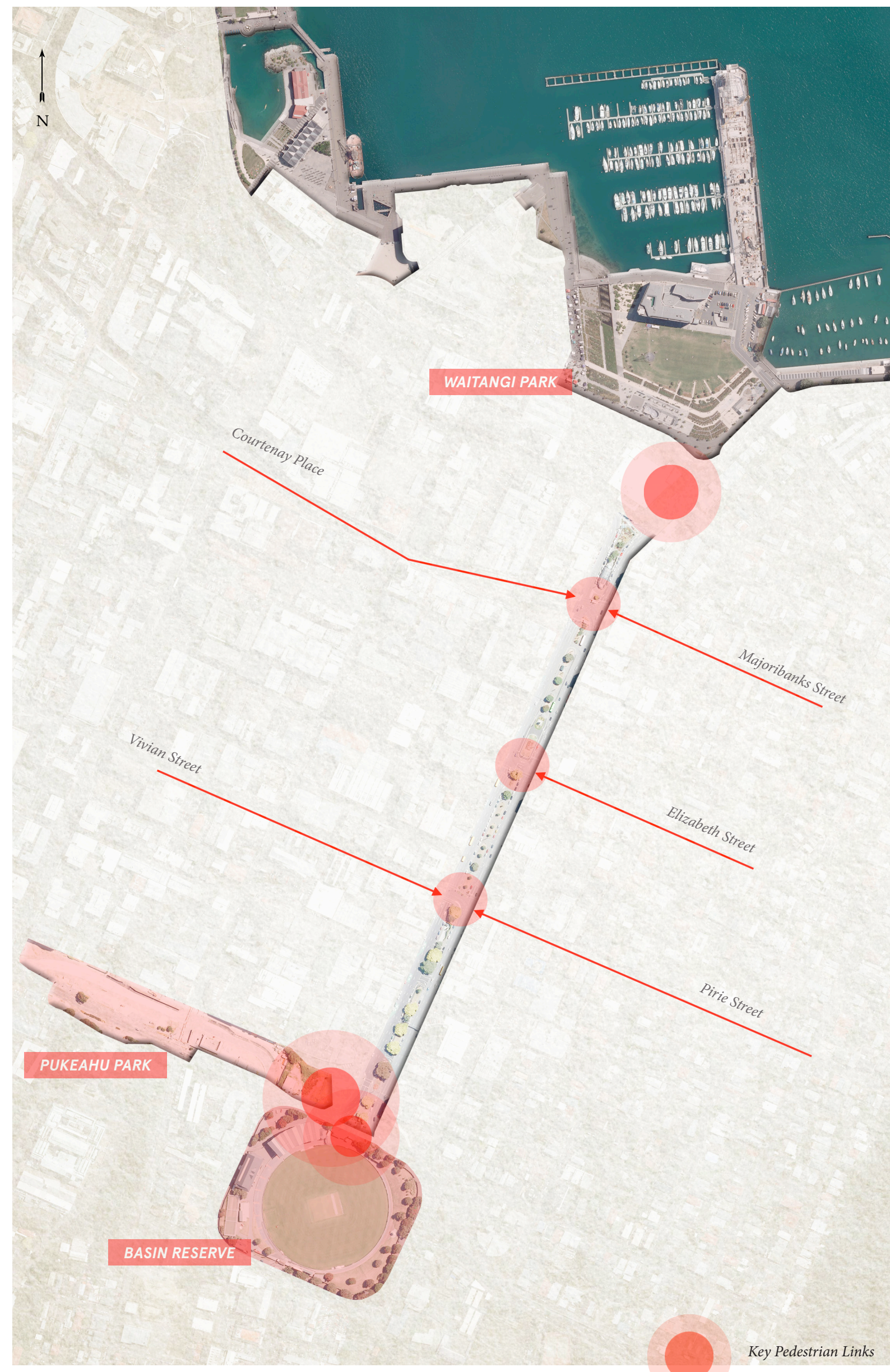

Fiqure 2.14. Map of site's important pedestrian links to other open spaces and main connections.

Key Pedestrian Links 


\subsubsection{Opportunities}

Since inhabiting the site at street level after a large seismic disaster is implausible due to likely liquefaction and tsunami inundation, the median would need to be elevated above the ground level in order to allow the site to be occupied in post seismic disaster situation. Elevating the median and its cross connections could establish resilient connections to Mount Victoria, which shown by DepthmapX simulations, would be significantly secluded in a large seismic disaster (Figure 1.14).

Making the median more continuous and with greater formal links to the sidewalk would allow pedestrians to have greater accessibility to and along the site. It would remove the safety and efficiency issues of crossing between medians giving priority to pedestrians over vehicles. This was what the median was in the past, and a return to this direction of typology would make the median easier to interact with and occupy for pedestrians.

Strengthening the connections to other open spaces would allow the site to become a tangible path to exploring Wellington's open space network (Figure 2.14). Particularly from the waterfront to the Basin Reserve and Pukeahu National War Memorial Park. In a post disaster scenario, these connections would better help people evacuate the shore, but also, travel between potential distribution and assembly areas efficiently and safely.

\subsubsection{Threats}

Considering Kent and Cambridge Terraces are still relatively low lying areas, any plans to elevate the median above the reach of a worst possible tsunami surge would require the height of the park to extend beyond the first floor of the buildings on the site. This would increase the difficulty of accessing this elevated space, especially for those who struggle with mobility. Lateral sightlines from Cambridge Terrace to Kent Terrace can be compromised if the method of elevating the median space is not permeable. Intentionally moving people to a different level than street level can also cause street level environments to become less active.

Considerations to give priority to pedestrians will have ramifications on how motorised traffic will behave. Alterations to the median should not have undermining effects on the vehicular efficiency of the roads, as the roads still have to maintain their vehicle capacity. 


\subsection{Proposed Redevelopment}

Local authorities are aware of the site's need for redevelopment. The Wellington City Council has recognised this, referring to the terraces as corridors instead of places where people want to spend time. They understand the overwhelming presence of vehicular activity, the wasted potential of the median strip for pedestrian use, and the unattractiveness of the area for pedestrians. The Council, in their 'Central City Framework' is proposing to redevelop the site within the next decade with the intention of:

- transforming the median strip into a linear park, strengthening connections to the Basin Reserve, Waitangi Park, and Pukeahu National War Memorial Park (61)

- transforming the streets into boulevards through landscaping (34)

- promoting active uses at the street level through residential development and creating more opportunities for businesses to open (70)

- introduce filtration and hydrological systems within the median landscaping to improve street run off and reduce surface flooding (59)

- strengthen transport connections for buses, cycles, pedestrians, and private cars (34)

\subsection{Conclusion}

The site analysis in this chapter has created a set of fundamental design considerations that can be investigated during the design experiment: The guidelines that have arisen from this site analysis include:

- elevating the site so that inhabitable spaces can function post-disturbance

- create opportunity for intentional pedestrian activity

- retain important north south sight lines

- not hinder current traffic activities

- reintroduce the historical significance of the site, and how it can be adapted to the connection between waterfront to basin reserve and the war memorial park

- be inclusive of surrounding stakeholders, ensuring life on the footpath is not impaired with an elevated space overhead the site 


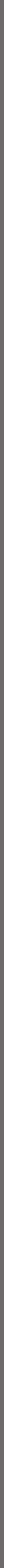




\section{0}

\section{PROGRAMME ANALYSIS}

Incorporating the complexities of Kent and Cambridge Terrace, and the foreseeable hazards the site and the city are at risk of, this section oversees the necessary features for the site to be efficiently utilised in a post disaster scenario. Guidelines provided by The International Federation of Red Cross for refugee planned settlements provides specifications on the infrastructure needed to ensure displaced people occupying the site for week long to monthly periods can do so safely and healthily. 


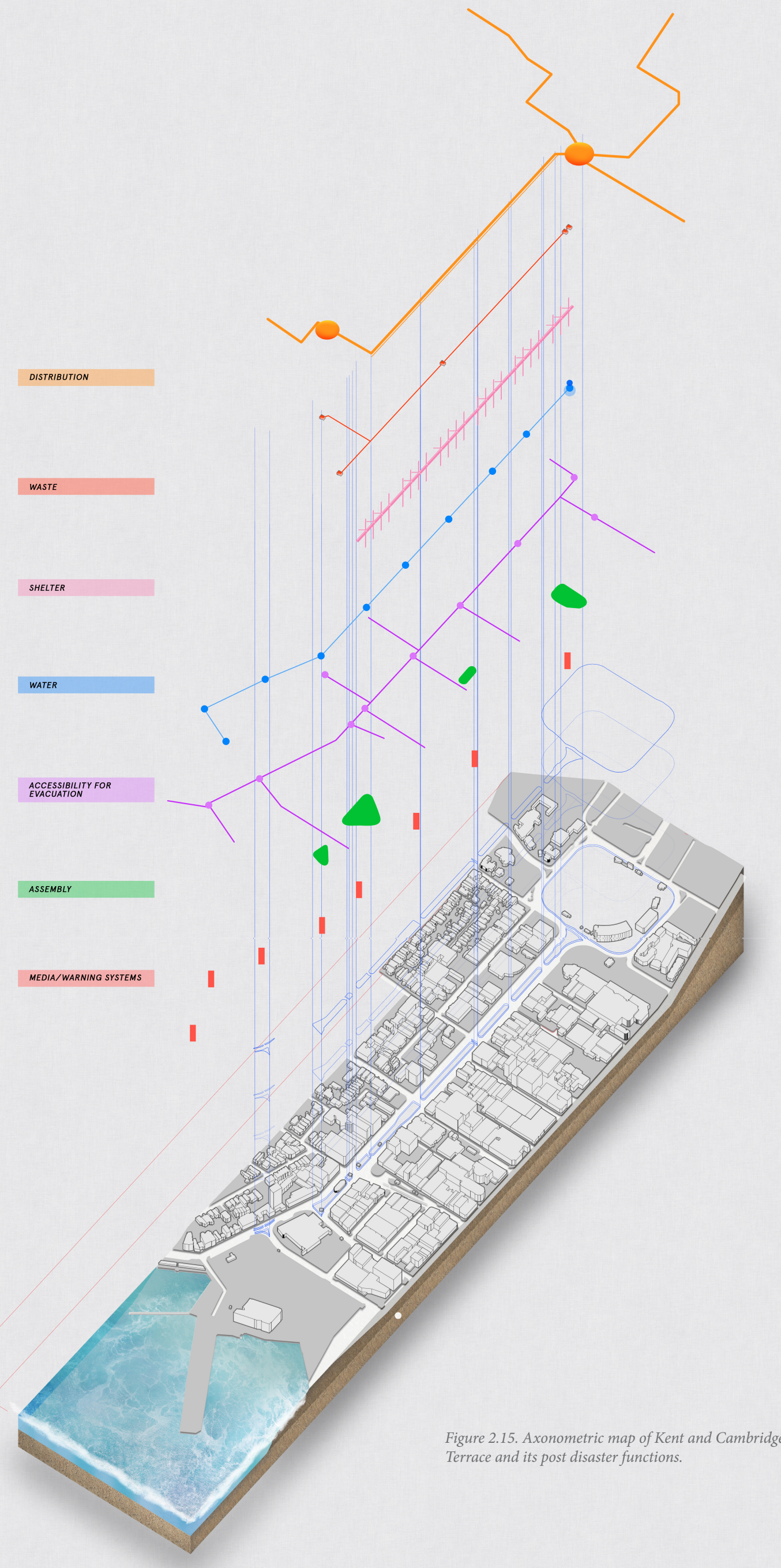




\subsection{Vertical Garden and Walkway}

A vertical garden and walkway can provide a physical and psychological refuge from the forecasted inundation below. Elevating the site is a adaptive strategy that accepts the reality Wellington's seismic risks. The vertical garden will look to provide surrounding residents with a sense of ownership of the site. The vertical garden is a specialised programme to entice users from street level to engage with the elevated space. The intention is for these elevated spaces to become adaptable in the recovery of seismic events. Incorporating semi private and public areas with permeable thresholds that can be fortified to create formal spaces for meeting, sleeping, and leisure will ensure the social activities required in a post disaster scenario can be efficiently accomplished. The walkway and garden will provide direct physical connections to pedestrian amenities including, Waitangi Park, the Basin Reserve, War Memorial Park, Courtenay Place, and Mount Victoria. These links will supply central communities with efficient pathways to assemble and evacuate low lying areas in a post disaster scenario.

\subsection{International Federation of Red Cross and Red Crescent Societies Guidelines}

The International Federation of Red Cross and Red Crescent Societies (IFRC) have published guidelines for parks that have the capacity to function as planned and managed camps for refugees. These guidelines are targeted towards a highly specified displacement of people who do not have a home to go back to visit, and who may be ethnic minorities escaping from a politically driven disturbances in their home countries. They include infrastructural guidelines including, settlement planning, collective spaces and services, sleeping arrangements, water, sanitation, and waste.

The target group of IFRC Planned Settlement Guidelines differ from the target from in this thesis investigation. The expected displacement of people in this thesis are those living within Wellington's City Centre, whose homes may be temporarily uninhabitable, but almost not all permanently inaccessible. The project area of this thesis is within the city centre, meaning infrastructure that can be provided elsewhere in the city does not need to provided on site. Additionally, as inner city utilities will coexist with the garden and walkway typology, permanent indoor provisions pertaining to sleeping arrangements, dining rooms, leisure rooms, staff rooms, kitchens, and security will not be explicitly followed. However, these guidelines supply valuable understanding of how essential necessities are to be provided in open areas, should they be used for emergency sheltering. Table 1 


\begin{tabular}{|c|c|}
\hline \multicolumn{2}{|l|}{ Settlement Planning Guidelines } \\
\hline Surface & $\begin{array}{l}30 m^{2} \text { per person if facilities can be provided } \\
\text { outside of site }\end{array}$ \\
\hline Safe Access & Including those with impaired moblity \\
\hline Fire & Fire breaks, escape routes, and assembly areas \\
\hline \multicolumn{2}{|l|}{ Collected Spaces and Services Guidelines } \\
\hline Necessary Spaces for Services and Activities & $\begin{array}{l}\text { Security } \\
\text { Registration } \\
\text { Information } \\
\text { Distribution areas } \\
\text { Administration and management } \\
\text { Dining areas } \\
\text { Leisure areas } \\
\text { Spaces for children }\end{array}$ \\
\hline \multicolumn{2}{|l|}{ Sleeping Arrangements } \\
\hline Surface & $\begin{array}{l}5 m^{2} \text { per person } \\
\text { Provide privacy using partitions or separate } \\
\text { rooms }\end{array}$ \\
\hline \multicolumn{2}{|l|}{ Water } \\
\hline Waterpoint Distances & $\begin{array}{l}\text { Maximum of } 50 m \text { from sleeping arrangements } \\
\text { or collective spaces, should be safely accessible } \\
\text { with good illumination }\end{array}$ \\
\hline Washing & $\begin{array}{l}\text { Atleast one basin per } 100 \text { people } \\
\text { One showerhead per } 50 \text { people }\end{array}$ \\
\hline \multicolumn{2}{|l|}{ Sanitation } \\
\hline Toilets & 1 toilet per 20 persons \\
\hline Distances & $\begin{array}{l}50 m \text { from sleeping arrangements, } 20 \mathrm{~m} \text { from } \\
\text { dining areas }\end{array}$ \\
\hline
\end{tabular}

Table 1. Spatial guidelines as prescribed by the IFRC Planned Settlement Guidelines. (Source: International Federation of Red Cross and Red Crescent Societies, 2016)

specifies the spatial requirements from IFRC Planned Settlement Guidelines for medium term stay. 


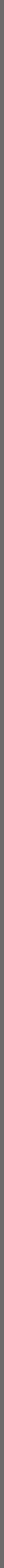




\section{0}

\section{PROJECT REVIEW}

This section investigates four architectural projects that either demonstrate an urban proficiency in resilience, provide an approach to design that is insightful in addressing the site complexities of Kent and Cambridge Terrace, or exhibit design approaches to this project's interested programmes. 
Figure 3.0. Aerial rendering of The Dryline, Lower Manhattan. Source: BIG Architects

\subsection{The Dryline}

Location: New York City, USA

Development: 2014 (conceived), plans ongoing Designer: BIG (Bjarke Ingels Group) with One Architecture

The Dryline was originally an entry into the design competition, 'Rebuild by Design,' launched by the U.S Department of Housing and Urban Development to invite organisations and communities into a conversation of response, preparedness, and resilience following the devastating events of Hurricane Sandy. The Dryline proposes to encircle 12 kilometres of the coast of Manhattan, mitigating the foreseeable threat of storm surges and rising sea levels (Figure 3.0). The proposal is not merely a fortress of technology to combat the threat of rising waters. It focuses on the needs of the surrounding communities, accommodating their wants and needs through an intentional inclusion of social amenity and recreation. 
This content is unavailable.

Please consult the print version for access.

Figure 3.1. Big Bench flood protection. Source: Bjarke Ingels Group
This content is unavailable.

Please consult the print version for access.

Figure 3.2. Proposed flip-down flood walls. Source: Bjarke Ingels Group

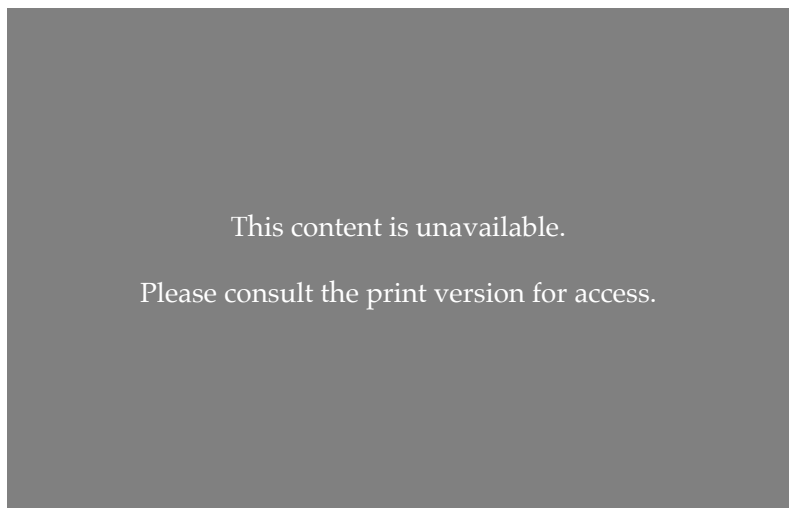

Figure 3.3. The proposed undulating berm to connect communities to the coastline. Source: Bjarke Ingels Group

It is undeniable that the intention of The Dryline's is to mitigate the effects of rising sea levels, however, based upon what is illustrated the public will actually see and experience something entirely different. What is functionally a flood safeguarding mechanism has the appearance of a skating ramp, a terraced bench, or a projected shelter (Figures 3.1 and 3.2). The Dryline is a project of adaptability, where each infrastructural safeguarding intervention disguises itself as a social utility. Their communication of design through before and after scenarios easily allows Lower Manhattan communities to visualise the delight and pleasure of the space, as well as their hazard mitigating qualities.

However, the nature of the multi-functioning embankment will obstruct any opportunity for a waterfront view if behind the embankment. Additionally, the 15 foot undulating berm between the inner city and The Dryline may act like a dividing wall between the city and the waterfront, detering spontaneous visits from people passing by (Figure 3.3). 


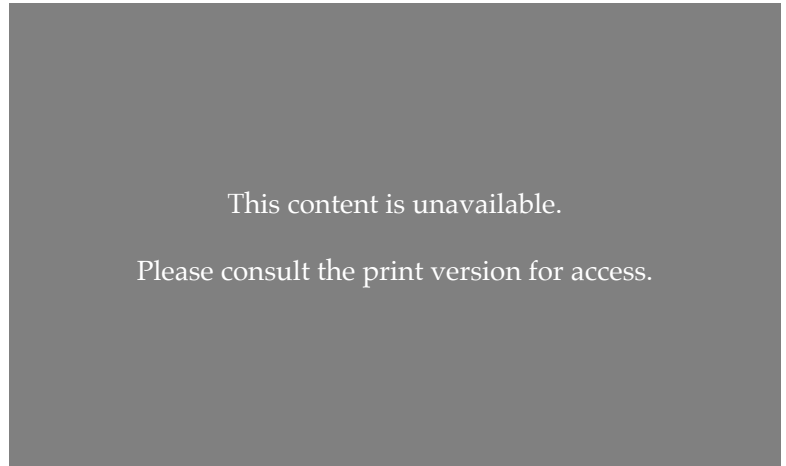

Figure 3.5. The walkway provides an alternative way to experience the park. (Source: Turenscape, 2016)

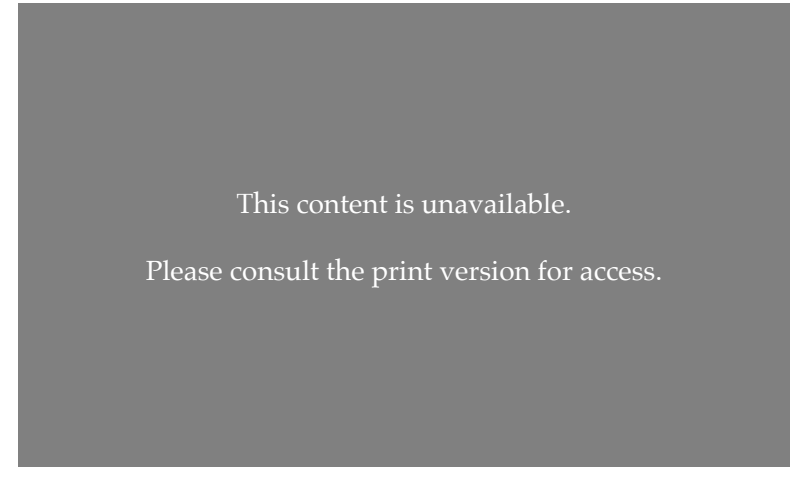

Figure 3.6. The terraced river embankments are evoke a sense of serenity and invite leisurely paced walking. (Source: Turenscape, 2016)

\title{
6.2
}

\author{
Yanweizhou Park \\ Location: Jinhua, China \\ Development: 2015 (completed) \\ Designer: Turenscape Landscape Architecture
}

Jinhua is a city split into three parts by three rivers, two of which converge into Jinhua River. Connectivity between the three bodies of land has been difficult, especially since the site of Yanweizhou Park is a peninsula that forms the point at which Yiwu and Wiyu Rivers converge into Jinhua River. Yanweizhou is a wetland that floods annually due to monsoon seasons. Original plans to fortify this peninsula with concrete terraces to create a dry land would destroy the natural ecology of the site and inhibit the any waterfront amenity. The proneness of flooding, the separation of communities across $100 \mathrm{~m}$ wide rivers, and the preservation of the city's ecology are the drivers of Turenscape's Yanweizhou Park, the winner of World's Landscape of the Year prize at the 2015 World Architecture Festival.

The park's ecological resilience is proven. A natural river embankment was 
This content is unavailable.

Please consult the print version for access.

Figure 3.7. An aerial view of the terrace river embankment and its diverse range of flood adapted vegetation. (Source: Turenscape, 2016)
This content is unavailable.

Please consult the print version for access.

Figure 3.8. A before and after aerial view of the park when river embankments are breached during wet seasons. (Source: Turenscape, 2016)

implemented around the edge of the Yanweizhou wetland. This is full of vegetation that is able to absorb the nutrients in the silt of rising waters, and store it for drier periods (Figure 3.7) As a result, the landscape does not require fertilizer nor irrigation for sustenance. Rising water levels from monsoon seasons has no longer become a disturbance for the area of Yanweizhou, but rather, is relied upon for the vitality of the site's ecology. The river embankment is terraced with a shallow gradient, and contains footpaths that allows the public to interact with the waterfront in drier seasons (Figure 3.6).

Yet, the most iconic element of Yanweizhou Park is the pedestrian bridge (Figures 3.4 and 3.5). It extends over both the Wiyu and Yiwu rivers, connecting the three islands of the city together. It serves a duality of purposes, to allow residents to navigate Yanweizhou park during wet seasons when the park cannot be inhabited, but also, to provide a scenic and intimate connection between distant communities. The pedestrian bridge provides redundancy in the way the park can be experienced (Figure 3.8). In its entirety, Yanweizhou Park is an innovative and successful resolution to the complex social and environmental issues the site and its context originally held. 


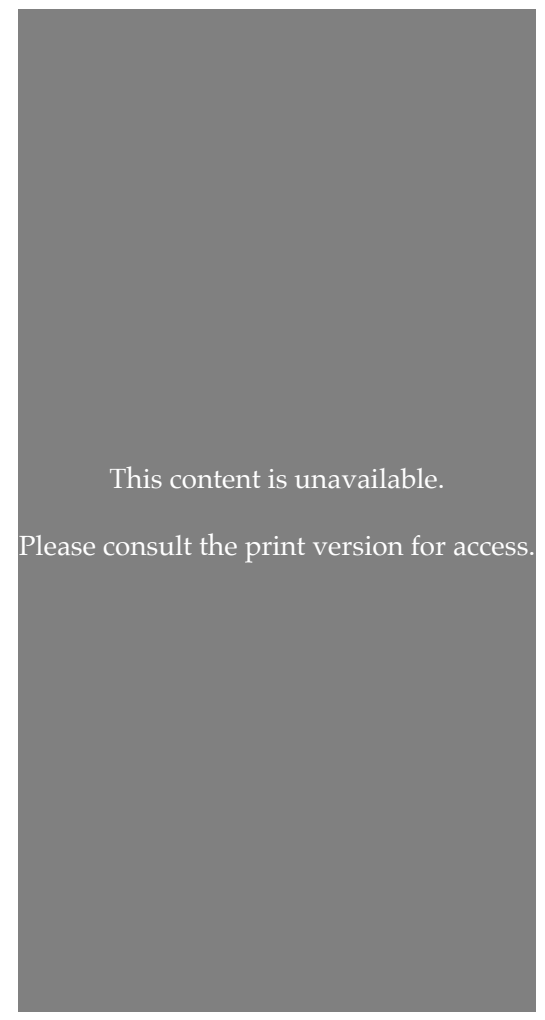

Figure 3.9. Elevation of The Highline's previous railway structure (Source: Iwan Baan 2009)

Figure 3.10. Aerial view of The Highline from West 30th Street looking south. (Source: Iwan Baan 2011)

\subsection{The Highline}

\section{Location: New York, USA}

Development: First opened (2009), Completed (2014)

\section{Designer: James Corner Field Operations}

The Highline is the most renown contemporary example of a successful elevated park in an urban context. Formerly intended as a freight rail way line in the 1930s-80s, the largely obstructive rail way overhead the streets of Manhattan was officially closed for commercial or public use in the 1980s. Nearly three decades later, the Highline was open to the public for the first time as a pedestrian friendly park and access way, retaining much of the original character of the railway (Figure 3.9 and 3.13). The intention behind this revitalisation shares similarities to the motivation behind Gensler's Town Square Initiative.

Given the elevated nature of the Highline, the park is highly resistant to flooding. The structure incorporates a green roof style drainage system that handles heavy rainfall and retains excess water for plant sustenance during drier periods. This takes some of the load away from the city's draining infrastructure. By running offset to the north south avenues of Manhattan the Highline avoids blocking substantial sunlight from pedestrian and vehicle links below (Figure 3.10). 
Figure 3.11. The Highline caters for differerent pedestrian speeds (Source: Iwan Baan 2011)

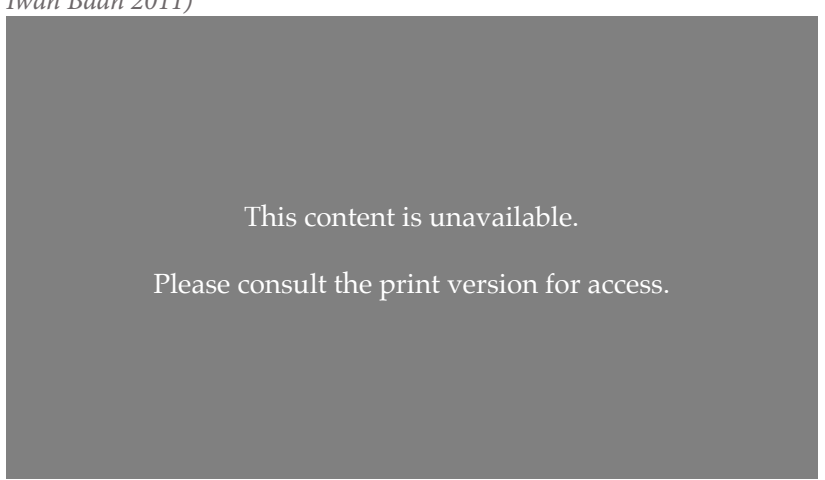

Figure 3.12. Remnants of the rail line lines remain and clearly separate separate the walkway into multiple pedestrian zones. (Source: Iwan Baan 2014)

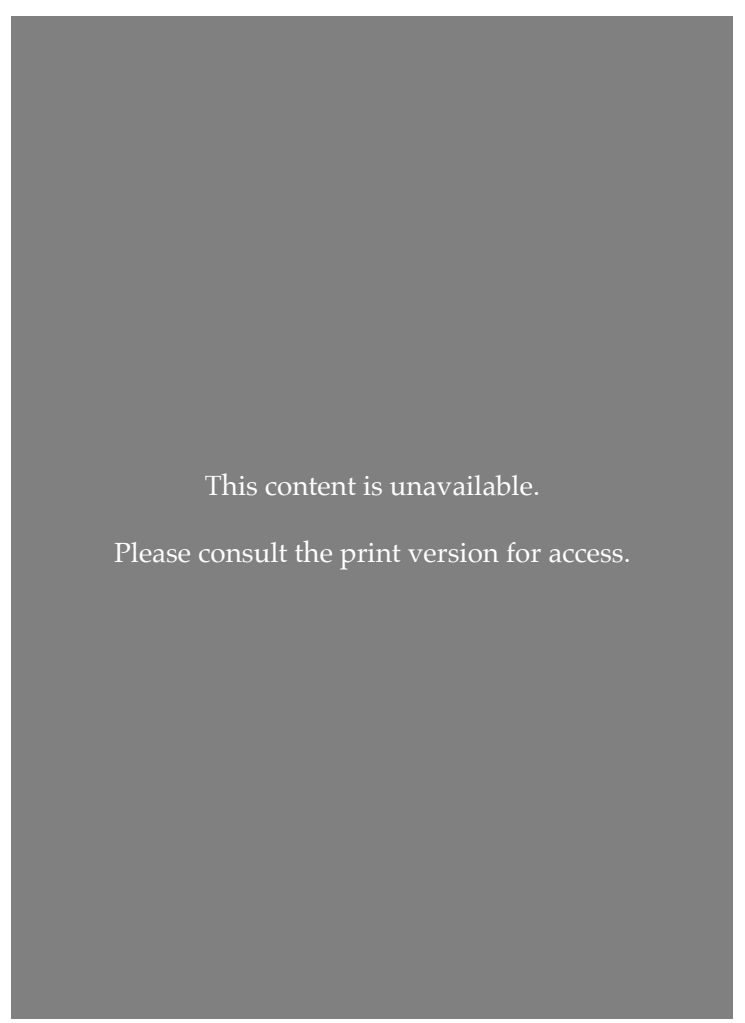

Figure 3.13. The High Line 23, evidence of the glamour The Highline was bestowed upon the area. (Source: Iwan Baan 2011)

The high attendance of visitors to the Highline are not without cost. Particularly in how it has impacted the surrounding area. The Highline has gentrified west Manhattan, bringing glamour into an originally residential and industrial area (Moss). Architects have seized the opportunity to build upon the elegance of the The Highline, erecting multilevel contemporary estates such as The Highline 23 (Figure 3.13). The original character of the precinct is on the verge of fading whilst corporations, businesses, and first-class residents, the only ones able to afford to live in the area, begin their migration. The Highline can appear to be corporate owned as the walkway is not publicly accessible all hours of the day and there are strict rules set on the space.

In light of this, The Highline finds continuing success in its ability to attract people from street level. It has little specialised amenity but offers an unprecedented walking experience. Being elevated with little specialised amenity are two design strategies not recommended by Jane Jacobs and Jan Gehl. The Highline is full of spatial intricacy thanks to the ever changing layout of the walkway which reduces the amount of spatial repetition many long and narrow parks notoriously adopt. 


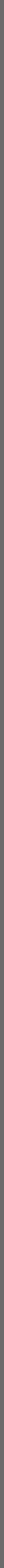




\section{0}

\section{PRELIMINARY DESIGN}

Taking into consideration theoretical resilience and urban design methods, contextual specificities, disaster risks, precedent design strategies, and programme necessities, this section looks to further investigate preliminary design concepts on the site of Kent and Cambridge Terrace to provide Wellington's city centre and its residents with a formal refuge area during a post disaster scenario. Areas of focus include

- being structurally resistant, ensuring inhabitants are safeguarded

- meet IFRC guidelines

- creating spaces and mechanisms that can dually function for everyday and post disaster purposes

- pedestrian links to the Basin Reserve, Waterfront, Courtenay Place, and Mount Victoria 


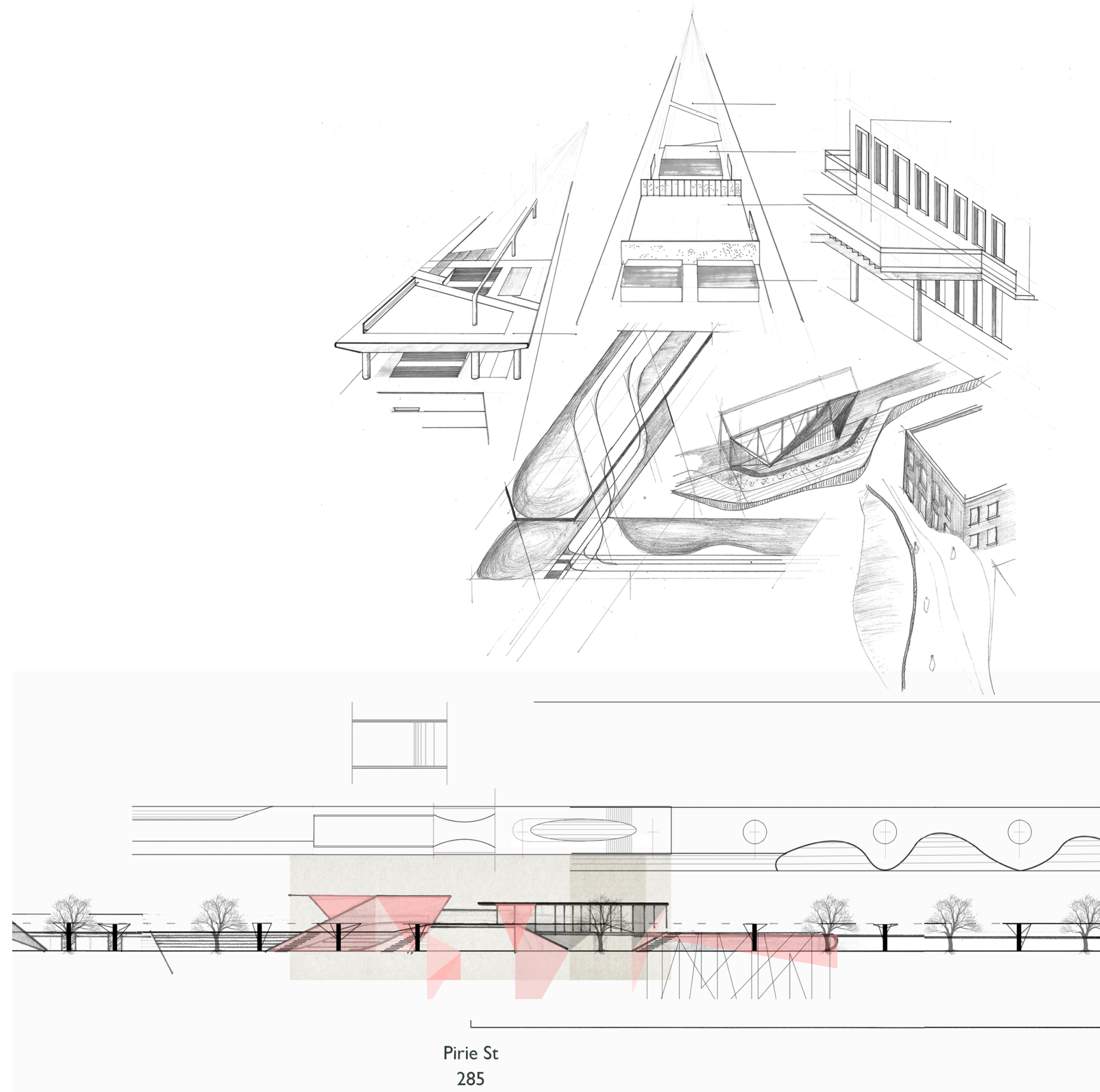

The task of creating an elevated walkway across a narrow site whose intention is to accommodate masses of displaced people in a disaster is extremely problematic.

Early sketches seen in Figures 4.0 and 4.2 demonstrate an emphasis placed upon conventional enclosures, simply being that they have a natural typology whose multiple levels allow for the maximum concentration of people. In light 


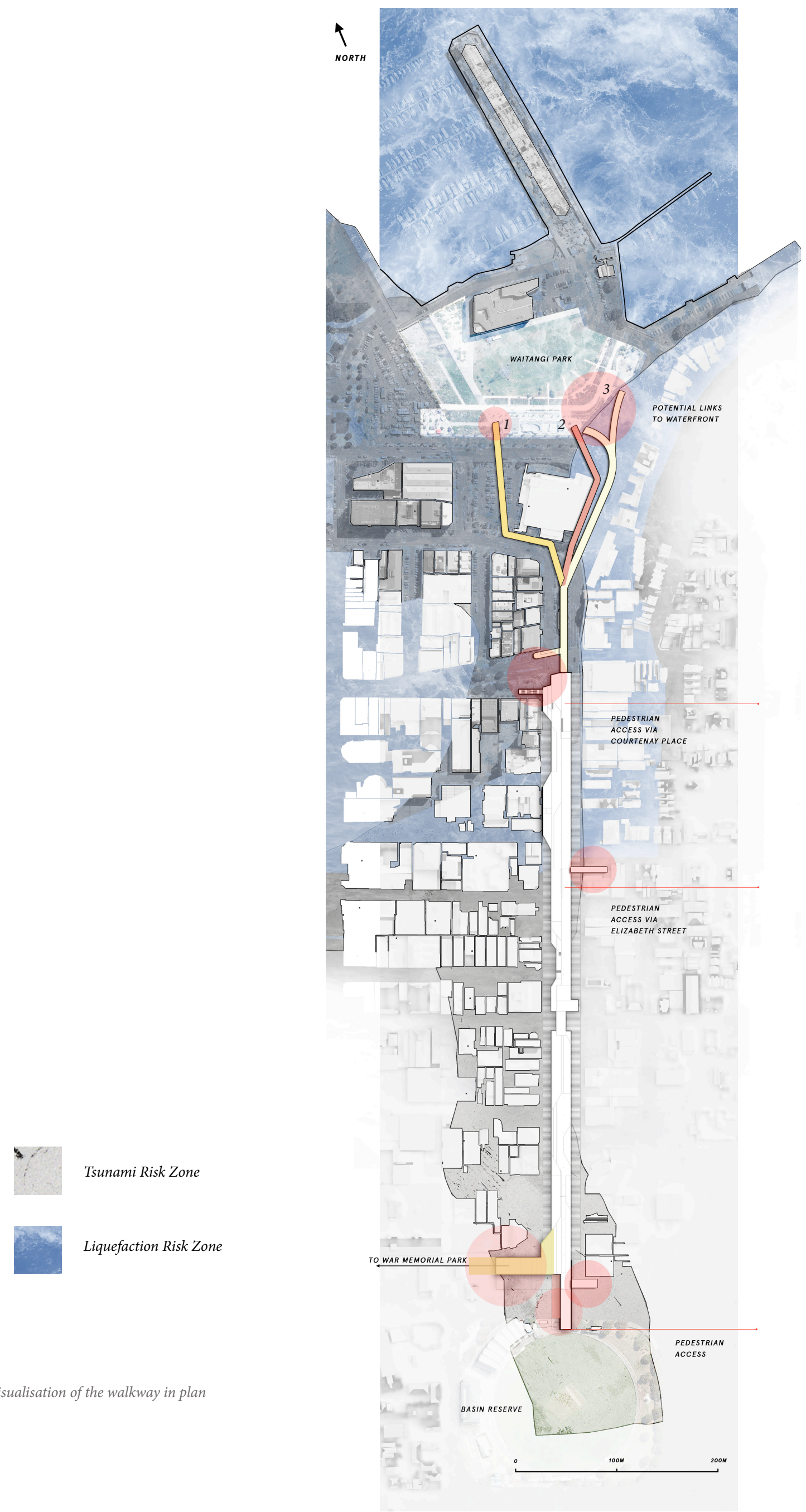


damaged and require reconstruction, this interface may hinder these procedures, and put those reducing the usability of the walkway.

Early model making gave insight into the consequential daylight conditions at street level if a walkway were to extend wider than the current $18 \mathrm{~m}$ width of the median strip (Figure 4.1). Although a wider walkway provides more usable space for more displaced residents to gather, there exists a heavy cost to the site's ecology, quality of life, and performance of local businesses. Ways to remedy this would be raising the height of the walkway, or creating punctures within the walkway to expose areas of the street level with direct daylight.

Overlapping hazard zones on top of the site provides clarity in how important a walkway can be in providing access to potentially isolated areas of the city. Conceptualised in Figure 4.3, Waitangi Park sits 100m north of Kent and Cambridge Terrace, obstructed by New World Supermarket. The obstruction provides obscurity in how a connection can be made, as there is minimal space for the structural elements of a walkway to exist along each of the lines. Out of the three lines routes drawn, connection 2 provides the most feasible route on the basis that the structure of the walkway will not impede on current traffic activity.

Given the current nature of the median is heavily underutilised, and the further unavoidable daylighting reductions of the median once a walkway is constructed, the thought of creating an ecological use of the median seemed appropriate. Stream streets are used to assist in the filtration of storm water and build flood resistance, which are risks Kent and Cambridge Terrace can be prone to. However, elevated walkways will be exposed to the majority of the site's rain exposure, and as the New York Highline has demonstrated, can reduce storm water run off and harness excess rainfall for vegetation. 

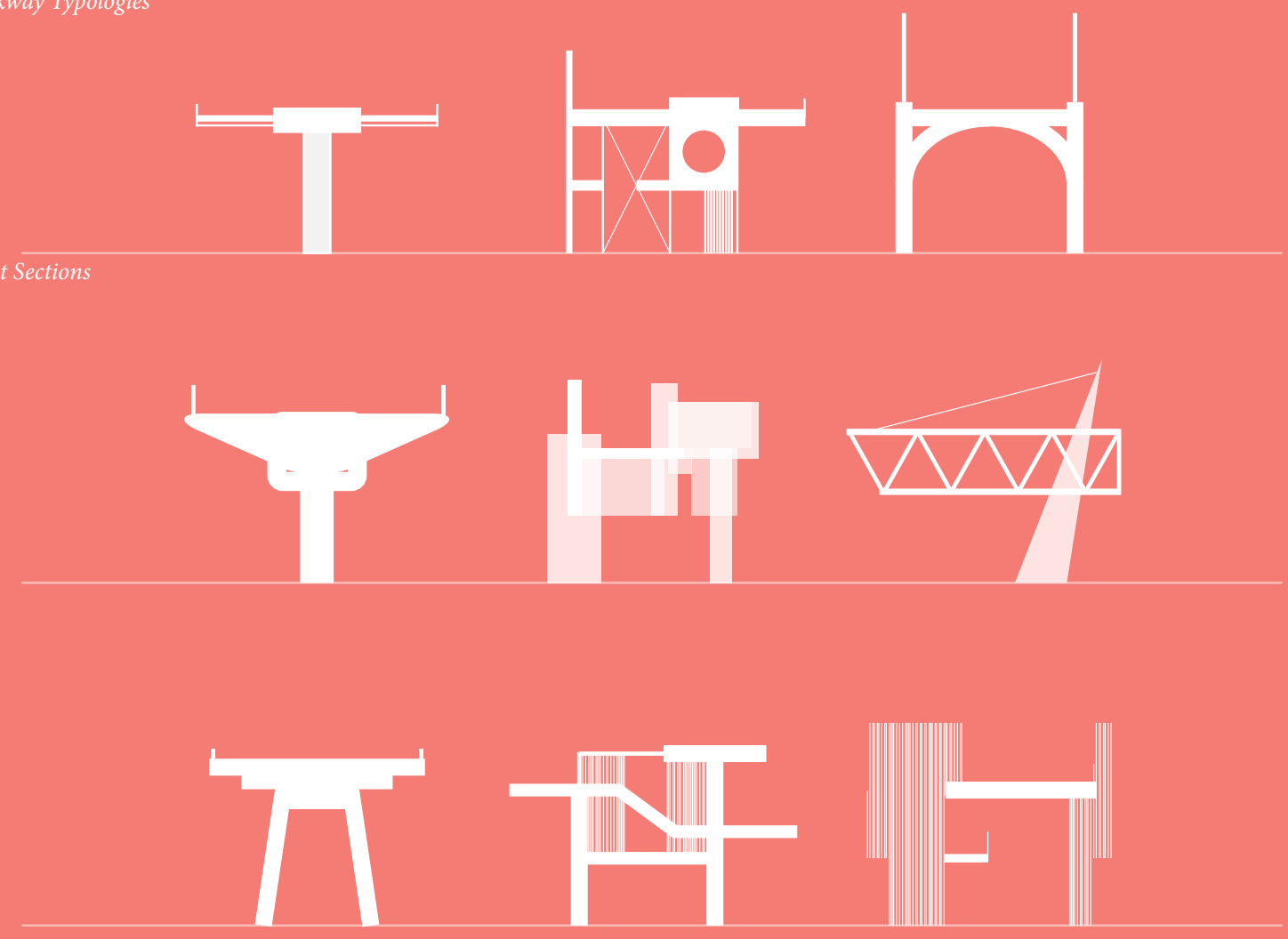

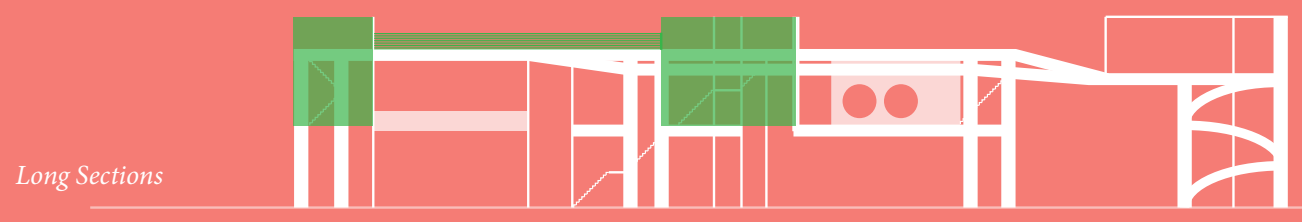

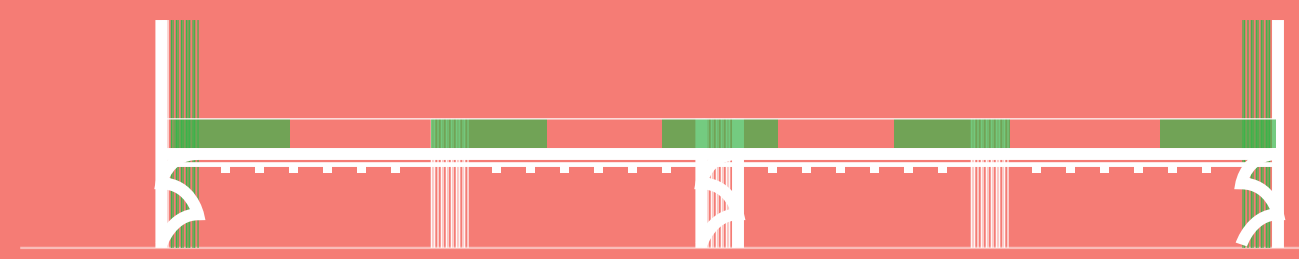




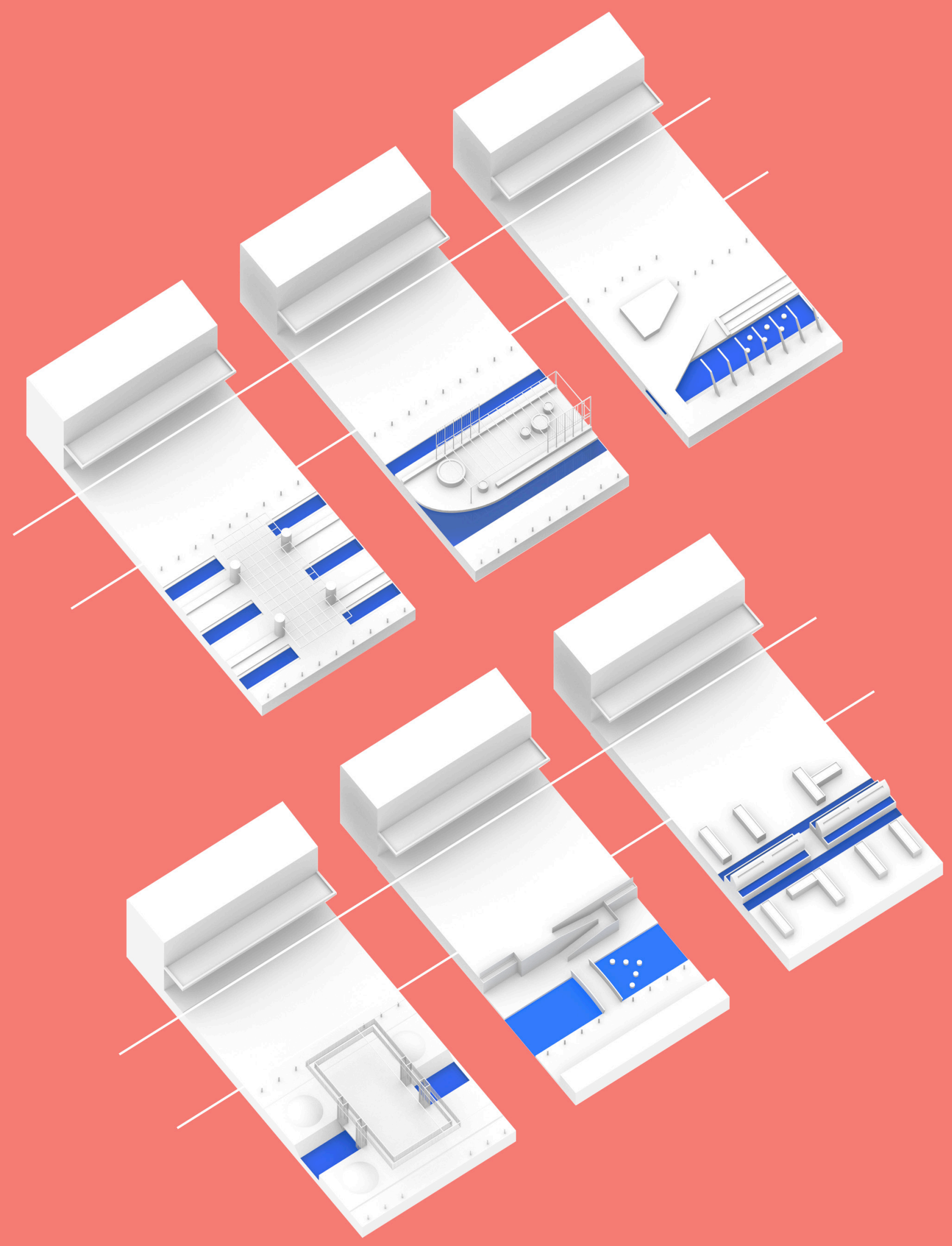

Figure 4.5 Stream Street Typologies 

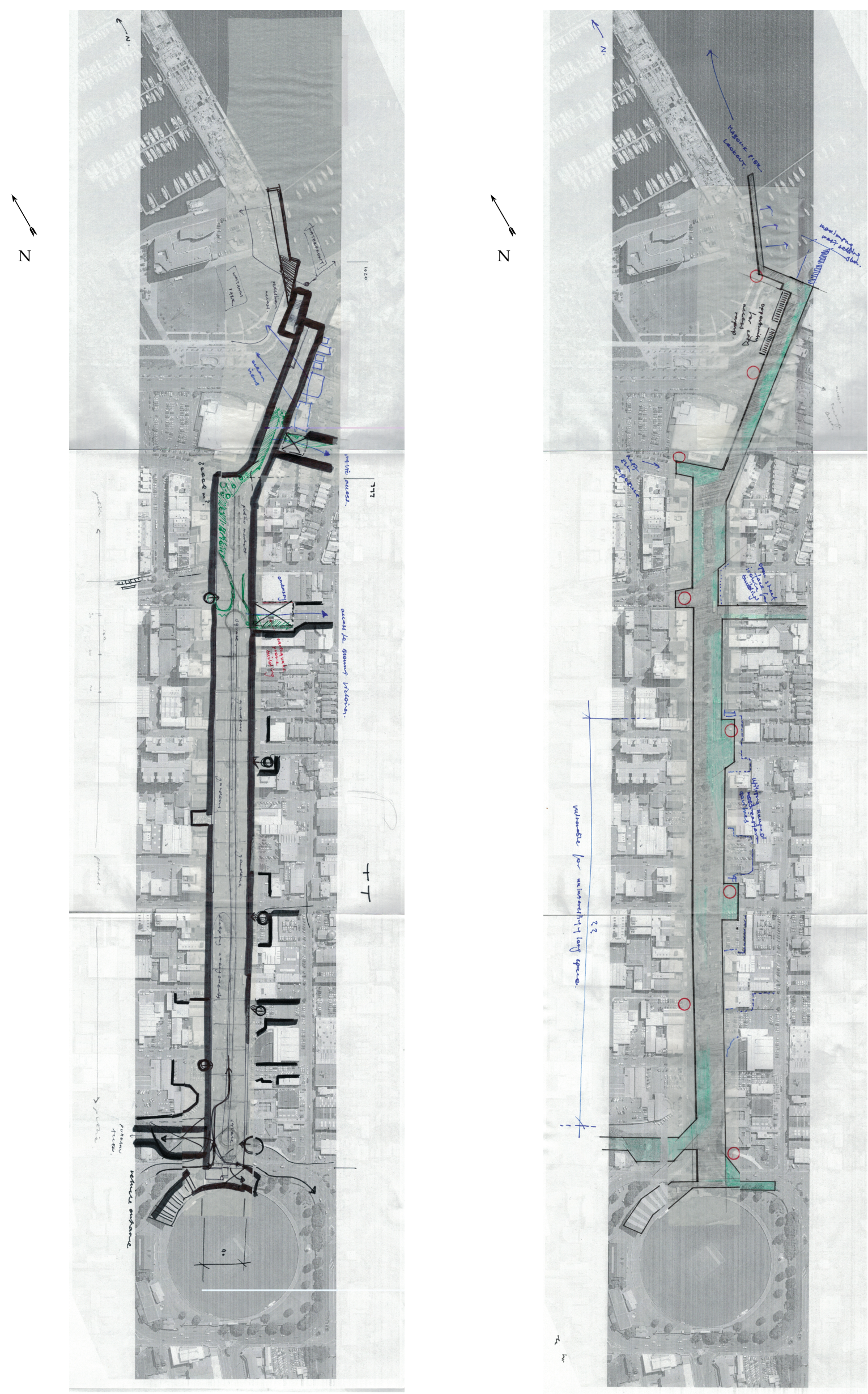

Figure 4.6 Iterative walkway designs in plan 

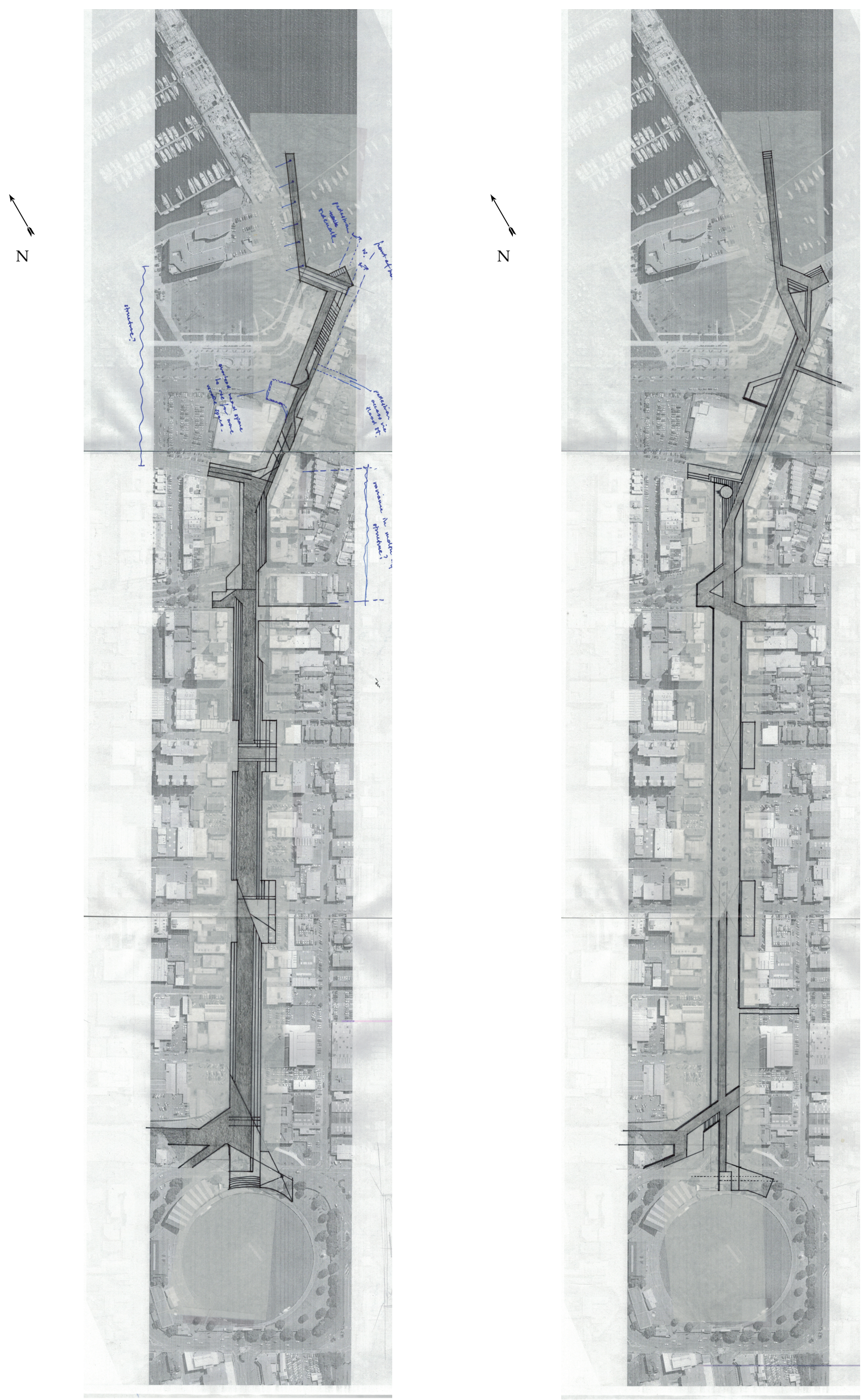

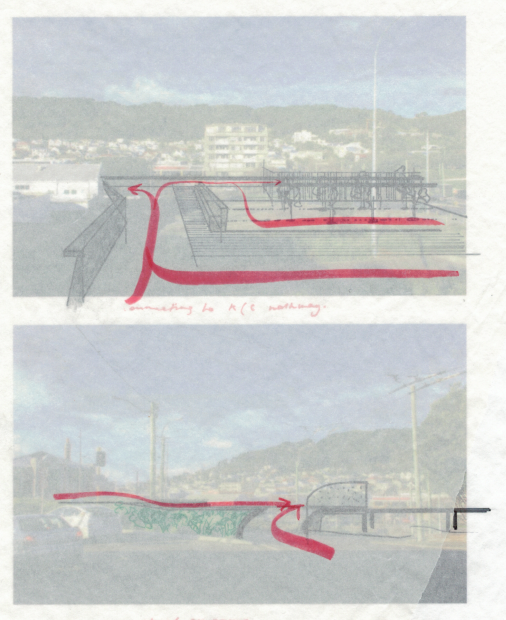

War Memorial Park Connection
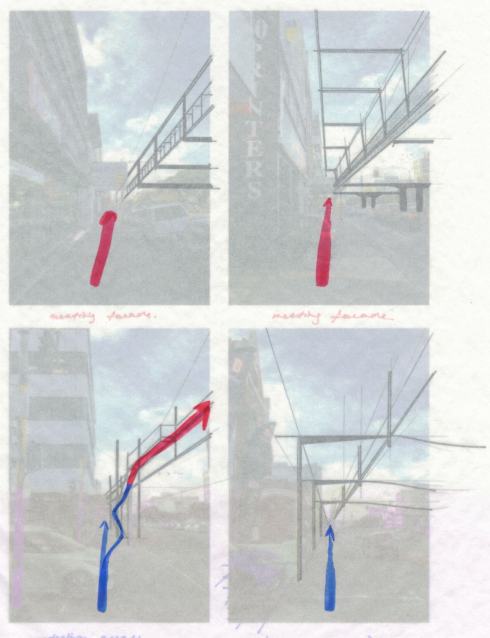

Sidewalk interaction
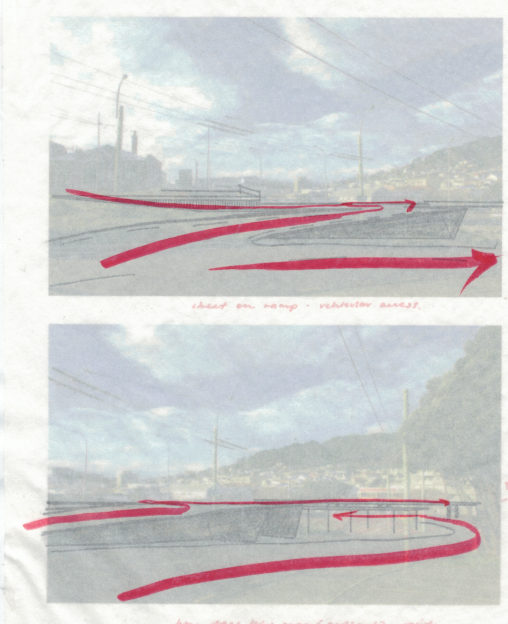

Vehicle Access to Walkway via Buckle St
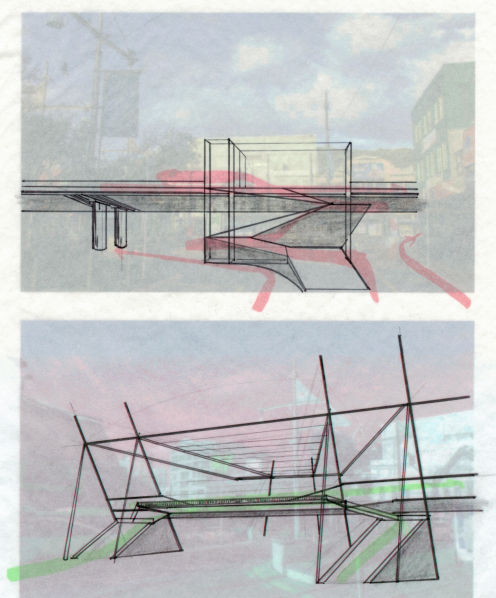

Courtenay Place Accessibility
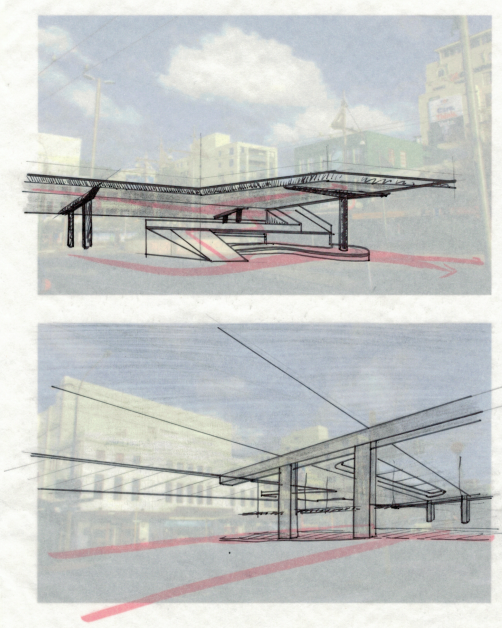

In front of the Embassy Theatre

Figure 4.7 Sketching motion and form on site

Sequential sketches in plan helped to reinforce the connections the site has to its immediate surroundings and find edges where the walkway could detract and retract from neighbouring buildings. In scenarios where the project area is inundated with liquefaction, there are no clear routes aid vehicles can take to easily access Mount Victoria. However, 13 Kent Terrace, which has been stickered for demolition, has a clear connection to Lipman Street behind the building. In the assumption that this link to Mount Victoria is opened, an entrance to the elevated walkway could exist here as a way for vehicles to efficiently enter and access an otherwise secluded community. 


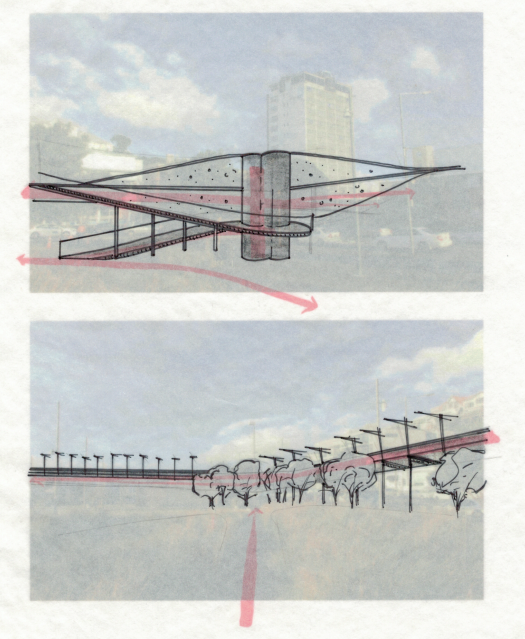

Oriental Parade Accessibility
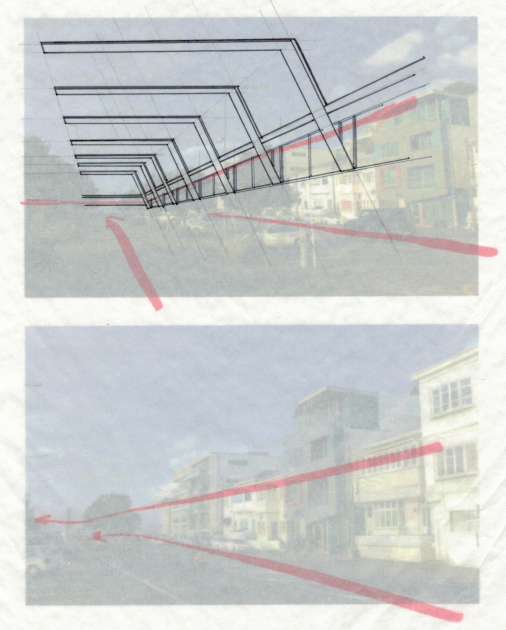

Hinderances to Waterside Views

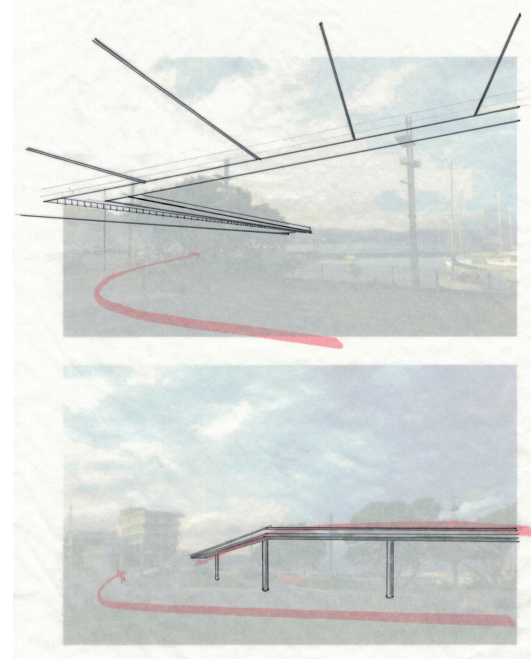

Waitangi Park

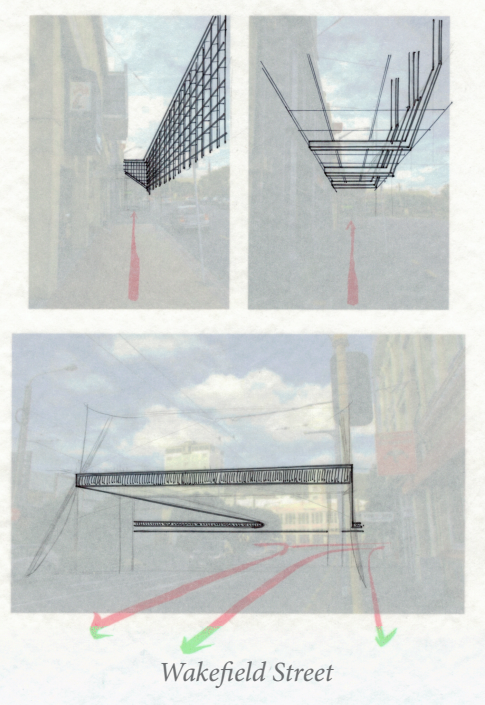

Extension of the walkway beyond Kent and Cambridge Terrace was aggressively pursued in an attempt to substantiate the project area's linkages with Wellington's prized public amenities. But in an environment so densely occupied by Waitangi Park and Oriental Parade integration of a walkway would do little for post disaster relief. This was further reinforced by the blocking forms that were generated in the waterfront drawings in Figure 4.7. This method of drawing over site imagery clearly articulated the scale of would actually be realised. The clip art renditions of structural systems in Figure 4.4 do not communicate the integrity found within these drawings. 


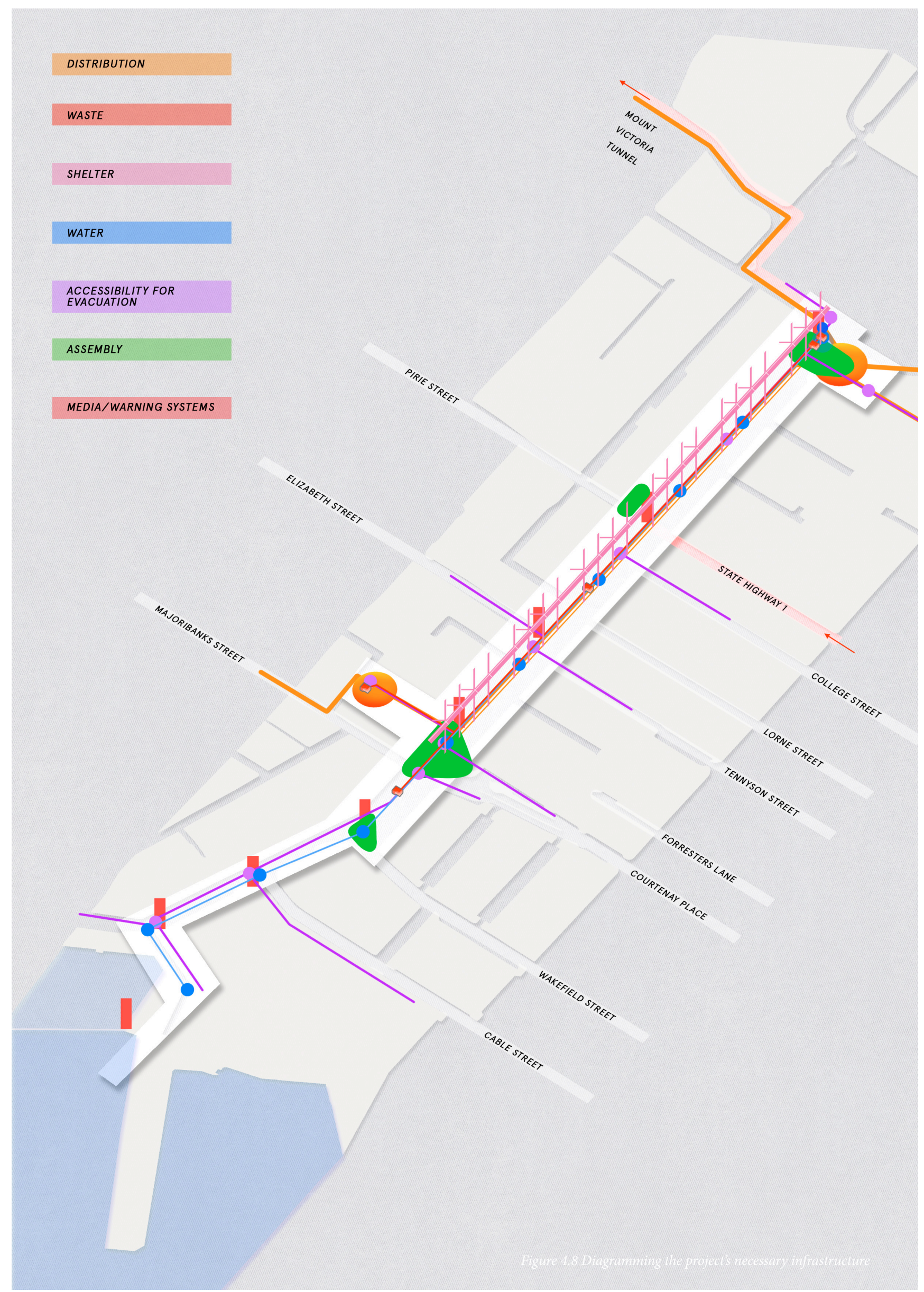




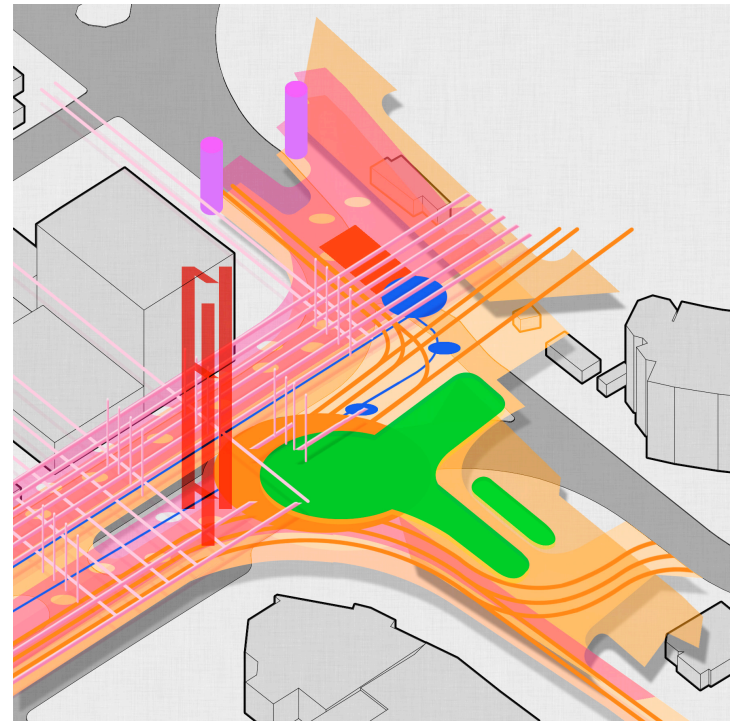

The Basin Reserve

MEDIA/WARNING SYSTEMS

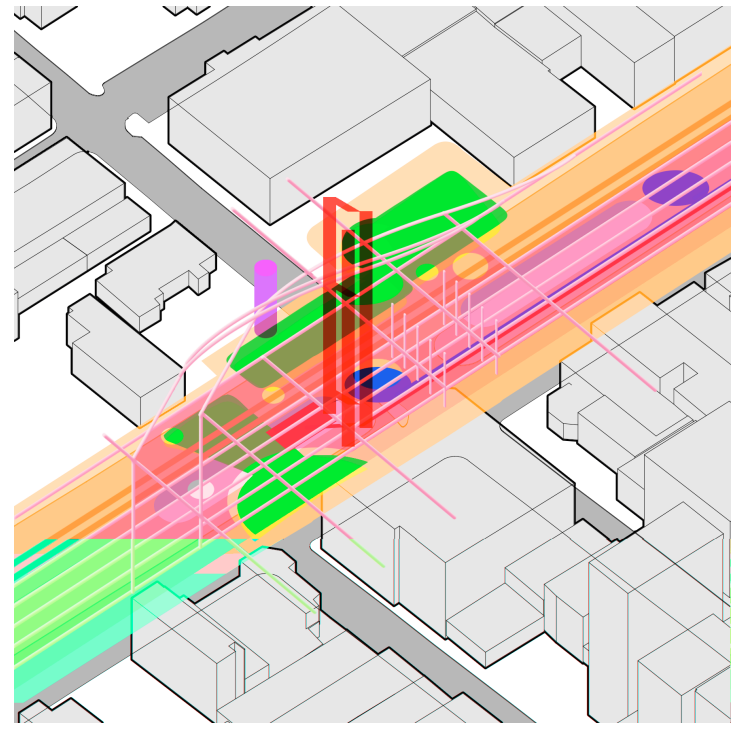

Vivian Street

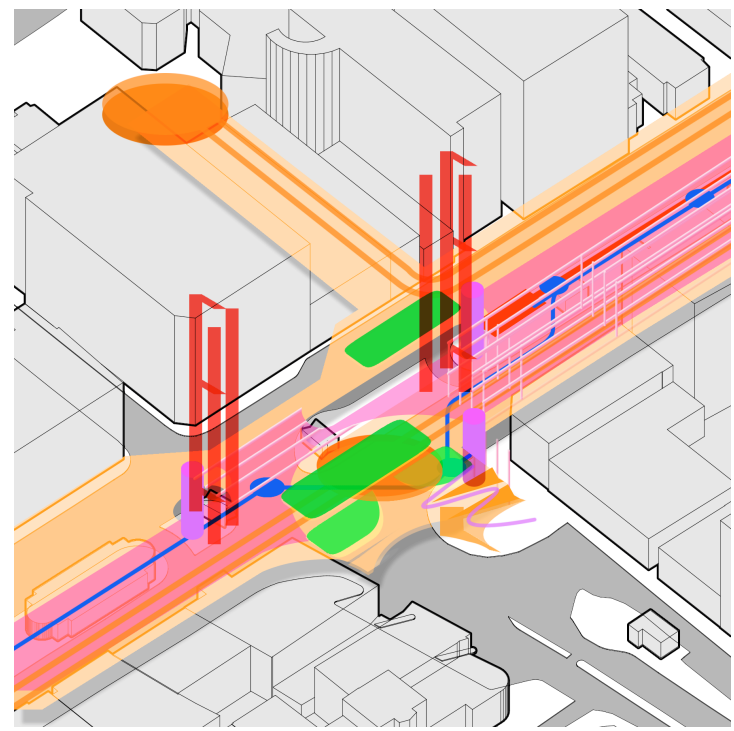

Courtenay Place

Figure 4.9 Spatially diagramming infrastructure 
The way in which Bjarke Ingels Group proposed to architecturally harmonise with resilient infrastructure in their project, The Dryline, influenced the drawings of Figures 4.8 and 4.9. Giving different infrastructural elements a particular colour and form creates visual intrigue, but also investigates if their relations between one another can manifest spatially. In these drawings, locations for assembly areas and distribution areas are intentionally allocated, whilst areas of shelter exist everywhere else. Shelter, in some ways, simply requires floor space for a pop up tent. But so do assembly areas, and even distribution areas. Differentiating these spaces clearly will be beneficial, particularly during periods of unrest.

During the series of structural drawings in Figures 4.10-4.12, examining the height of the walkway structure was of notable importance for media and wayfinding issues. This is because residents of Wellington were confused by great uncertainty in whether to evacuate during the 2016 Kaikoura Earthquake. Equipping the walkway structure with visible lights and sirens during when unexpected events occur would provide greater clarity for residents living in close proximity to the site.

Two columned structural forms were investigated preferred over single column systems because there is an option to open apertures in the center of the walkway, bringing light to the spaces underneath the walkway. 

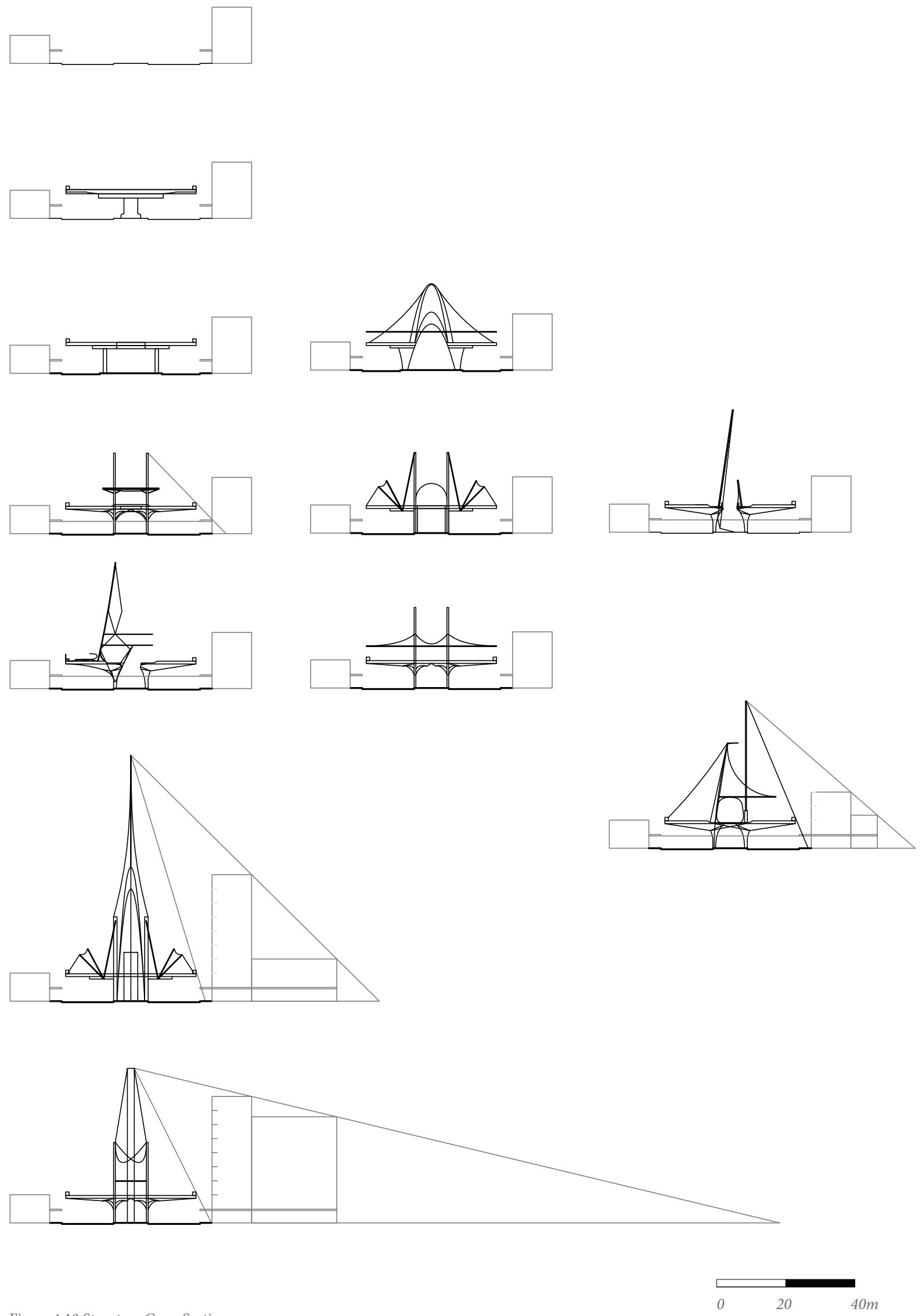

Figure 4.10 Structure Cross Sections

69 


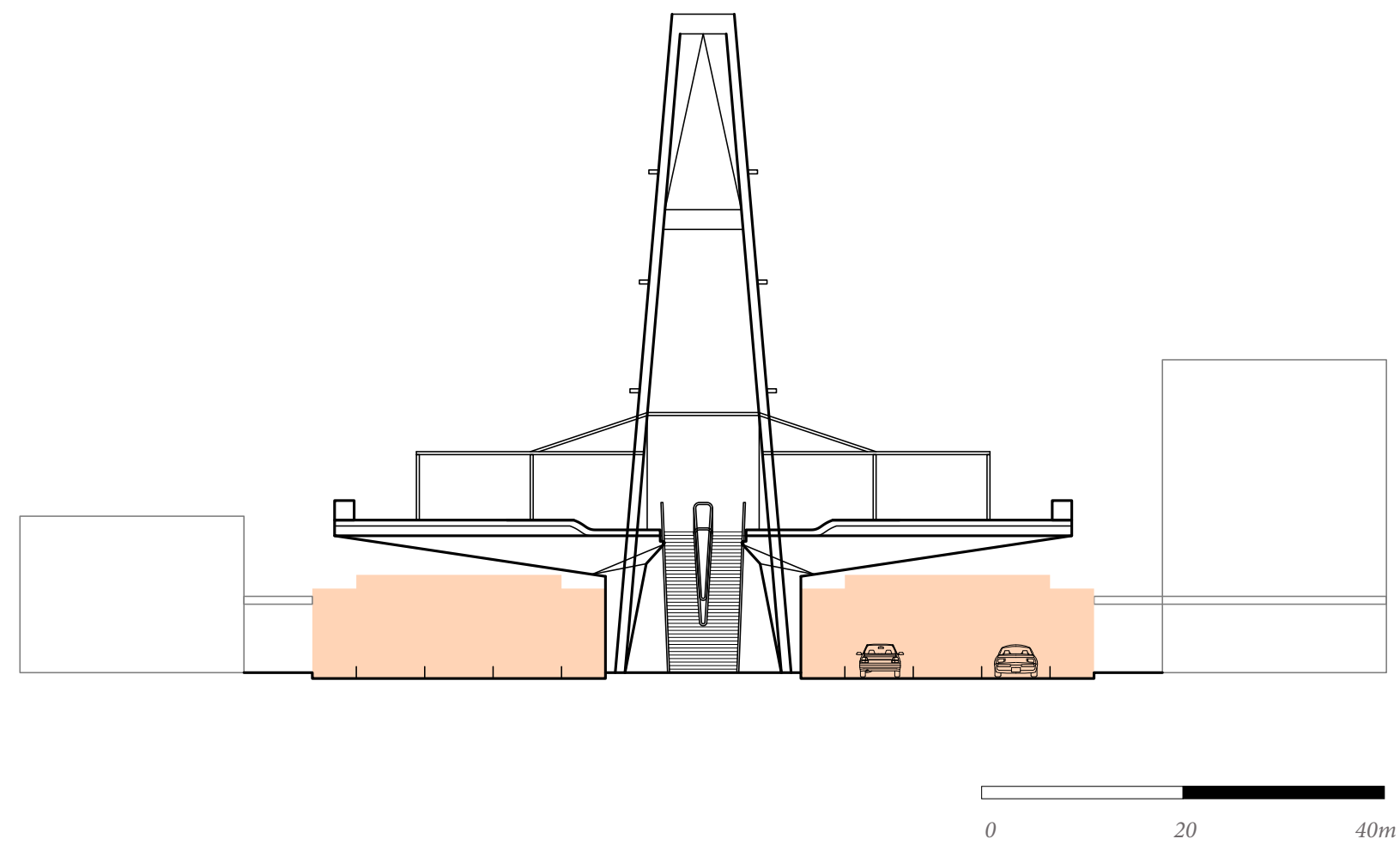

Figure 4.11 Structure Cross Section with minium road height clearance 


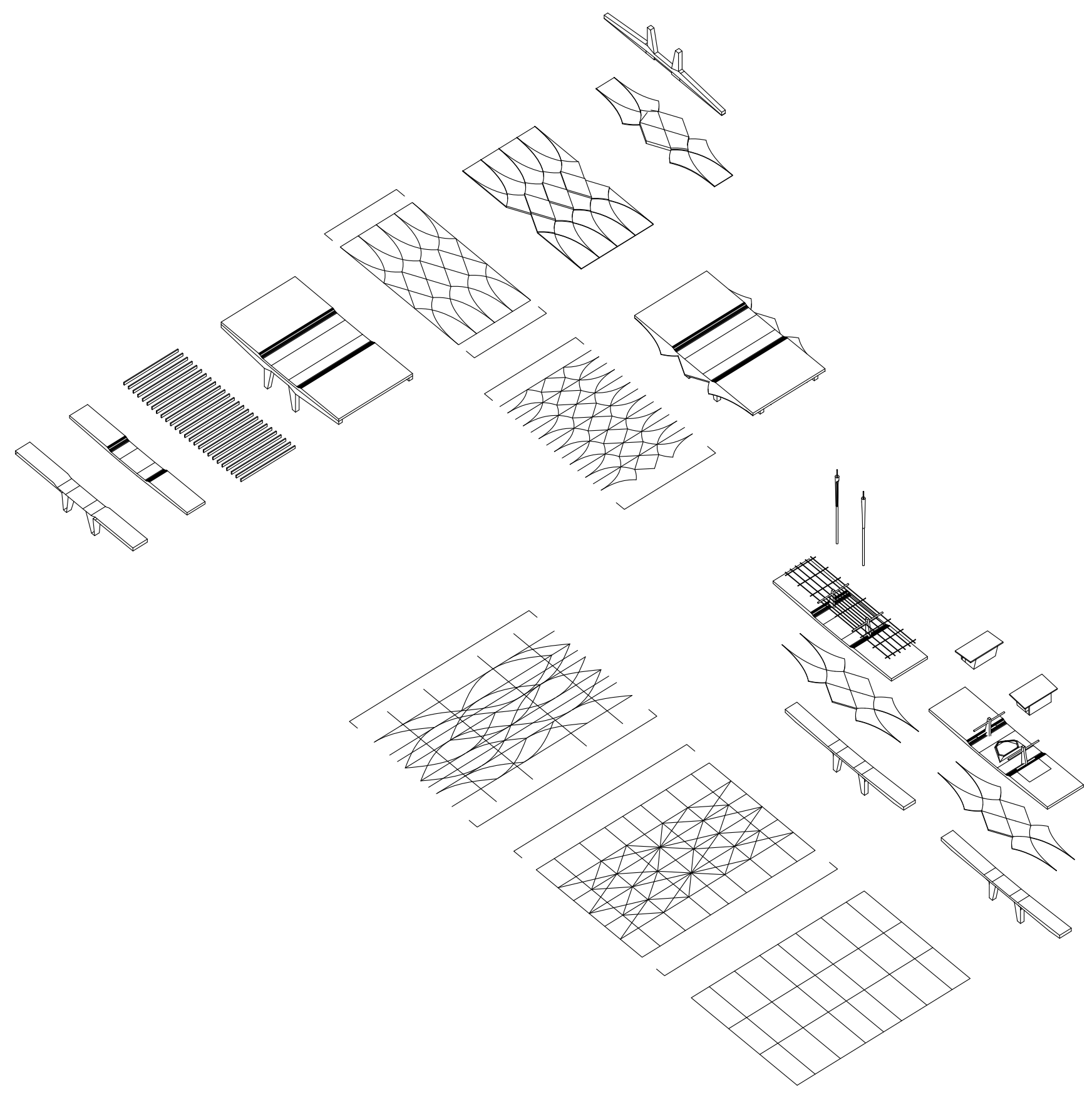

Figure 4.12 3-dimensional structure and patterns 


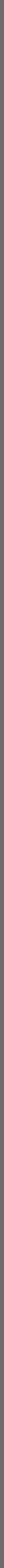


8.0

DEVELOPED DESIGN 
N

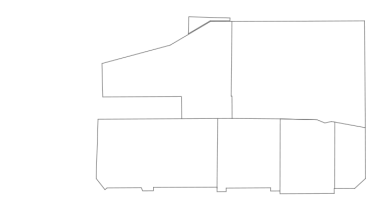

WAKEFIELD STREET

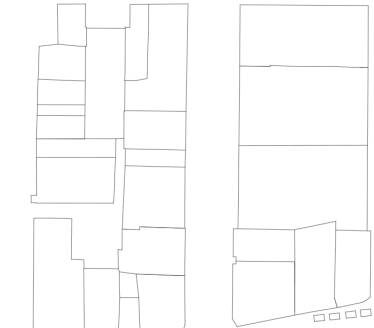

COURTENAY PLACE
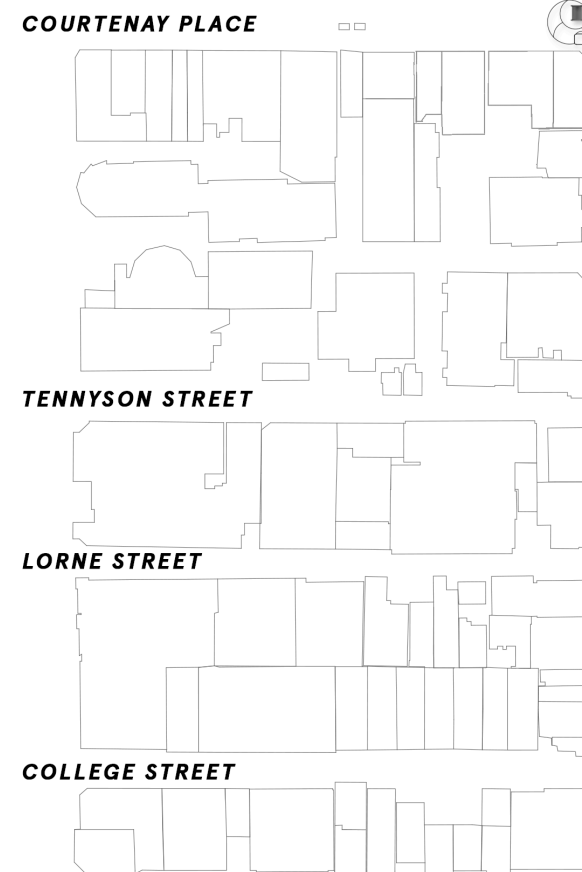

\section{VIVIAN STREET}
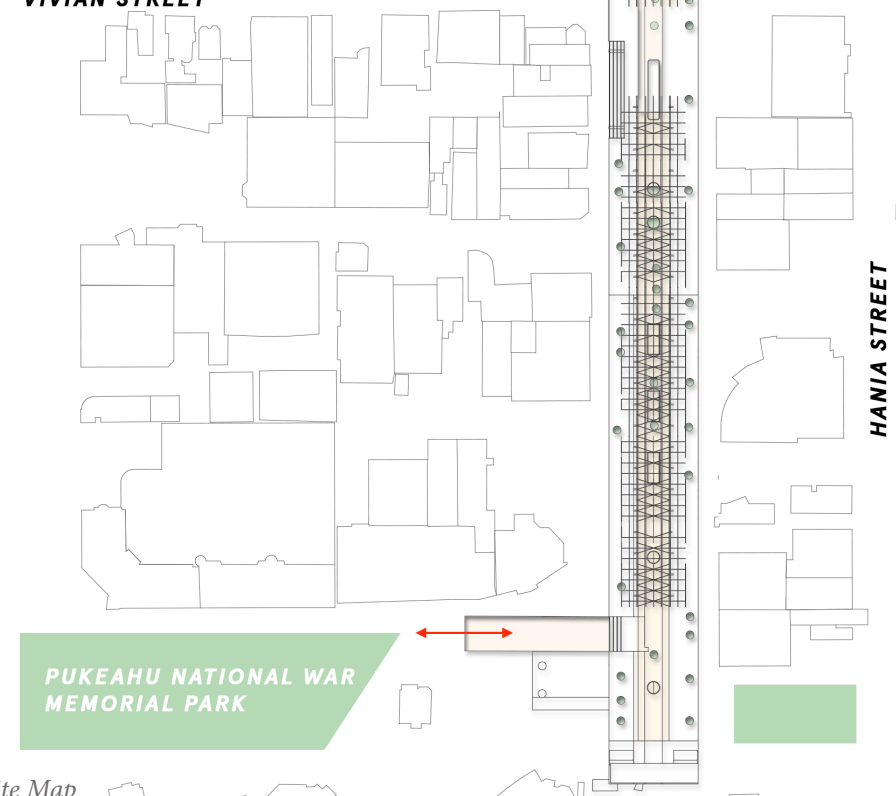

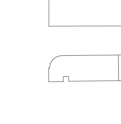

Figure 5.0 Site Map

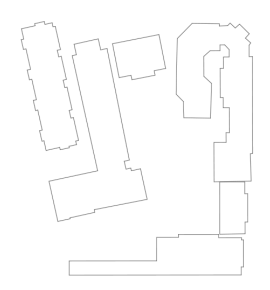


The resulting developed design has structurally encapsulated the size and scale of the design problem. Spanning 35 meters wide over Kent and Cambridge Terrace, and 900 meters from The Basin Reserve to Waitangi Park, the elevated walkway comfortably provides a refuge above with enough space for thousands of displaced residents should the need arise.

Vehicle access onto the $8 \mathrm{~m}$ high walkway via the National War Memorial Park, and Lipman street ensures that those who seek refuge on the walkway can be tended to from both humanitarian agencies and residents. Having access to Mount Victoria is also substantial as the very roads that inhibit their connectivity are the exact roads this design seeks to provide amenity over.

However, the method of vehicle access attributed in hindering the walkway's ability to create spatial intrigue and excitement. The general layout of the walkway consists of a middle lane and two perimeter lanes (Figure 4.11). The middle lane is mildly sunken in, creating a small degree of psychological shelter, as the center is where the structure is most rigid. This is also the lane of pedestrian thoroughfare, but is also wide enough to support two lanes of traffic, including an aperture for light to permeate to the ground below. In addition, the central area is also the most sheltered, meaning in a disaster scenario, the space with the greatest sense of refuge is also the area needed for vehicle thoroughfare. 


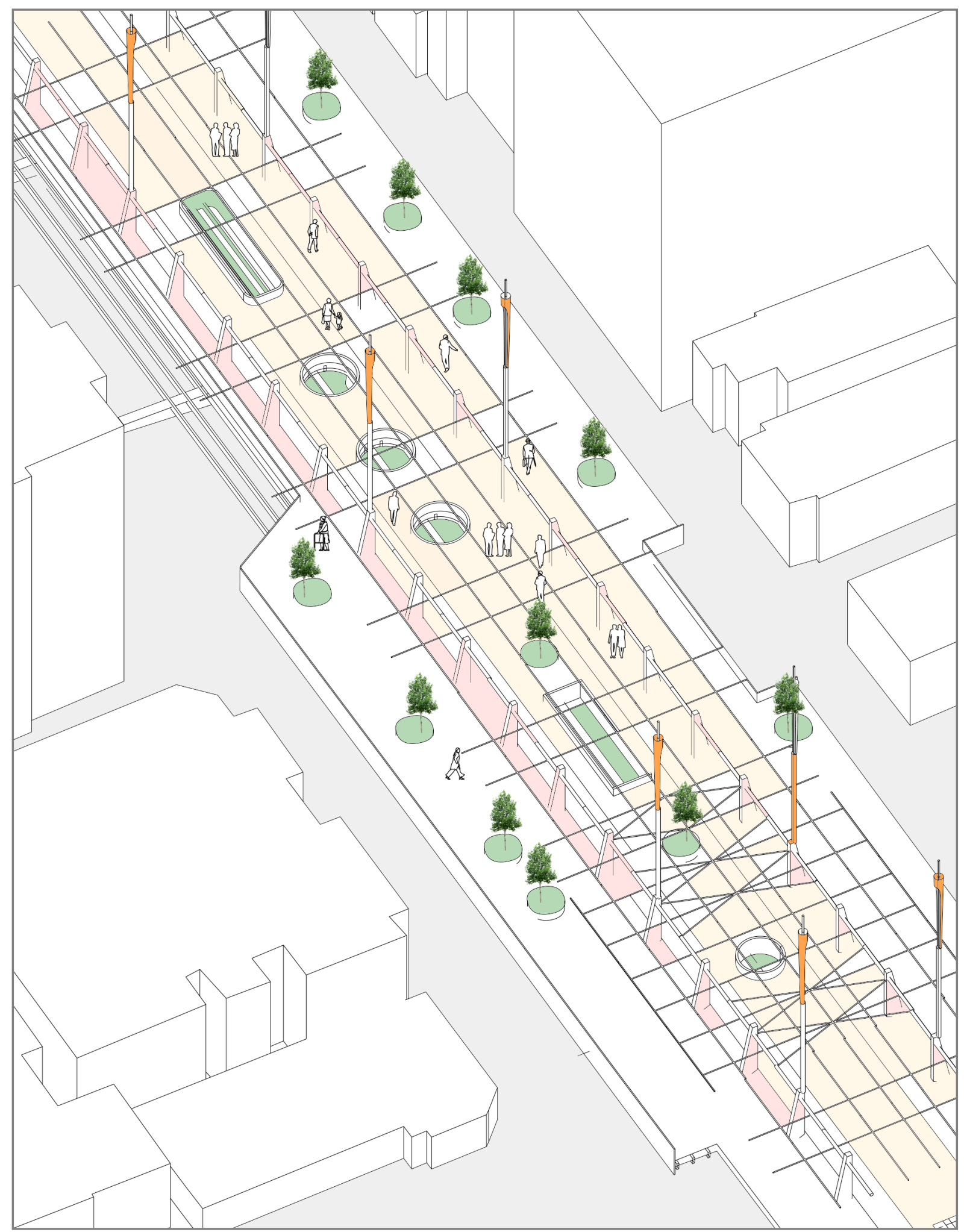

Figure 5.1 Axonometric view of the elevated walkway 


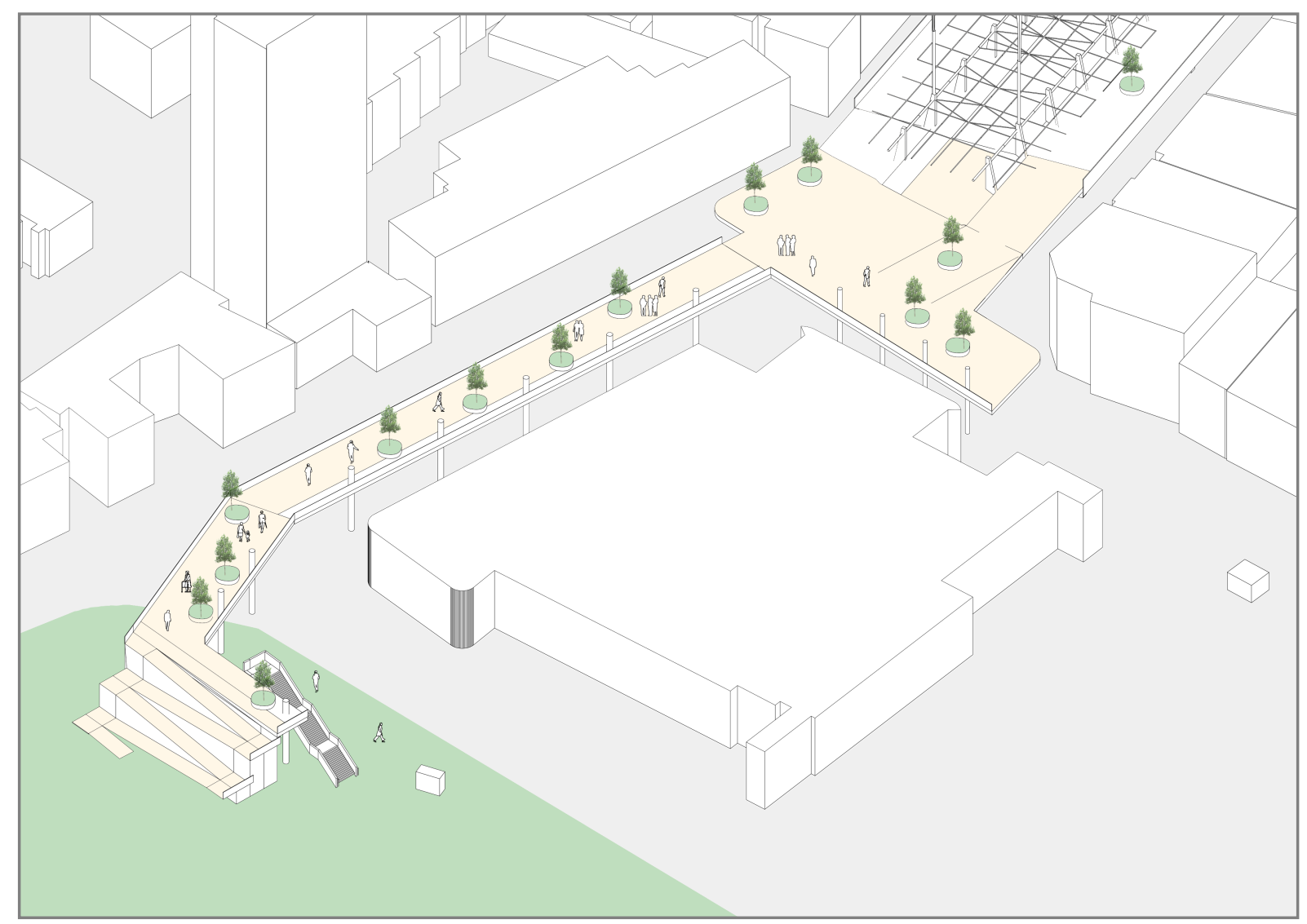

Figure 5.2 Axonometric view of the Waitangi Park link

The central concentration of amenity in this layout is continued throughout the entire walkway, accentuating the long and thin nature of the site, and limiting the desire to traverse the walkway's entirety. Though, in light of this, the site's close connections to Wellington's prized amenities does ensure that the site can be used as a thoroughfare. Amenities like the waterfront are difficult to access due to the high traffic roads that separate the city from the habour. This developed design provides a pathway to navigate around these difficulties to ensure parts of the city are more efficiently accessible.

An element that this developed design struggled with is the missed opportunity to address the current street levels issues of the site, this being the rampant vehicular presence and the ill defined park space of the median. There is a tension that exists with that opportunity. Where, building atop of an already underutilised walkway would diminish the majority of any opportunity to revive such a space. The design does however, feature apertures along the centre of the walkway in an attempt to bring light down into the median space below. It is uncertain whether this would provide sufficient lighting. Further development of the walkway would see the implementation of artificial lighting to create greater delight and functionality in the space below. 


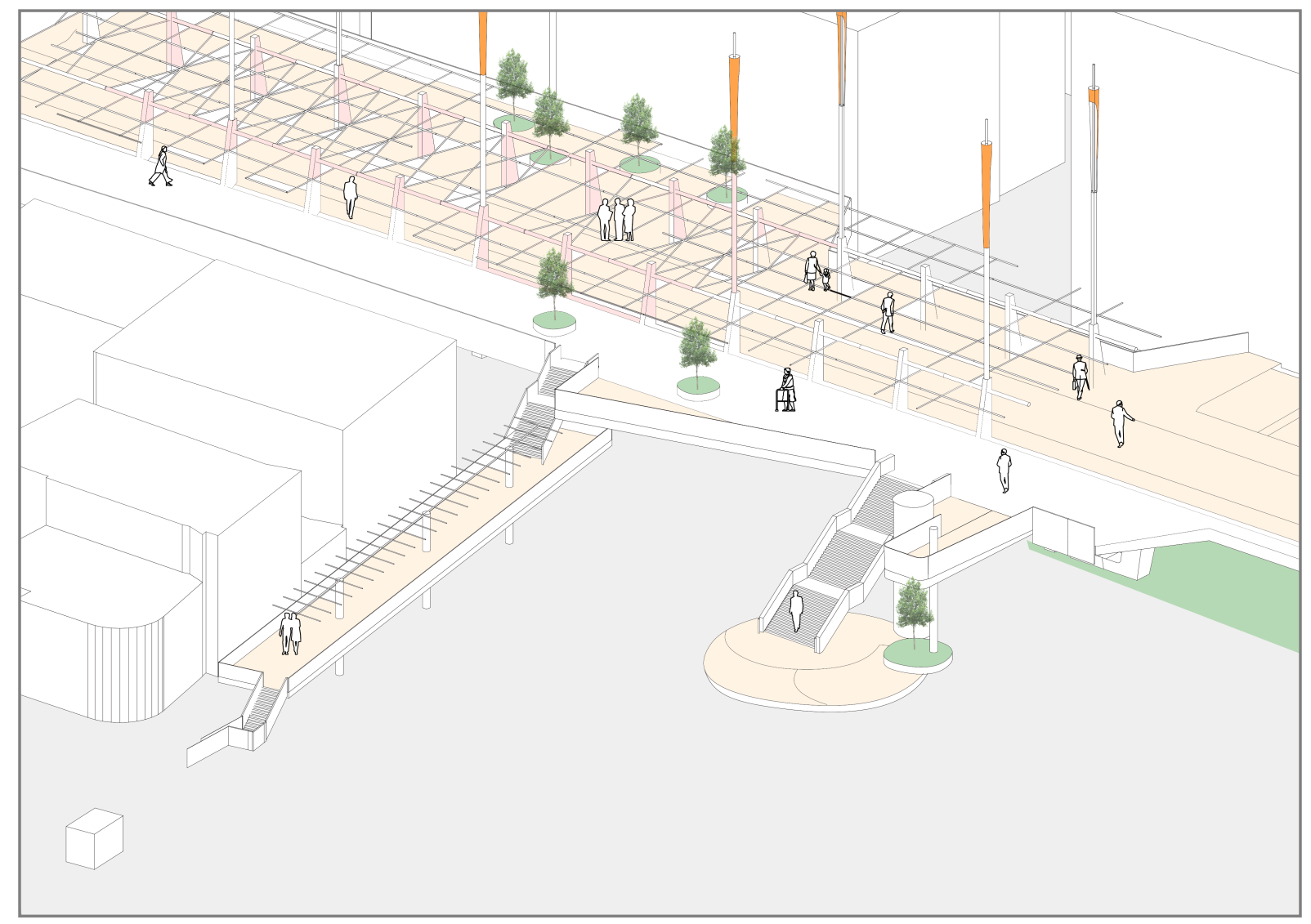

Figure 5.3 Axonometric view of the Courtenay Place Entrance

This design succeeds in its ability to communicate to the very real threat a catastrophic seismic disaster would have on Wellington. Its sheer size and form, the two storey climb needed to access the walkway level, and the surplus amount of over head beams for make shift shelters and walls are all things that typical open spaces heavily lack and traditionally stray away from. Although the design struggles to meet the entirety of its requirements, it does the one thing it needs to correctly, and that is to structurally withstand the threats of Wellington's forecasted seismic activities. It needs to be reiterated that Central Wellington does not have a open space network capable of housing or accommodating thousands of displaced residents. The city requires an intervention of this scale to provide refuge for its central city residents, as it does not currently have the provisions in place to face the magnitude of seismic activity that is forecasted to come. 


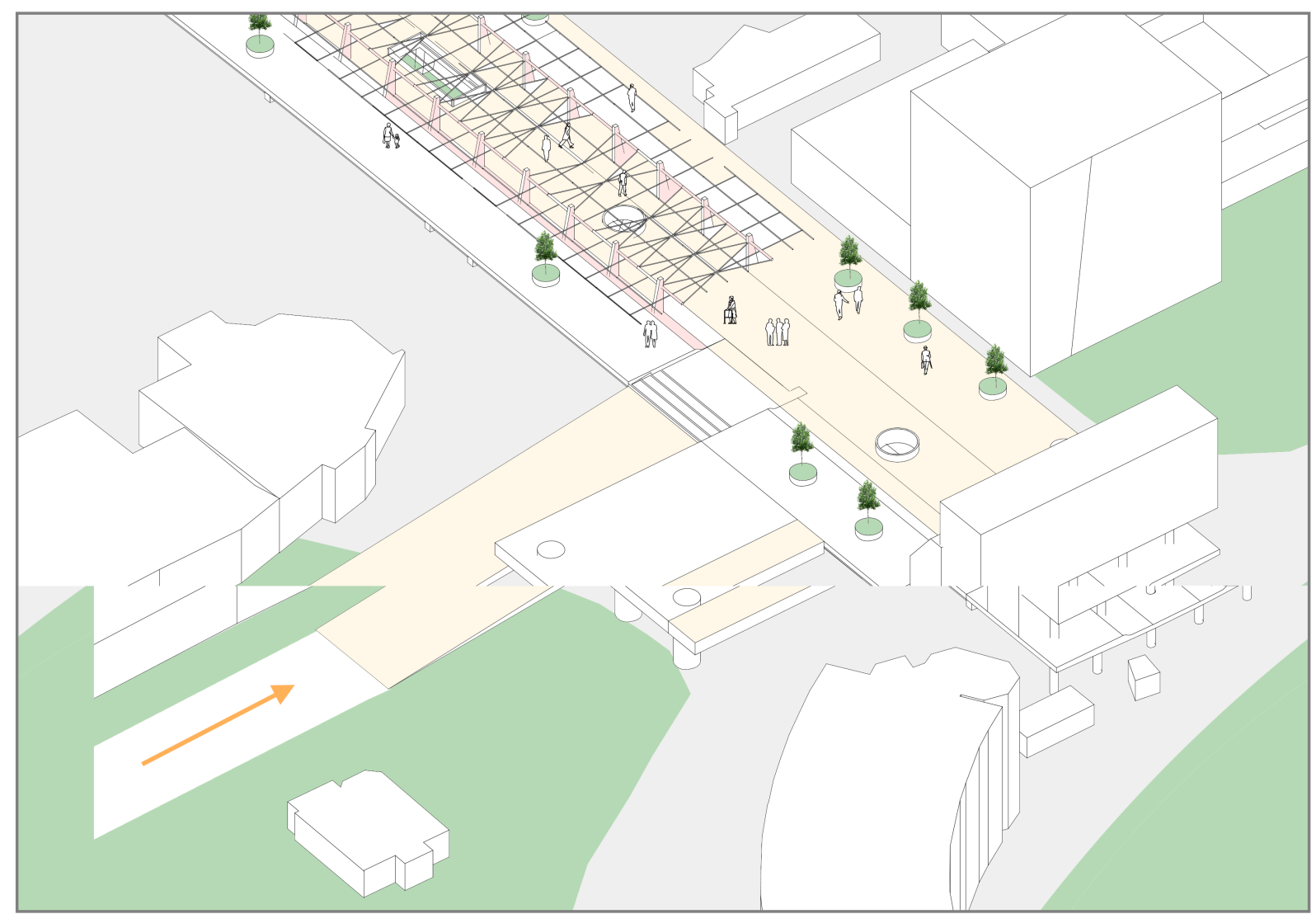

Figure 5.4 Axonometric view of the Basin Reserve and Pukeahu National Memorial Park connections 


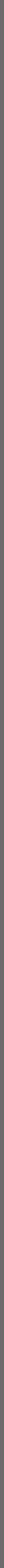




\section{0}

\section{CONCLUSION}

Disasters, whether man made or natural, are sudden occurrences that have long lasting damaging effects on people's livelihoods and their environments. Architecture is a discipline intimately involved with creatively uniting people with the built environment and disasters can be seen as a threat to that very relationship. There is potential for design to innovate the ways we are exposed to these threats, and like the research this thesis undertakes, explore the ways in which architecture can be a refuge during periods of displacement.

Although Wellington is an urban city with obvious foreseeable seismic risks, investigating elevated walkway typologies as a means of seismic refuge seemed to be limited by its context. Wellington faces a severe lingering threat of earthquakes as well as a limited functioning open space network. But creating large mother ship in an attempt to safeguard the central city's displaced population was on the 
one hand, necessary in order to cater for the sheer magnitude of the risk, but the other, so large that the surrounding context would be adversely affected. The low lying, compact nature of Wellington's city centre fueled this predicament. But this speaks to the resilience Wellington needs to work towards to fortify its city and its residents of a potential large disaster. Central Wellington is not the only vulnerable populous that requires this level of intervention. There are other low lying areas of the city along the east and south coast in high liquefaction and tsunami risk zones. Even households on high ground cannot all be considered safe because of severe ground shaking and potential landsliding. How the city can be spatially resilient in the face of these variances in risk is a line of equiry Wellington needs to continually investigate.

In regards to elevated walkways, they may be an uncommon sight in Wellington city, but are extremely common in large metropolis' around the globe, particularly those which are densely populated. Intended to provide pedestrians with efficient intercity transport routes, there is potential for such typologies to create new opportunities cultural and social exchanges. Given the lack of open spaces in densely populated countries, their ability to accommodate outdoor activities will become an increasing necessity, especially in scenarios where the streets are inundated. The idea that elevated transport structures could become disaster resilient spaces is an idea that formulated through thesis investigation. It lends well to the notion of having a literal escape from harms way, a refuge above the debris. 


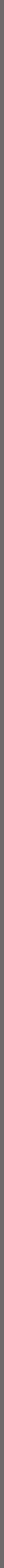


10.0

REFERENCES 


\subsection{List of References}

Allan, Penny and Martin Bryant. "Resilience as a framework for urbanism and recovery." Journal of Landscape Architecture 6.2 (2012): 34-45.

Charalambous, Nadia and Magda Mavridou. "Space Syntax: Spatial Integration Accessibility and Angular Segment Analysis by Metric Distance (ASAMeD)." Accessibility Instruments for Planning Practice, 2012.

Cousins, J. Wellington Without Water - Impacts of Large Earthquakes. GNS Science. Lower Hutt, 2013.

Cousins, W J, M Nayyerloo and R J Van Dissen. Estimated earthquake and tsunami losses from large earthquakes affecting Wellington Region. GNS Science. Lower Hutt, 2014.

Environment Cantebury. Liquefaction. 2017. 25 April $2017<w w w . e c a n . g o v t . n z>$.

Gehl, Jan. Life Between Buildings. Trans. Jo Koch. 6th Edition. Washington DC: Island Press, 2011.

Hokanson, J. Barry and James C. Schwab. "Anticipating Disruption." Association, American Planning. Planning for Post-Disaster Recovery: Next Generation. Ed. James C. Schwab. Chicago: American Planning Association, 2014. 24-41.

International Federation of Red Cross and Red Crescent Societies. Emergency Sheltering. Berlin: Deutsches Rotes Kreuz e.V, 2016.

Jacobs, Jane. The Death and Life of Great American Cities. New York: Random House Inc, 1961. Landscape Architecture Foundation. Cheonggyecheon Stream Restoration Project. 23 June 2017 $<$ landscapeperformance.org $>$.

Leonard, G, et al. "Interim tsunami evacuation planning zone boundary mapping for the Wellington and Horizons regions defined by a GIS-calculated attenuation rule." GNS Science, 2009.

McSaveney, Eileen. The 1855 Waiarapa Earthquake. 16 November 2016. 13 February 2017 $<$ teara.govt.nz>.

Moss, Jeremiah. Disney World on the Hudson. 21 August 2012. 2312017 <www.nytimes.com>.

Mowll, Richard. Lifeline Utilities Restoration Times for Metropolitan Wellington Following a Wellington Fault Earthquake. Report. Wellington, 2012.

Power, William. "Review of Tsunami Hazard in New Zealand (2013 Update)." Consultancy Report. GNS Science, 2013.

Sachdeva, Sam. Civil Defence overhaul 'inevitable' after tsunami warning confusion. 18 November 2016. 10 December 2016 <www.stuff.co.nz>. 
Shadwell, Talia. Post-earthquake question marks hang over apartment dwellers in central Wellington. 22 November 2016. 10 December $2016<$ www.stuff.co.nz>.

Stuff. Ghost city: Wellington residents abandon central city after 7.5 earthquake. 14 November 2016. 4 January $2016<$ www.stuff.co.nz>.

Topping, Kenneth C and James C Schwab. "Disaster Recovery Planning: Expectations Versus Reality." Association, American Planning. Planning for Post-Disaster Recovery: Next Generation. Ed. James C. Schwab. Chicago: American Planning Association, 2014. 42-59.

Walker, Brian, Salt and David. Resilience Thinking. Washington DC: Island Press, 2006.

Washburn, Alexandros. The Nature of Urban Design: A New York Perspective. Washington DC: Island Press, 2013.

Wellington City Council. Central City Framework. Wellington, 2010.

-. Redeveloping Kent and Cambridge Terraces. 2015. 15 July 2016 $<$ www.our10yearplan.co.nz $>$. 


\subsection{Sources of Figures}

All figures not attributed are author's own.

Figure 1.1 GNS Science. Main active faults in Wellington, 2009. Wellington, New Zealand. March 2017. Web. <gns.cri.nz>

Figure 1.2 GNS Science. Wellington's proximity to the colliding Australian and Pacific Plate, 2009. Wellington, New Zealand. March. Web. <gns.cri.nz>

Figure 1.3 Cousins, J. Wellington area bulk water supply system, 2013. Lower Hutt, New Zealand. Wellington Without Water - Impacts of Large Earthquakes. GNS Science Report 2012/30: 1. Print

Figure 1.8 NASA. Anaglyph, Landsat Overlay: Wellington, New Zealand, 2000. Sioux Falls, South Dakota. 8 February 2017. Web. <jpl.nasa.gov>

Figure 2.0 Land Information New Zealand. Wellington 0.1m Urban Aerial Photos (2012-2013), 2014. Hastings, New Zealand. 20 April 2017. Web. <data.linz.govt.nz>

Figure 2.1 Fitzgerald, Thomas Henry, Samuel Charles Brees, Louis Ernest Ward. Wellington sketch plan of original sections sold by ballot in 1839. Wellington, New Zealand. 13 January 2017. Web. <tiaki.natlib.govt.nz>

Figure 2.2 Wright, Henry. Walkway between Cambridge and Kent Terraces, 1890s. Wellington, New Zealand. 13 January 2017. Web <natlib.govt.nz>

Figure 2.3 Statue of Queen Victoria, 1955. Wellington, New Zealand. 13 January 2017. Web. $<$ natlib.govt.nz $>$

Figure 2.4 Transpress NZ. Trams on Kent Terrace towards the Basin Reserve, 1920s. 13 January 2017. Web. < transpressnz.blogspot.co.nz>

Figure 2.5 Thorley, W H. Kent and Cambridge Terraces, Wellington, 1927. 14 January 2017. Web. <natlib.govt.nz>

Figure 2.6 Niven, K E. James Smith Christmas Parade, 1960s. Wellington, New Zealand. 14 January 2017. Web. <natlib.govt.nz>

Figure 2.7 Southern part of Kent and Cambridge Terraces, 1931. Wellington, New Zealand. 14 January 2017. Web. <natlib.govt.nz>

Figure 3.0 Bjarke Ingels Group. BIG U from The Battery. New York, USA. 3 March 2017. Web $<$ lafargeholcim-foundation.org $>$ 
Figure 3.1 Bjarke Ingels Group. BIG Bench flood protection. New York, USA. 3 March 2017. Web. <lafargeholcim-foundation.org >

Figure 3.2 Bjarke Ingels Group. Flip down flood gates. New York, USA. 3 March 2017. Web. $<$ lafargeholcim-foundation.org $>$

Figure 3.3 Bjarke Ingels Group. The undulating berm. New York, USA. 3 March 2017. Web $<$ lafargeholcim-foundation.org>

Figure 3.4 Turenscape. Yanweizhou path, 2015. 13 March 2017. Web. <landezine.com>

Figure 3.5 Turenscape. Path viewing deck, 2016. 13 March 2017. Web. <arquitectes.cat>

Figure 3.6 Turenscape. Terraces river embankments, 2016. 15 March 2017. Web. $<$ arquitectes.cat $>$

Figure 3.7 Turenscape. Aerial of river embankment, 2016. 15 March 2017. Web. $<$ arquitectes.cat $>$

Figure 3.8 Turenscape. Before and after aerial view of park, 2016. 15 March 2017. Web. $<$ arquitectes.cat $>$

Figure 3.9 Baan, Iwan. Gansevoort End, Plaza, and Stairs, 2009. 17 March 2017. Web. $<$ archdaily.com>

Figure 3.10 Baan, Iwan. Aerial View, from West 30th Street, 2011. 17 March 2017. Web. $<$ archdaily.com $>$

Figure 3.11 Baan, Iwan. View looking west at the foot of the 11th Avenue Bridge, 2014. 17 March 2017. Web. <archdaily.com>

Figure 3.12 Baan, Iwan. Seating along the Interim Walkway, 2014. 17 March 2017. Web. $<$ archdaily.com $>$

Figure 3.13 Baan, Iwan. Old and new architecture, 2011. 17 March 2017. Web. <archdaily.com>

Figure 3.14 Mojave955. Overlooking the Cheonggyecheon Stream, 2015. 27 June 2017. Web

Figure 3.15 Mojave955. Users cooling down by the Cheonggyecheon Stream, 2015. 27 June 2017. Web

Figure 3.16 Artjouer Street Art. Overlooking the Cheonggyecheon Stream and one of its connecting bridges, 2012. 27 June 2017. Web. <flickr.com> 